\title{
OCEANOGRAPHIC INSTRUMENT SIMULATOR
}

\author{
A Thesis \\ presented to \\ the Faculty of California Polytechnic State University, \\ San Luis Obispo \\ In Partial Fulfillment \\ of the Requirements for the Degree \\ Master of Science in Electrical Engineering \\ by
}

Amy Yenyu Chen

March 2016 
(C) 2016

Amy Yenyu Chen ALL RIGHTS RESER VED 


\title{
COMMITTEE MEMBERSHIP
}

TITLE: Oceanographic Instrument Simulator

\author{
AUTHOR: Amy Yenyu Chen
}

DATE SUBMITTED: $\quad$ March 2016

COMMITTEE CHAIR: Vladimir Prodanov, Ph.D.

Associate Professor of Electrical Engineering

COMMITTEE MEMBER: Bridget Benson, Ph.D.

Assistant Professor of Electrical Engineering

COMMITTEE MEMBER: Chad Kecy, M.S.

Monterey Bay Aquarium Research Institute 


\author{
ABSTRACT \\ Oceanographic Instrument Simulator
}

Amy Yenyu Chen

The Monterey Bay Aquarium Research Institute (MBARI) established the Free Ocean Carbon Enrichment (FOCE) experiment to study the long-term effects of decreased ocean $\mathrm{pH}$ levels by developing in-situ platforms [1]. Deep FOCE (dpFOCE) was the first platform, which was deployed in 950 meters of water in Monterey Bay. After the conclusion of dpFOCE, MBARI developed an open source shallow water FOCE (swFOCE) platform located at around 250 meter of water to facilitate worldwide shallow water experiments on FOCE [1][2]. A shallow water platform can be more ubiquitous than a deep-water platform as shallow water instruments are less expensive (as it does not have to be designed to withstand the pressure at deep ocean depths) and more easily deployed (they can be deployed right along the coast).

The swFOCE experiment is an open source platform, and MBARI has made the plans available online to anyone interested in studying shallow water carbon enrichment. There is a gateway node what is connected to four sensor nodes within the swFOCE. In order to test the sensor node individually, an idea of designing an Oceanographic Instrument Simulator is purposed. The Oceanographic instrument simulator (OIS), described in this paper provides the means for MBARI engineers to test the swFOCE platform without attaching the numerous and expensive oceanographic instruments. The Oceanographic Instrument Simulator simulates the various scientific instruments that could be deployed in an actual experiment.

The Oceanographic Instrument Simulator (OIS) system includes the designed circuit board, Arduino Due and an SD Card shield. The designed circuit board will be connected to a computer through a USB cable, and be connected to MBARI's swFOCE sensor node through a serial connection. When a query is given from the sensor node, the Arduino Due will parse the data given from the sensor node, search through the pre-installed data in the SD card and return the appropriate data back to the sensor node. A user can also manually set up the input current through a computer terminal window to control the simulated signals from the PCB.

Key Words: oceanographic; electronic load; sensors; MBARI; open source; simulator 


\section{ACKNOWLEDGMENTS}

I would like to thank Dr. Vladimir Prodanov for directing and guiding me throughout the development of the oceanographic instrument simulator. He was always there to guide me and direct me to the right track whenever I needed to troubleshoot the simulator. Without his patience and guidance, I would not have been able to successfully troubleshoot the simulator.

I would like to thank Dr. Bridget Benson for pushing me to go above and beyond my expectations. She pushed me to write an abstract and publish a paper for IEEE Ocean's 15 and give a talk on the project during graduate seminar. She showed me all the possibilities I could have as I worked throughout the project.

I would like to thank Chad Kecy for the opportunity to work on this project. I would not have been able to work on the project without the opportunity that he provided. I would also like to thank MBARI for supporting the project and providing the summer internship opportunity for me to work on the OIS during the summer of 2015.

I would like to thank Matthew Mitchell and Richard Bae for working on the original OIS software programming. I was able to follow, modify, and improve the code.

Finally, I'd like to thank my family for their support and encouragement. Without their support, I would not be able to continue my education. 


\section{TABLE OF CONTENTS}

Page

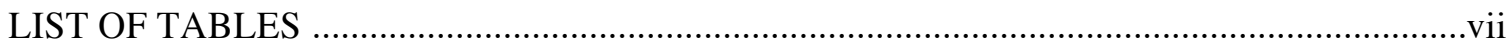

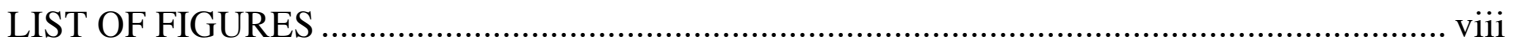

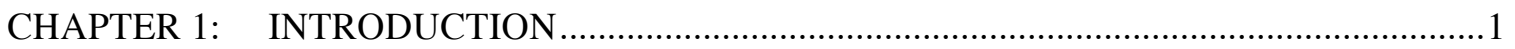

CHAPTER 2: $\quad$ BACKGROUND AND PREVIOUS WORK …..............................................

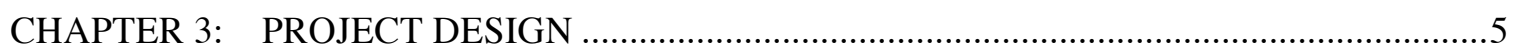

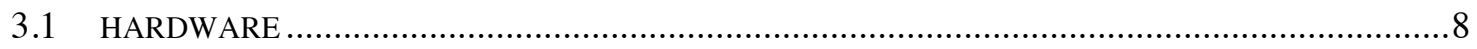

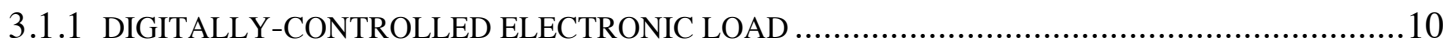

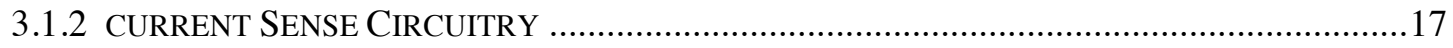

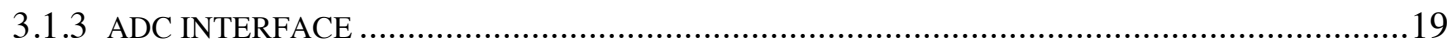

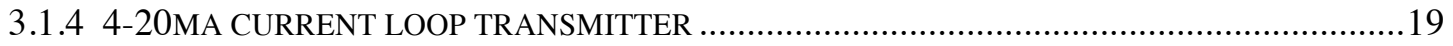

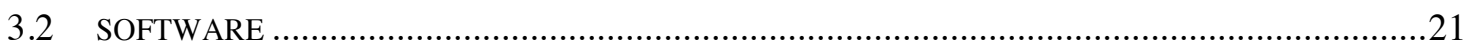

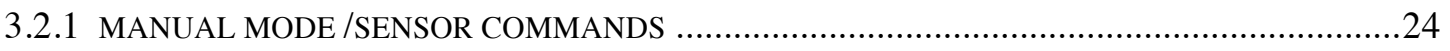

3.2.2 RS232 SERIAL PORT COMMUNICATIONS/ TRANSCEIVER CHIP .....................................27

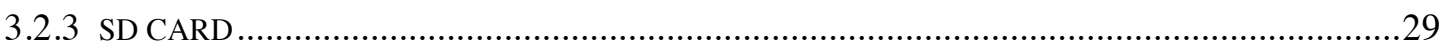

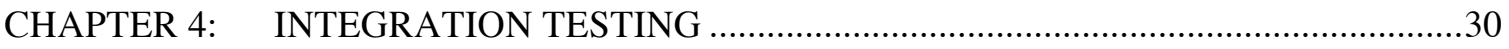

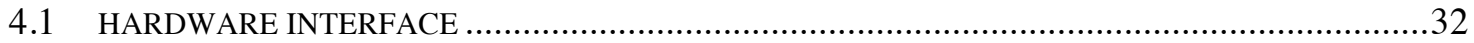

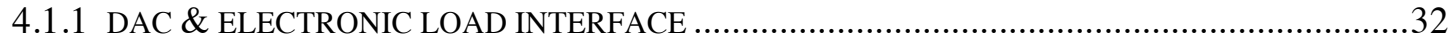

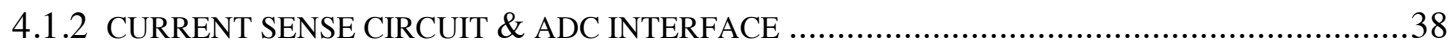

4.1.3 DAC \& ELECTRONIC LOAD \& CURRENT SENSE CIRCUITRY \& ADC INTERFACE ................39

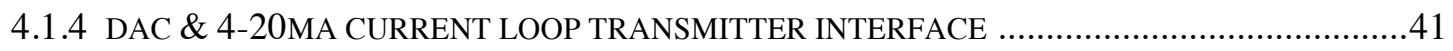

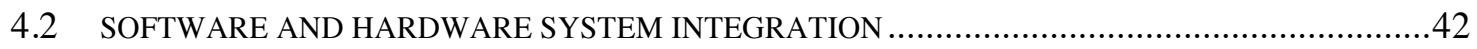

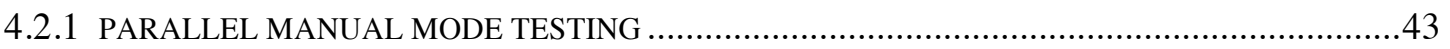

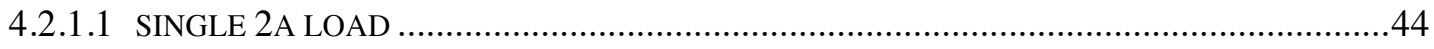

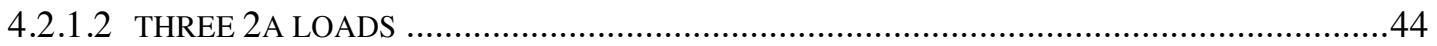

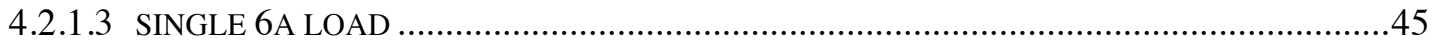

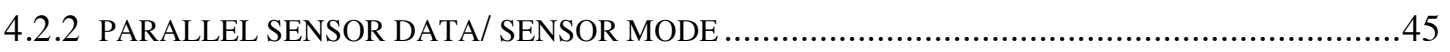

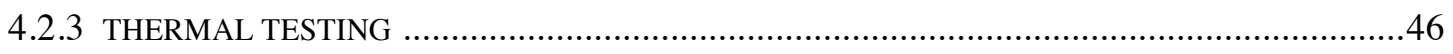

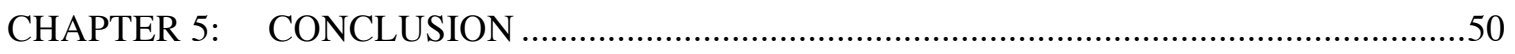

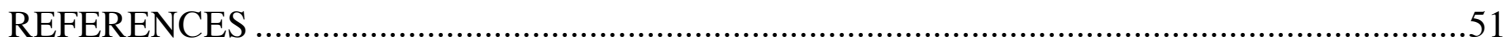

APPENDICES

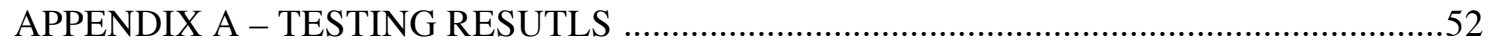

APPENDIX B - OCEANOGRAPHIC INSTRUMENT SIMULATOR SCHEMATICS ...........54

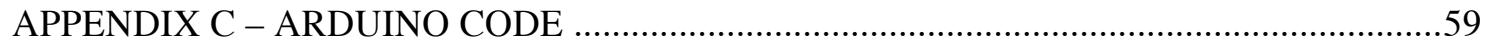

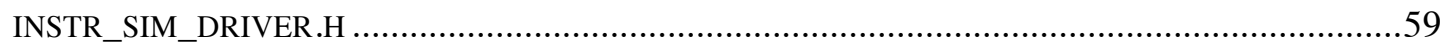

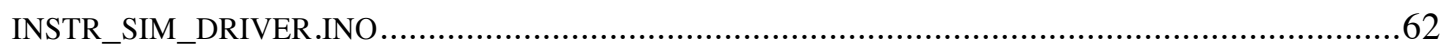




\section{LIST OF TABLES}

Table $\quad$ Page

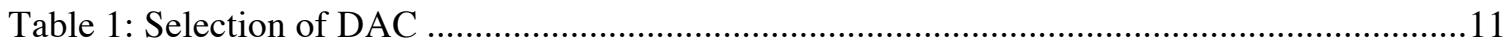

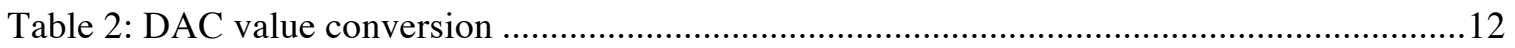

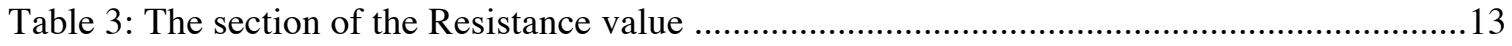

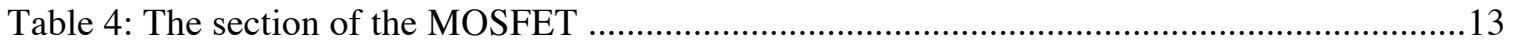

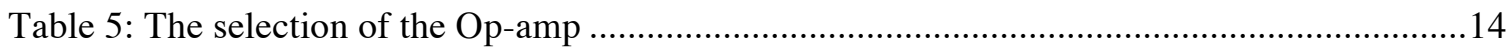

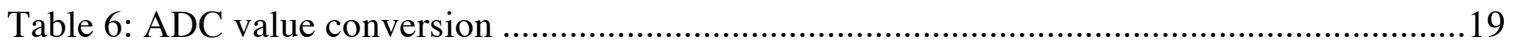

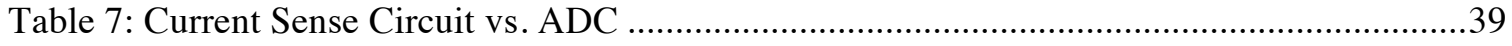

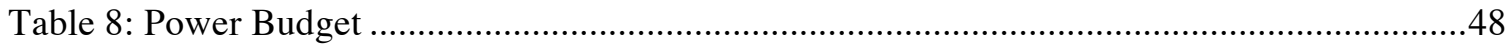




\section{LIST OF FIGURES}

Figure $\quad$ Page

Figure 1: Block Diagram of swFOCE Implementation [1] …................................................

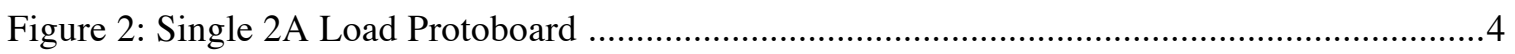

Figure 3: Oceanographic Instrument Simulator Block Diagram ................................................6

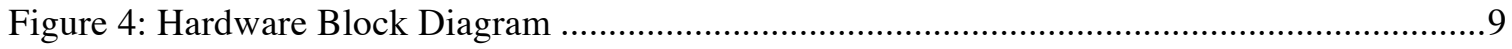

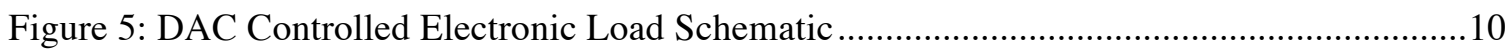

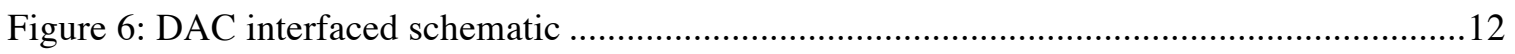

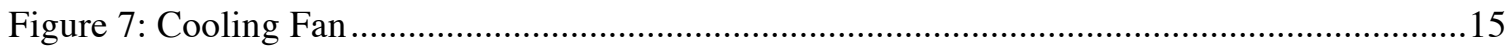

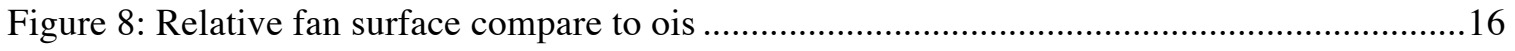

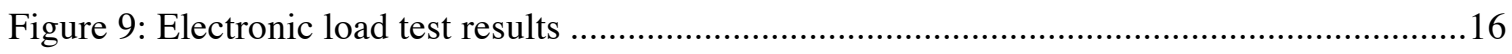

Figure 10: Block diagram for single 2A and Load and Single 6A load ......................................17

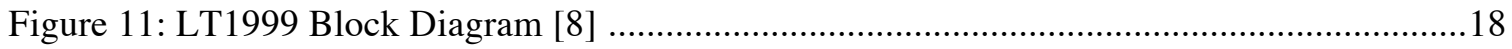

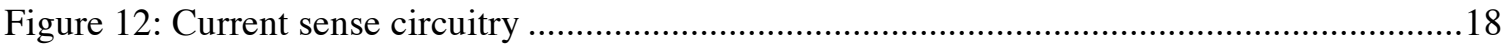

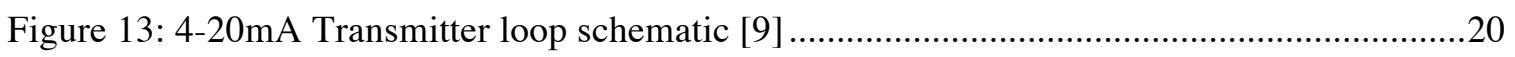

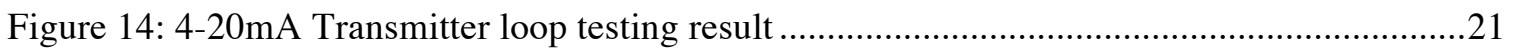

Figure 15: Main meau screen on hyperterminal window …....................................................22

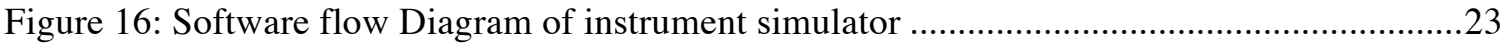

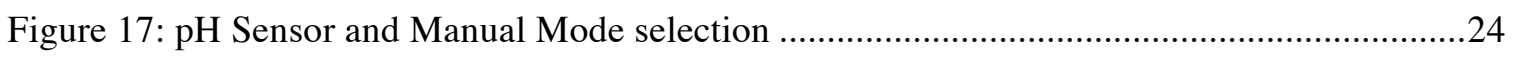

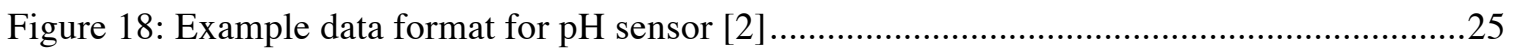

Figure 19: Arduino Due connected to a computer through a USB connection [2] .......................26

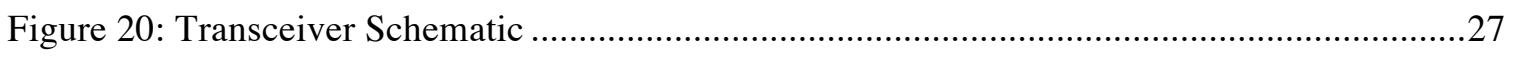

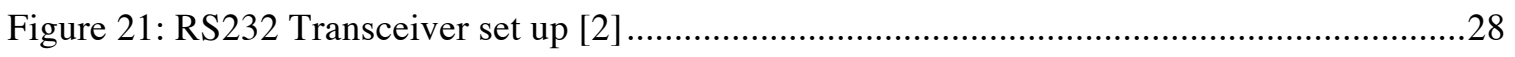

Figure 22: Arduino Due connected to RS232 connector [2] ....................................................28

Figure 23: Arduino Due with SD Card Shield Attached [2] ...................................................29

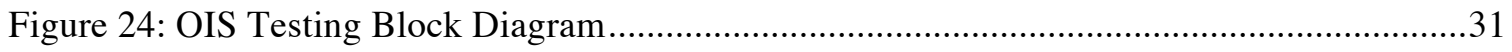


Figure 25: Input of 1Vpp (yellow); Output of gate voltage (blue)

Figure 26: Electronic Load with Small Signal Capacitors ........................................................33

Figure 27: Conceptual Electronic Load Control Loop ................................................................34

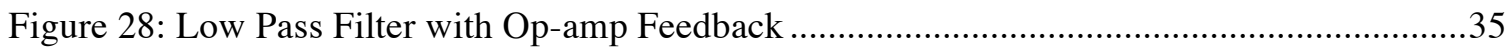

Figure 29: Electronic Load with Additional Resistor..................................................................

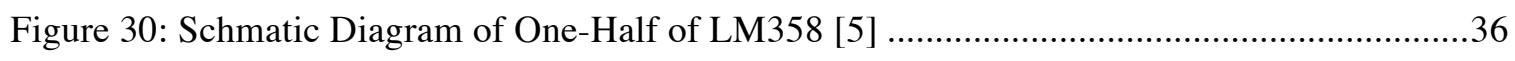

Figure 31: Input of 1Vpp (yellow); Output of gate votlage (blue) ..............................................37

Figure 32: DAC Controlled Electronic Load Schematic ............................................................37

Figure 33: Voltage Input from the DAC vs. Current Output to the 12V Supply Sensor Node.......38

Figure 34: Current Sense Circuit and ADC Schematic ............................................................39

Figure 35: DAC and Electronic Load and Current Sense Circuit and ADC Schematic ................40

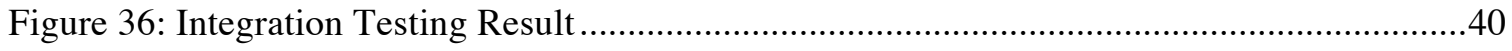

Figure 37: DAC 4-20mA current loop transmitter ....................................................................4

Figure 38: DAC and 4-20ma Current Loop Transmitter Result.................................................41

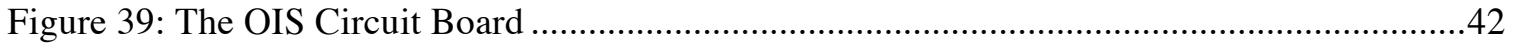

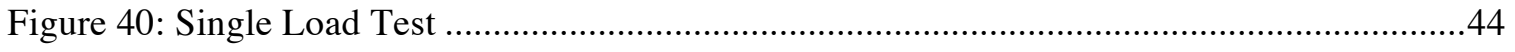

Figure 41: Parallel Testing for Three Loads at the same time ..................................................44

Figure 42: Parallel Testing for Load \#4 .............................................................................45

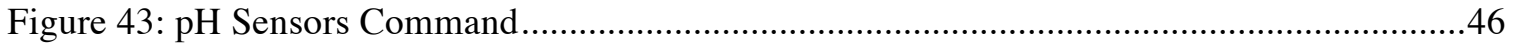

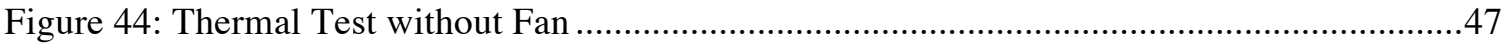

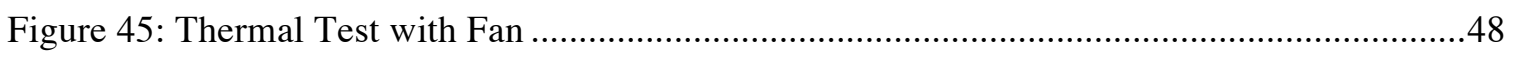

Figure 46: Current output vs. Power limits .......................................................................... 49

Figure 47: Electronic Load (without current sense circuitry) Testing Data ..................................53 
The Oceanographic Instrument Simulator (OIS), the topic of this paper, was designed to give test engineers the ability to test the functionality of the sensor node module within the swFOCE without the need for having the actual expensive oceanographic instruments connected to the system. The OIS simulates up to four oceanographic instruments by providing an equivalent electrical load and data stream as the real instrument. Thus, scientists and engineers can connect the OIS to the swFOCE, configure the OIS to simulate the oceanographic instruments they plan to deploy, and test the system to ensure the power limits of the system are not exceeded and the data from the 'sensor' accurately flows through the various modules of the system.

The rest of this paper is organized as follows: In chapter 3, the project design including the hardware board and the software user interface will be introduced and explained. The subchapters within chapter 3 will cover the design of both hardware and software. Chapter 4 will include the interface testing from hardware to software. Chapter 5 will then conclude with relating the project to the oceanographic community and describing possible future work. 


\section{CHAPTER 2: BACKGROUND AND PREVIOUS WORK}

For the swFOCE experiment, sensors will be used to measure various characteristics of the shallow ocean water such as $\mathrm{pH}$ level, oxidation level, etc. The sensors will be connected to swFOCE sensor node, which is connected to the swFOCE gateway node. The gateway node is then connected to swFOCE device's main electrical housing, which is connected to the central node of the swFOCE experiment system, shown in Figure 1. Each of the four sensor nodes, shown at the bottom of the figure, allows the user to connect four different sensors (three with a current limit of $2 \mathrm{~A}$ and one with a current limit of $6 \mathrm{~A}$ ). The sensor node gathers readings from each of its attached sensors and sends the data back to a shore station through the gateway node. The swFOCE experiment could generate a large amount of data from a variety of instruments, including $\mathrm{pH}$ sensors, CTDs, $\mathrm{O}_{2}$ sensors, water flow-meters, and ADCPs. This data propagates through a number of subsea housings prior to being stored on a local shore computer and disseminated over the web.

The sensor node module, designed by MBARI, is used to interface a wide range of scientific instruments. The sensor node provides power and serial communication to a maximum of three instruments. The third channel can be switched to interface a 4-20mA instrument. The fourth channel is designed to have high current, up to 6A, for devices such as lights or simple motors. The sensor node can provide a maximum of 75 watts and can be configured for 12 Volts, 24Volts, or 48Volts. 


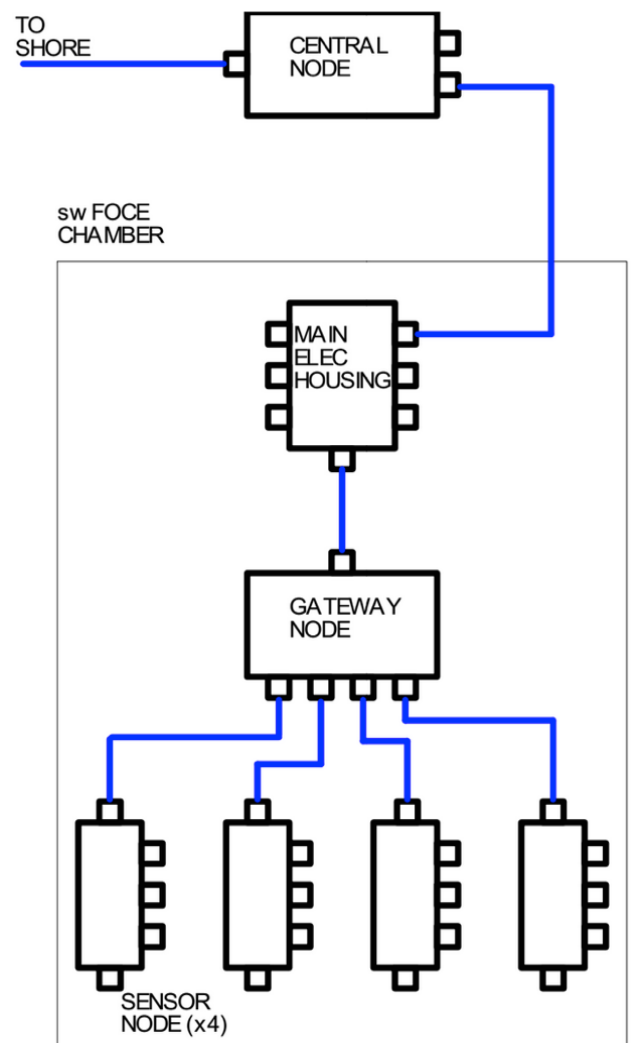

FIGURE 1: BLOCK DIAGRAM OF SWFOCE IMPLEMENTATION [1]

Prior to the development of the OIS in this thesis, there was a single 2A prototype built for the senior project for the OIS. The single 2 Amperes electronic load has a user interface controlled by the Arduino Due software program. The user can either manually control the 2A single load or use $\mathrm{pH}$ sensor, the sensor mode to simulate $\mathrm{pH}$ sensor behavior. 


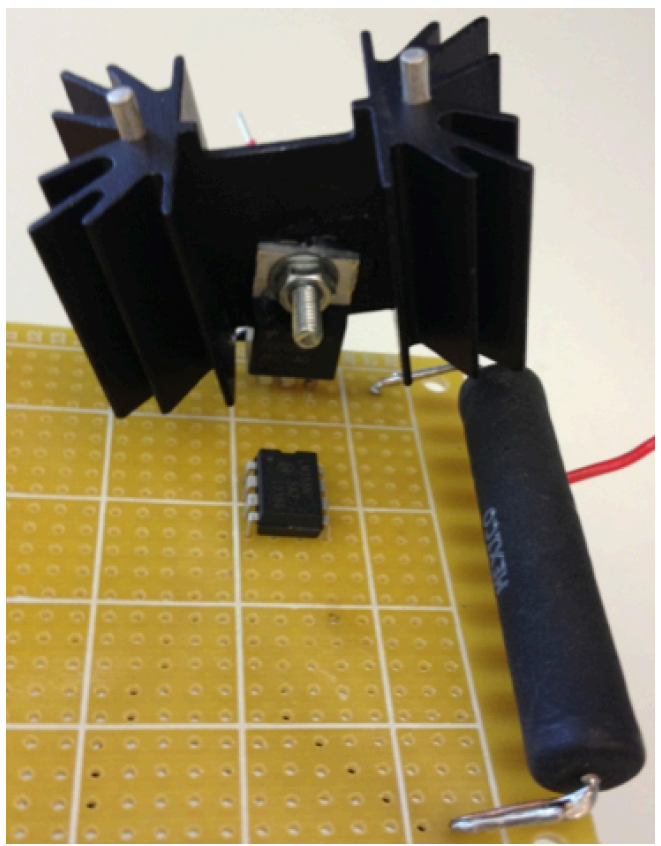

FIGURE 2: SINGLE 2A LOAD PROTOBOARD

This thesis will include the complete integration of the OIS, the PCB board and the Arduino Due, that simulates up to 4 sensors: three 2 Amperes loads and one 6 Amperes load. The software program of the OIS will be able to simultaneously test all 4 sensors through either manual mode or sensor mode. This thesis includes the write-up of the hardware and software design and the integration test results. 


\section{CHAPTER 3: PROJECT DESIGN}

The Oceanographic Instrument Simulator (OIS) is designed to be a simple portable test system for swFOCE platform. It can be used in a lab or office without additional oceanographic instruments. The OIS will be connected directly to the sensor node from the swFOCE to simulate sensor behaviors. There are four channels on the sensor node. Three of the four oceanographic instruments have a current limit of 2 Amperes and one of the four oceanographic instruments has a current limit of 6 Amperes. The specifications of the OIS are specified according to the sensor node form the swFOCE [1]. The overall power rating of the sensor node is 75 Watts therefore the OIS board cannot exceed 75 Watts. The OIS is designed to run on 12 Volts, 24 Volts, or 48 Volts, because those are commonly used power supplies for oceanographic instruments.

The OIS will be connected to the computer for the user to run the OIS with the terminal. A terminal will appear after the USB port from the OIS successfully connects to a computer. The software program initializes the OIS and ensures the connection between the sensor node and the OIS. 


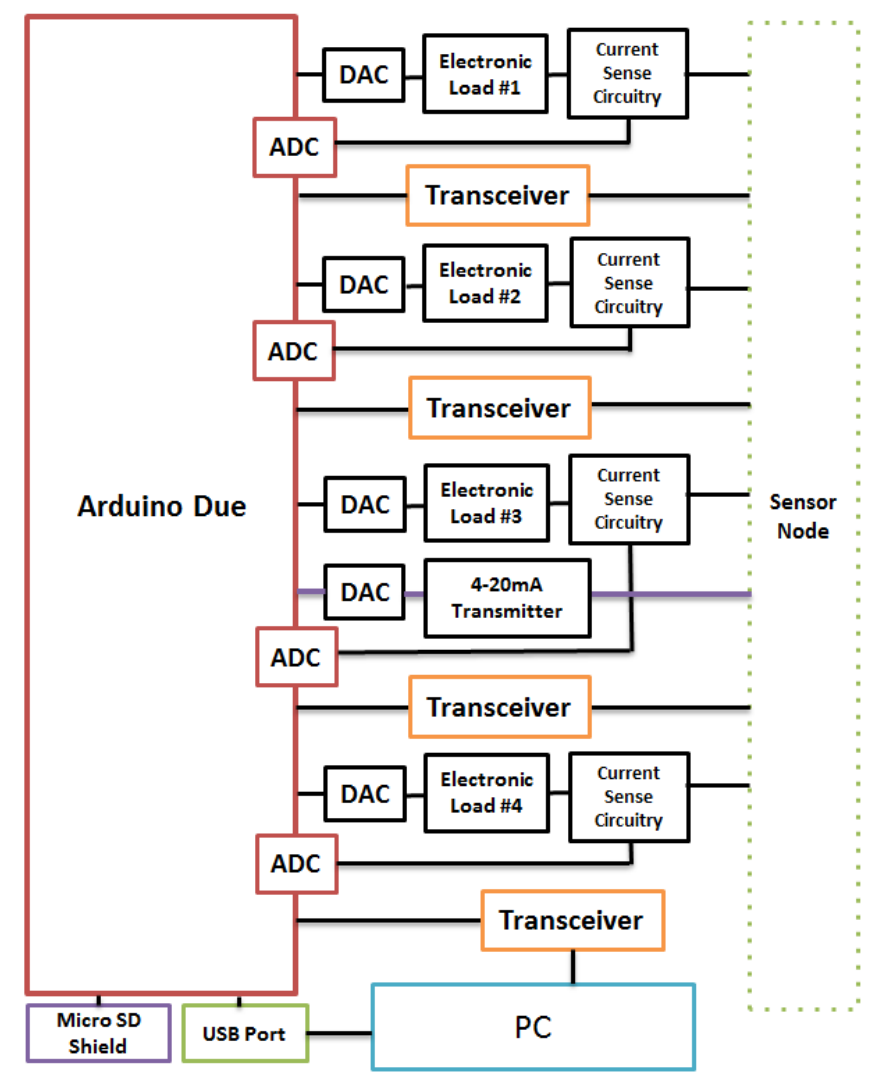

FIGURE 3: OCEANOGRAPHIC INSTRUMENT SIMULATOR BLOCK DIAGRAM The OIS block diagram and its connection to the swFOCE sensor node is depicted in Figure 3. Electronic Loads \#1, \#2, and \#3 simulate the three instruments with a current limit of 2 Amperes and Electronic Load \#4 simulates an instrument with a current limit of 6 Amperes. Note that Port \#3 can also be switched to interface a 4-20mA instrument per the sensor node's design. The three transceivers depicted below electronic loads \#1, \#2, and \#3 emulate serial data transfer from each of the simulated sensors. The high current port \#4 was not designed for serial interface as it is meant to interface to LEDs or motors. The Micro SD shield is connected to an SD card, which stores simulated sensor data. The user can configure each load and each communication port to simulate a sensor of interest (either manually or from a drop down list of sensors such as the SeaBird SBE18s pH sensor [9]). Once the OIS is configured, the user can attach the OIS to the sensor node of the swFOCE for full system testing. 
The Arduino Due sets up the configuration, shows the instructions and monitors the OIS through a terminal window. The USB Port on the Arduino Due connects to the personal computer (PC) for the user to have access to the terminal. The Arduino Due was selected because unlike other Arduino boards, it contains four UART ports. The Arduino board sets the output voltage of the DAC, takes in feedback from the current sense circuit via the ADC and verifies the functionality of the UART ports.

The overall design of the OIS can be categorized into hardware and software. The following sections will go into detail on the hardware design and software design. The hardware design will contain the detailed schematic and testing of each hardware component used in the OIS. The software design will contain the detailed functionality of the main menu and the power protection function that turns off the OIS to prevent damage of the hardware. 


\subsection{HARDWARE}

The hardware design of the OIS includes the DAC design, the electronic load design, the current sense circuit design, the 4-20mA current loop transmitter design and the ADC design. All these designs were built onto a single PCB, as shown in Figure 4. The components on the OIS printed circuit board (PCB) are shown in solid lines and the Arduino Due and the power supply are the other hardware components that are connected to the PCB.

There are a total of five DACs: four of the DACs are used to simulate three 2A loads and one 6A load and the other DAC is used for the 4-20mA current loop transmitter. In order to simulate each individual port, each instrument simulator port includes an electronic load, current sense circuit and an ADC. The Arduino Due contains the software user interface program. The power supply that supplies the OIS will be replaced with the sensor node from the swFOCE once connected to the sensor node. 


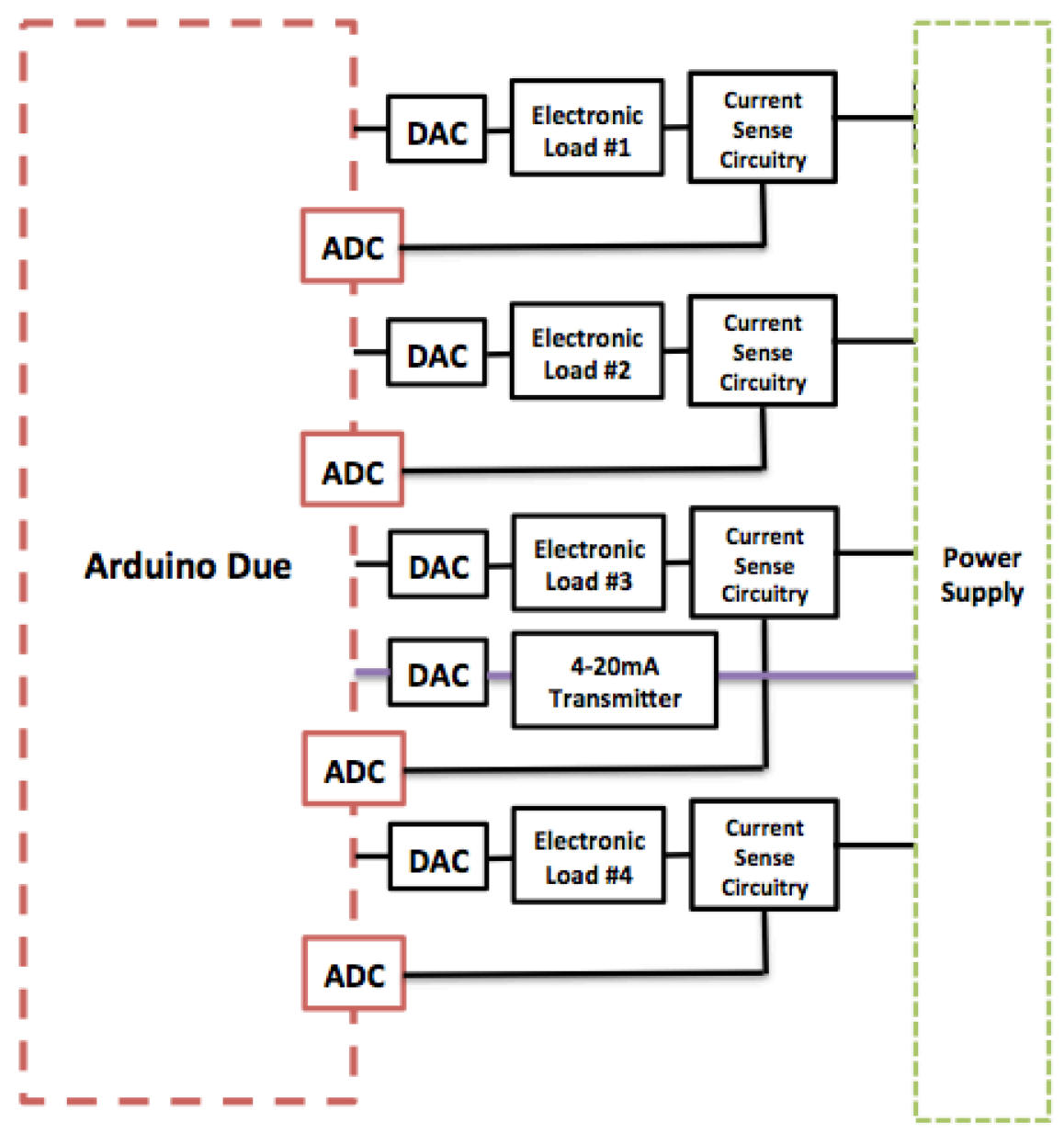

FIGURE 4: HARDWARE BLOCK DIAGRAM 


\subsubsection{DIGITALLY-CONTROLLED ELECTRONIC LOAD}

The electronic loads are designed to connect to the sensor nodes from the swFOCE. The OIS consists of four electronic loads. Channels 1, 2, and 3 have an electronic load of 2A and Channel 4 has an electronic load of 6A. Each individual electronic load consists of a DAC, an op-amp, MOSFET and a resistor. The purpose of the $2 \mathrm{~A}$ electronic load is to sink in current from $0 \mathrm{~A}$ to 2A, as shown in Figure 5. The sensor node will provide voltages that vary from $12 \mathrm{~V}, 24 \mathrm{~V}$ and $48 \mathrm{~V}$ to supply the electronic load.

Figure 5 shows the DAC controlled electronic load. The Arduino Due will control the DAC and the electronic load by inputting a digital value to the DAC. The digital value will be converted to an analog voltage at the output of the DAC. The voltage input to the op-amp will control the voltage at the gate and source, which causes the MOSFET to sink in current varying from 0A to 2A.

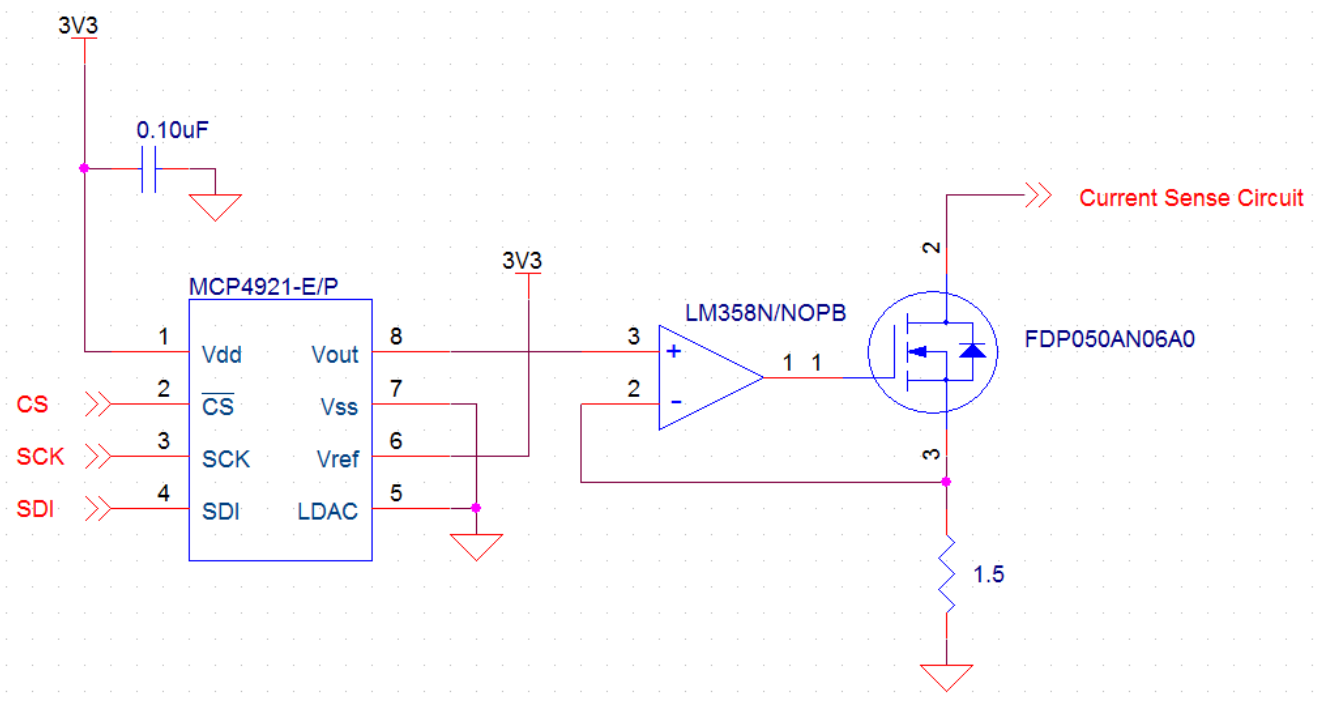

FIGURE 5: DAC CONTROLLED ELECTRONIC LOAD SCHEMATIC

The DAC is controlled by the Arduino Due to convert the digital voltage signal to an analog signal in order to input an analog value to the electronic load. The DAC provides a fixed voltage 
to the positive terminal of the op-amp. The selection of the DAC based on design requirements is shown in Table 1.

TABLE 1: SELECTION OF DAC

\begin{tabular}{|c|c|c|}
\hline & Design & Selected (MCP4921) \\
\hline Resolution & 12 bits & 12 bits \\
\hline Supply voltage & $3.3 \mathrm{~V}$ & $2.7 \mathrm{~V} \sim 5.5 \mathrm{~V}$ \\
\hline Output voltage range & Un-determined & Up to 3V \\
\hline
\end{tabular}

The MCP4921 is selected for the DAC, based on the supply voltage of $3.3 \mathrm{~V}$, which is compatible to the output voltage from the Arduino Due [3]. The Arduino Due is selected based on its four UART port capability. The Arduino Due can only handle up to $3.3 \mathrm{~V}$ for each of the onboard pins. The DAC selection was also based on the $3.3 \mathrm{~V}$ due to the $3.3 \mathrm{~V}$ supply specification from the Arduino Due. The input voltage of the op-amp is limited to $3 \mathrm{~V}$ based on the $3.3 \mathrm{~V}$ supply rail. According to the datasheet, the MCP4921 is a DAC that operates from $0 \mathrm{~V}$ to $3 \mathrm{~V}$ to control the op-amp [3].

The DAC utilizes serial communication, which means it sends one bit at a time sequentially. The resolution of the DAC is 12 bit, which means it has a resolution of 4096. The purpose of the DAC is to convert digital inputs from the Arduino Due to analog output in order for the electronic load to function. MCP4921 is the DAC used for the OIS as shown in Figure 6 [3]. 


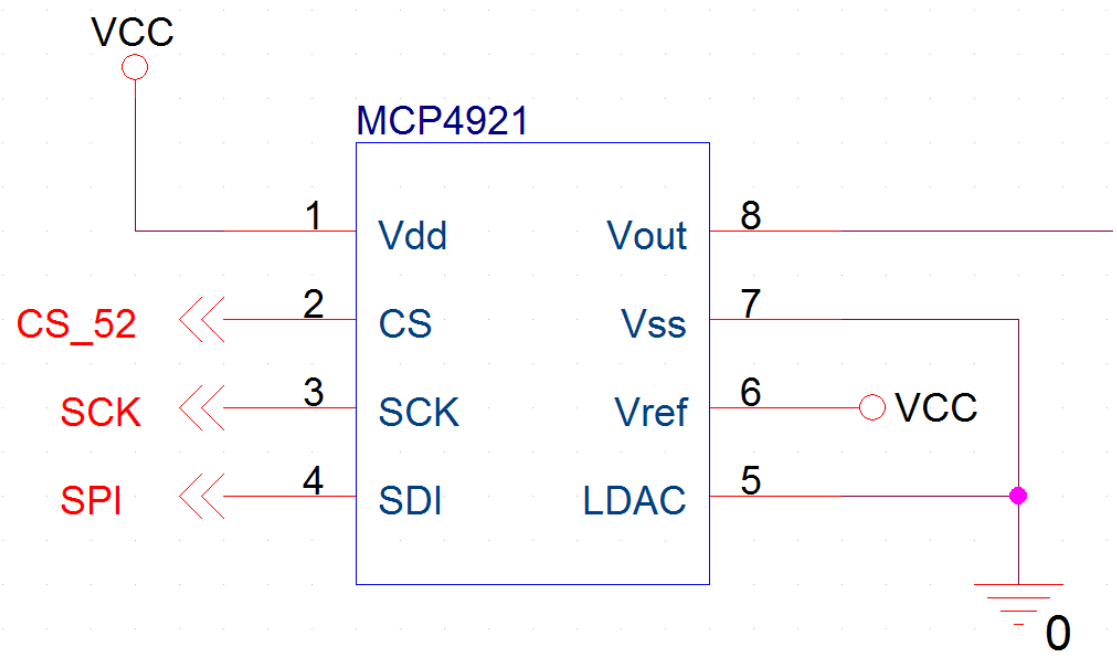

FIGURE 6: DAC INTERFACED SCHEMATIC

According to the resolution of the DAC, the voltages would correspond to the bits of the digital signal. As shown in Table 2, the digital bits correspond to the voltages ranging from $0 \mathrm{~V}$ to $3 \mathrm{~A}$.

TABLE 2: DAC VALUE CONVERSION

\begin{tabular}{|c|c|}
\hline $\begin{array}{c}\text { Digital Input } \\
\text { (From Arduino Due) }\end{array}$ & $\begin{array}{c}\text { Analog voltage output } \\
\text { (Power Supply) }\end{array}$ \\
\hline 4095 & 3 \\
\hline 3413 & 2.5 \\
\hline 2730 & 1.5 \\
\hline 2048 & 1 \\
\hline 1233 & 0.5 \\
\hline 683 & 2 \\
\hline
\end{tabular}

According to Figure 5, the op-amp creates a negative feedback loop from the gate of the MOSFET via the resistor then back to the negative terminal of the op-amp. Depending upon the input voltage from the DAC, the current conducted by the MOSFET and resistor varies. The output voltage from the Arduino goes up to 3.3V; therefore the range of the DAC output is set to vary from $0 \mathrm{~V}$ to $3 \mathrm{~V}$. To sink in $0 \mathrm{~A}$ to $2 \mathrm{~A}$, a resistor with value $1.5 \Omega$ is selected. The selection of the resistance value for the resistor is based on the input voltage from the DAC, MCP4921. The 
input voltage will range from $0 \mathrm{~V}$ to $3 \mathrm{~V}$. The current sink current will be from $0 \mathrm{~A}$ to $2 \mathrm{~A}$. In order to sink in current up to $2 \mathrm{~A}$, the $1.5 \Omega$ resistor is selected. The power rating is calculated to be $\mathrm{RxI}^{2}=1.5 \mathrm{x}\left(2^{2}\right)=6 \mathrm{~W}$. In order to increase the range, a $10 \mathrm{~W}$ power-rating resistor was selected as shown in Table 3.

TABLE 3: THE SECTION OF THE RESISTANCE VALUE

\begin{tabular}{|c|c|c|}
\hline & Design & Selected (71-RS) \\
\hline Resistor value & $1.5 \Omega$ & $1.5 \Omega$ \\
\hline Power rating & $6 \mathrm{~W}$ & $10 \mathrm{~W}$ \\
\hline
\end{tabular}

Base of the specification shown in Table 3 the FD050AN is selected for the MOSFET. The intended mode of operation of the MOSFET is at the continuous conduction mode at saturation mode. As shown in Table 4, at $125^{\circ} \mathrm{C}$, the MOSFET can handle up to $73.5 \mathrm{~W}$ [4]. The voltage threshold at $2 \mathrm{~A}$ is around $5 \mathrm{~V}$, according to Figure 7 on the datasheet [4]. Shown in the testing data, the $\mathrm{V}_{\mathrm{GS}}$ will be within $4 \mathrm{~V}$ [4]. There are further temperature testing discussion and solutions presented in the "4.2.3 Thermal Testing" section. The testing showed that the OIS would require a fan to withstand the high current condition. The MOSFET on the OIS can possibly reach $125^{\circ} \mathrm{C}$ as an extreme condition [4]. However, it is obvious that at room temperature, the OIS can take much more heat before it overheats.

TABLE 4: THE SECTION OF THE MOSFET

\begin{tabular}{|c|c|c|}
\hline & Design & Selected (FD050AN) \\
\hline $\mathrm{V}_{\mathrm{DS}}$ & $>48 \mathrm{~V}$ & $60 \mathrm{~V}$ \\
\hline $\mathrm{I}_{\mathrm{D}}$ & $>2 \mathrm{~A}$ & $80 \mathrm{~A}$ \\
\hline $\mathrm{P}_{\mathrm{AVG}}$ & $>96 \mathrm{~W}$ & $245 \mathrm{~W} @ \mathrm{~T}<=25^{\circ} \mathrm{C}$ \\
\hline & & $73.5 \mathrm{~W} @ \mathrm{~T}<=125^{\circ} \mathrm{C}$ \\
\hline
\end{tabular}


Table 5 shows the selection process of the op-amp, LM358. With the maximum input of $3 \mathrm{~V}$ from the DAC, $\mathrm{V}_{\mathrm{DD}}$ of the op-amp is calculated through the maximum input of the op-amp, $3 \mathrm{~V}$, added to the maximum V_GS, 5V, of the LM358 which is selected due to the wide range of supply and the under $0 \mathrm{~V}$ GND sensing. $3 \mathrm{~V}+5 \mathrm{~V}=8 \mathrm{~V}$ [5]. However, to expand the supply range of the opamp, $2 \mathrm{~V}$ was added to secure the functionality of the op-amp. $8 \mathrm{~V}+2 \mathrm{~V}=10 \mathrm{~V}$. A supply voltage of $12 \mathrm{~V}$ is selected for the op-amp to increase the stability of the electronic load.

TABLE 5: THE SELECTION OF THE OP-AMP

\begin{tabular}{|c|c|c|}
\hline & Design & Selected (LM358) \\
\hline $\mathrm{V}_{\mathrm{DD}}$ & $>=10 \mathrm{~V}$ & $3 \mathrm{~V} \sim 32 \mathrm{~V}$ \\
\hline Input GND Sense & $<0 \mathrm{~V}$ & $-0.3 \mathrm{~V}$ \\
\hline Output GND Sense & $\sim 2 \mathrm{~V}$ & $5 \mathrm{mV}$ \\
\hline
\end{tabular}

According to the LM358 datasheet, the ground sensing capability, Input common mode voltage range starts from $-0.3 \mathrm{~V}[5]$. This shows that the op-amp would still be on continuously even when the input of the op-amp is at $0 \mathrm{~V}$. It is crucial for the electronic load to be operating when the input from the Arduino Due is 0V. According to the LM358 datasheet, the output GND sense will be running continuously at $5 \mathrm{mV}$, which ensures the op-amp running at the output when the input voltage is at $0 \mathrm{~V}[5]$.

LM358 is selected based on the specification provided by MBARI [1]. The sensor node will take in voltage inputs: $12 \mathrm{~V}, 24 \mathrm{~V}$ or $48 \mathrm{~V}$. Due to the voltage inputs from the sensor node, the MOSFET of the OIS should be able to withstand up to $48 \mathrm{~V}$ and the maximum current that the MOSFET should conduct at 2A. Therefore, the requirement of the MOSFET will have to be able to handle $2 \mathrm{~A}$. The power limitation of the MOSFET will be $75 \mathrm{~W}$. Specification provided by MBARI requires the OIS to handle up to $75 \mathrm{~W}$, therefore each individual sensor has to be able to handle up to $75 \mathrm{~W}[1]$. 
A cooling fan was selected after testing the electronic load. As shown in the Figure 7, the electronic load can heat up to $145^{\circ} \mathrm{C}$ without the fan. A fan was selected due to the power supply at $12 \mathrm{~V}$. The $12 \mathrm{~V}$ power supply can be used to supply the op-amp and the fan. The fan was selected for the surface that the fan covers, $92 \times 92 \times 25 \mathrm{~mm}$. The fan will cover the vertical surface of all the heat sinks, which are mounted onto the MOSFET, and dissipate the heat on the heat sink, as shown in Figure 8.

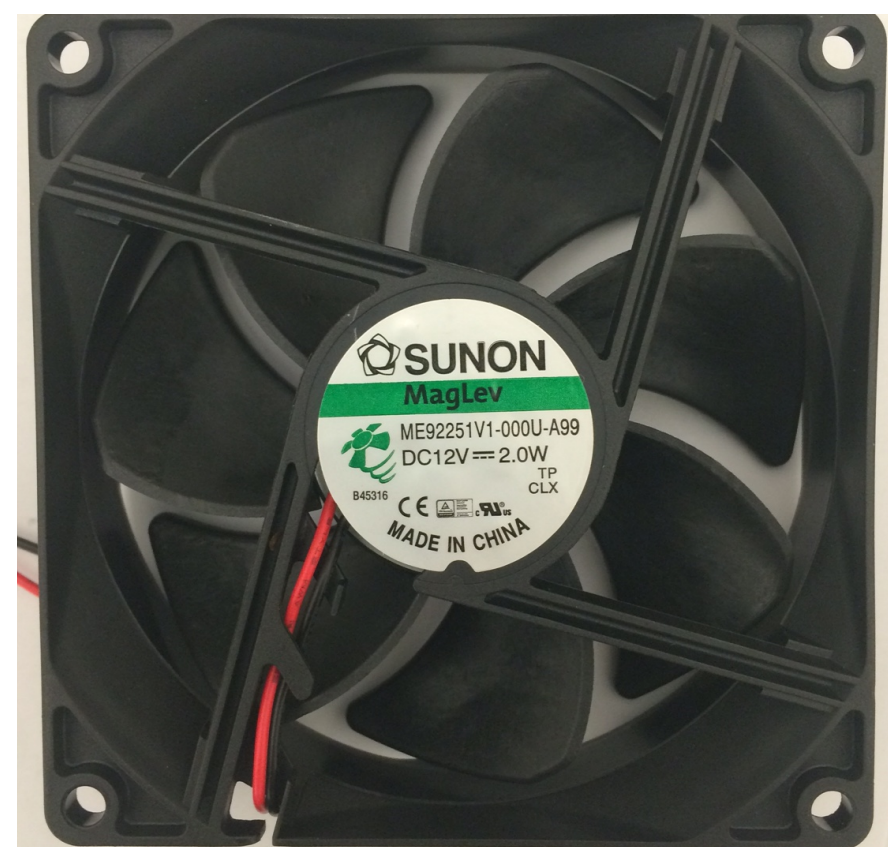

FIGURE 7: COOLING FAN 


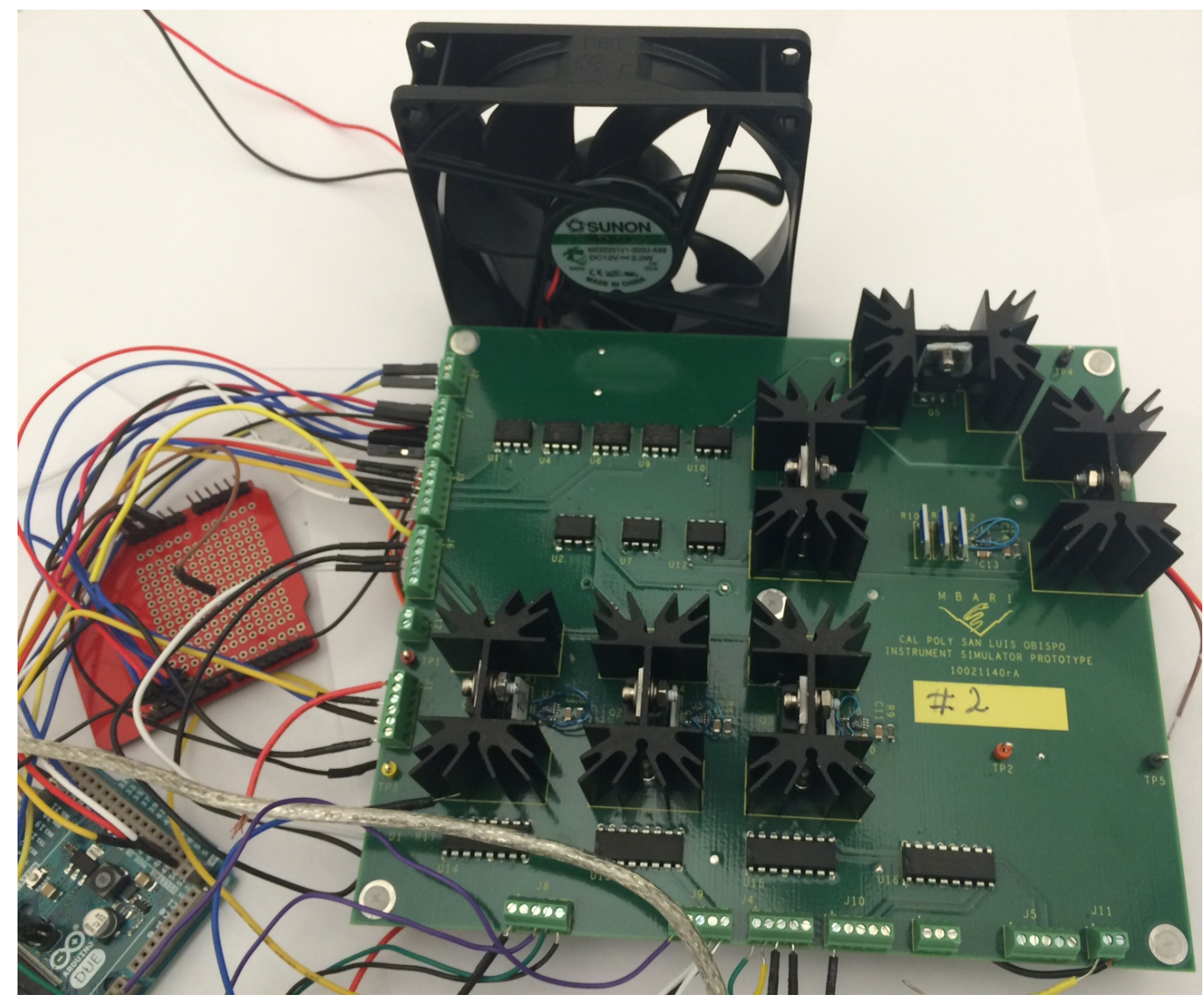

FIGURE 8: RELATIVE FAN SURFACE COMPARE TO OIS

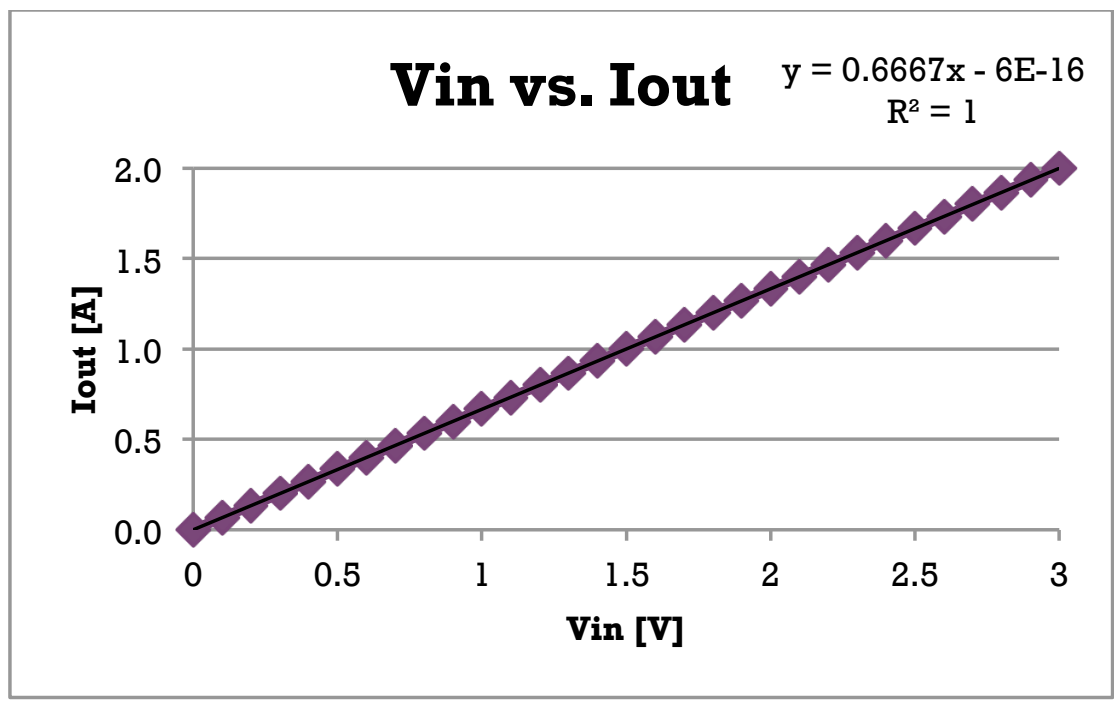

FIGURE 9: ELECTRONIC LOAD TEST RESULTS 
Figure 9 shows the result of the stable input from the power supply varying from $0 \mathrm{~V}$ to $3 \mathrm{~V}$ and the output of the electronic load from $0 \mathrm{~A}$ to $2 \mathrm{~A}$. By varying voltages from $0 \mathrm{~V}$ to $3 \mathrm{~V}$, the electronic load is able to sink in current ranges from $0 \mathrm{~A}$ to $2 \mathrm{~A}$.

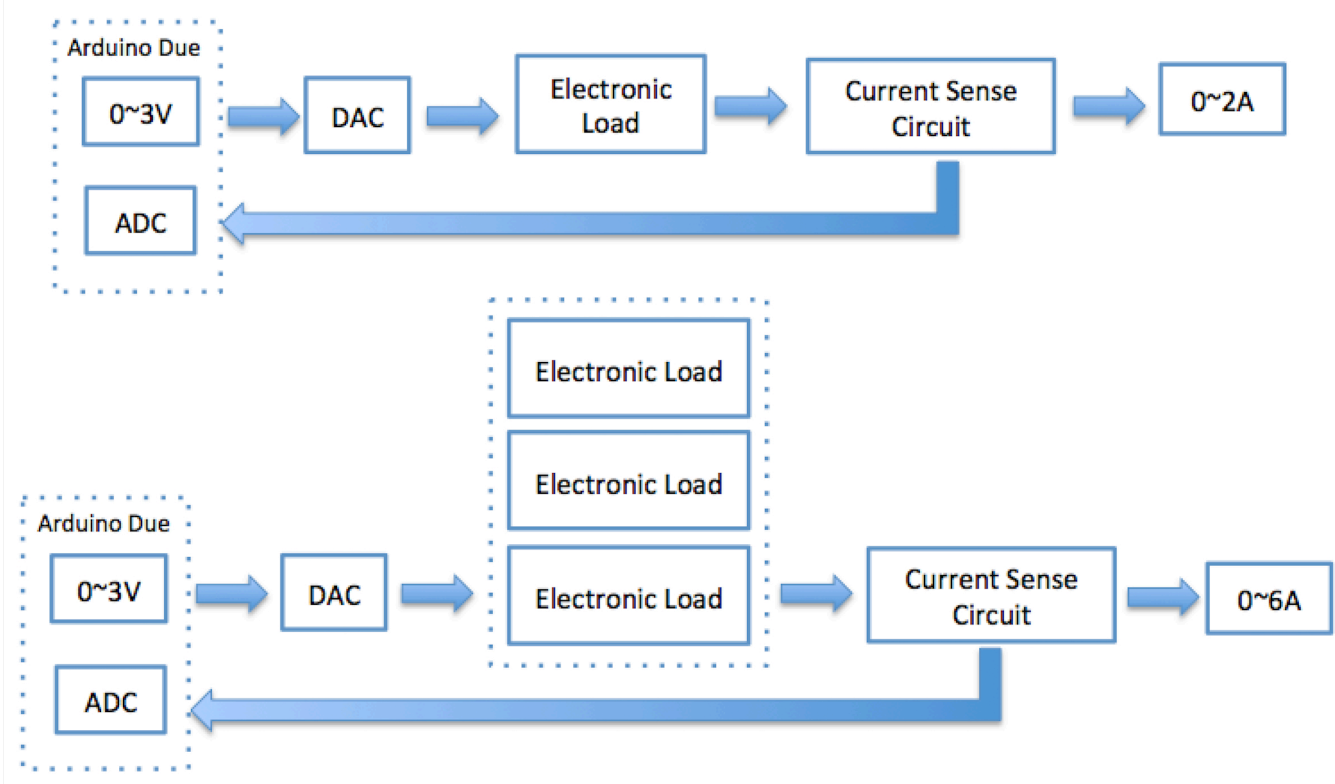

FIGURE 10: BLOCK DIAGRAM FOR SINGLE 2A AND LOAD AND SINGLE 6A LOAD

In order to achieve the fourth $0-6 \mathrm{~A}$ load, three $2 \mathrm{~A}$ electronic loads are connected in parallel, as shown in Figure 10. When the three 2A load are connected in parallel the current multiplies for channel 4 to sink in $6 \mathrm{~A}$ load, as shown in the equation below.

$$
6 A=3 \times 2 A
$$

The load will sink into the electronic load and will be the output current from the sensor node.

\subsubsection{CURRENT SENSE CIRCUITRY}

The current sense circuit is used to monitor the output current of the electronic load and shut down the OIS when the overall power of the OIS exceeds 75W. The LT1999 is selected due to its simplicity and practicality. To increase the resolution of the current sense circuit, the offset of the $\mathrm{V}_{\mathrm{REF}}$ is set at $1 \mathrm{~V}$, which provides a resolution of $2 \mathrm{~V}, 1$ volt to 3 volt, for the ADC. The current 
sense circuit can sense voltages ranging from $1 \mathrm{~V}$ to $3 \mathrm{~V}$ due to the offset of the $\mathrm{V}_{\mathrm{REF}}$. The original application of the LT1999 chip has an offset of $2.5 \mathrm{~V}$ at $\mathrm{V}_{\mathrm{REF}}$, shown in Figure 11. In order to lower the $\mathrm{V}_{\mathrm{REF}}$, an additional $52.3 \mathrm{k}$ resistor is added, in parallel with the $160 \mathrm{k} \Omega$ connected to ground, to lower the $\mathrm{V}_{\mathrm{REF}}$ to $1 \mathrm{~V}$, as shown in Figure 12.

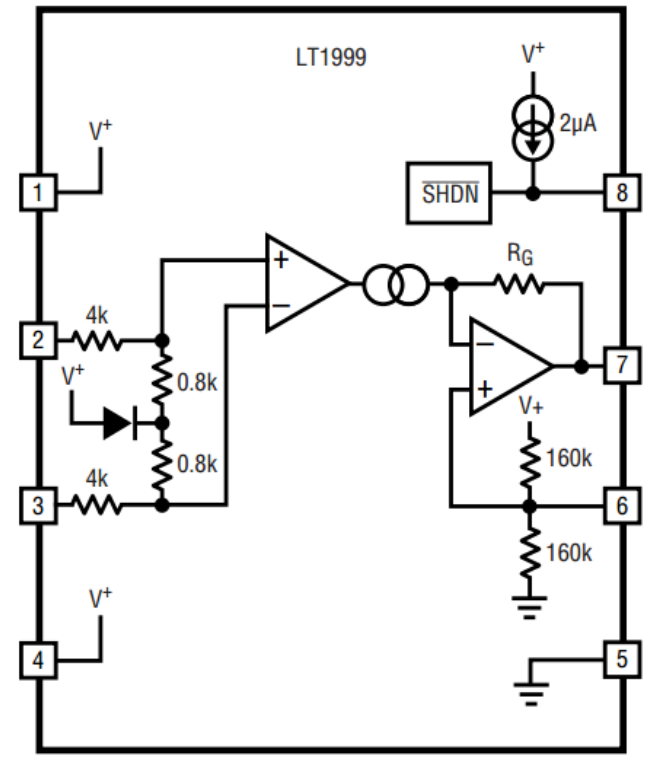

FIGURE 11: LT1999 BLOCK DIAGRAM [8]

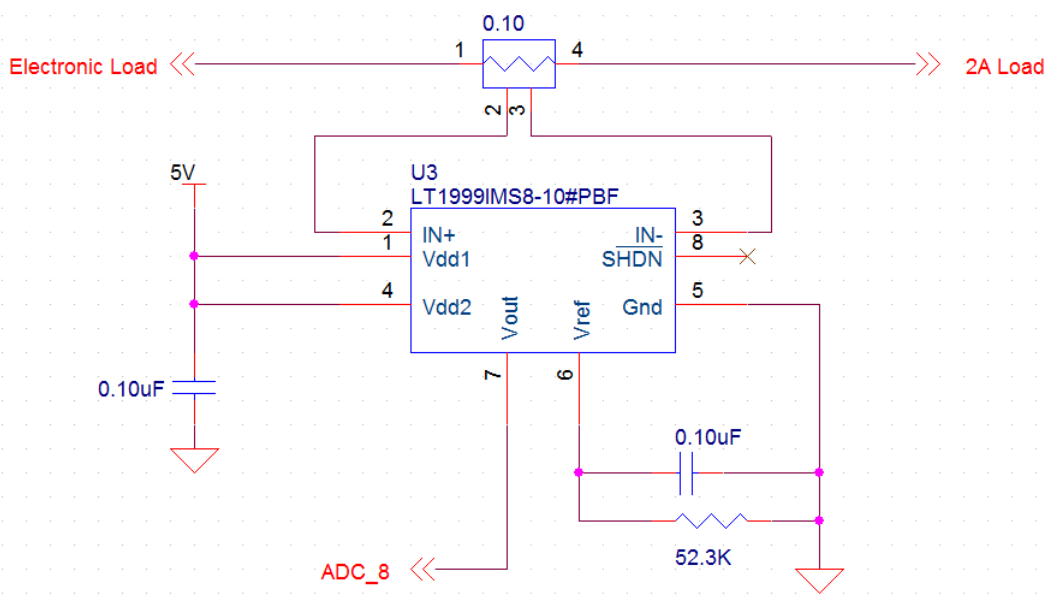

FIGURE 12: CURRENT SENSE CIRCUITRY

The modified current sense circuit shown in Figure 12 will obtain $2 \mathrm{~V}$ when the output current is $1 \mathrm{~A}$, the offset of $1 \mathrm{~V}$ added to the $1 \mathrm{~V}$ that the current sense circuit obtained. When the 
output current is $2 \mathrm{~A}$, the current sense circuit will obtain $3 \mathrm{~V}$, the offset of $1 \mathrm{~A}$ added to the $2 \mathrm{~V}$ that the current sense obtained.

\subsubsection{ADC INTERFACE}

The ADC interfaces the current sense circuit and the Arduino Due. The onboard ADC is selected. The onboard ADC has a resolution of 12 bits, which provides resolution of 4096 . The onboard ADC will take in the voltage from the current sense circuitry, 0volt to 3 volts, and convert the analog value into digital value and the Arduino Due will calculate the overall power to ensure the board does not exceed $75 \mathrm{~W}$.

To ensure the functionality of the ADC, the voltage measured by the multi-meter from the current sense circuit should match the voltage read from the ADC, as shown in Table 6.

TABLE 6: ADC VALUE CONVERSION

\begin{tabular}{|c|c|}
\hline Voltage from current sense resistor & Digital value \\
\hline 3 & 4095 \\
\hline 2.5 & 3413 \\
\hline 2 & 2730 \\
\hline 1.5 & 2048 \\
\hline 1 & 1233 \\
\hline
\end{tabular}

\subsubsection{4-20MA CURRENT LOOP TRANSMITTER}

A single 4-20mA current loop transmitter is designed for only load \#3, channel 3, on the OIS to communicate with 4-20mA instruments on the sensor node. The 4-20ma current loop transmitter, XTR117 [9], shown in Figure 13, from Texas Instruments is selected. According to the datasheet, 
the chip is built around Eq. (1). According to the DAC voltage range from $0 \mathrm{~V}$ to $3 \mathrm{~V}$, Eq. (1) is used to calculate the resistance of $15 \mathrm{k}$.

$$
I_{o}=\frac{100 V_{\text {in }}}{R_{\text {in }}}
$$

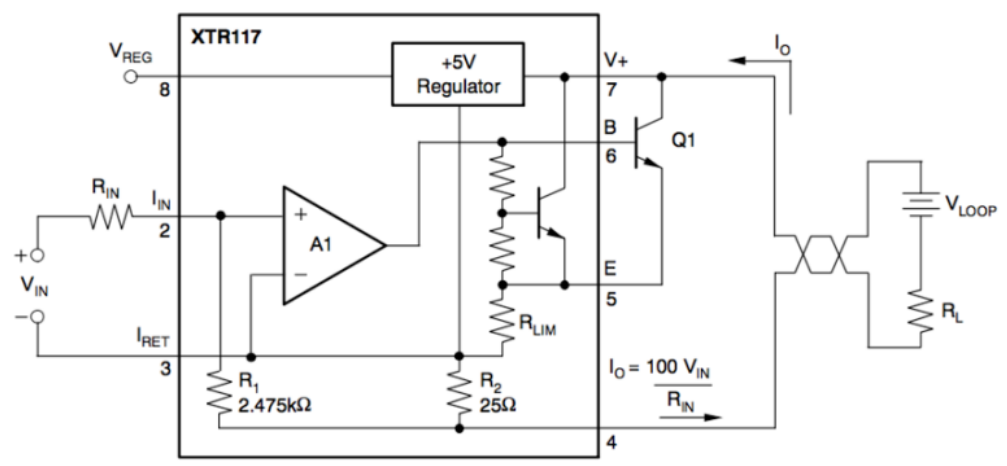

FIGURE 13: 4-20MA TRANSMITTER LOOP SCHEMATIC [9]

The $4-20 \mathrm{~mA}$ will take in voltages ranging from $0 \mathrm{~V}$ to $3 \mathrm{~V}$ and convert the voltages to $0 \mathrm{~mA}$ to 20mA. The following Figure 13 shows the test results of the 4-20mA current loop transmitter. The voltage to the current loop transmitter is supplied by the power supply and the receiving end of the current loop is represented by the $250 \Omega$. 


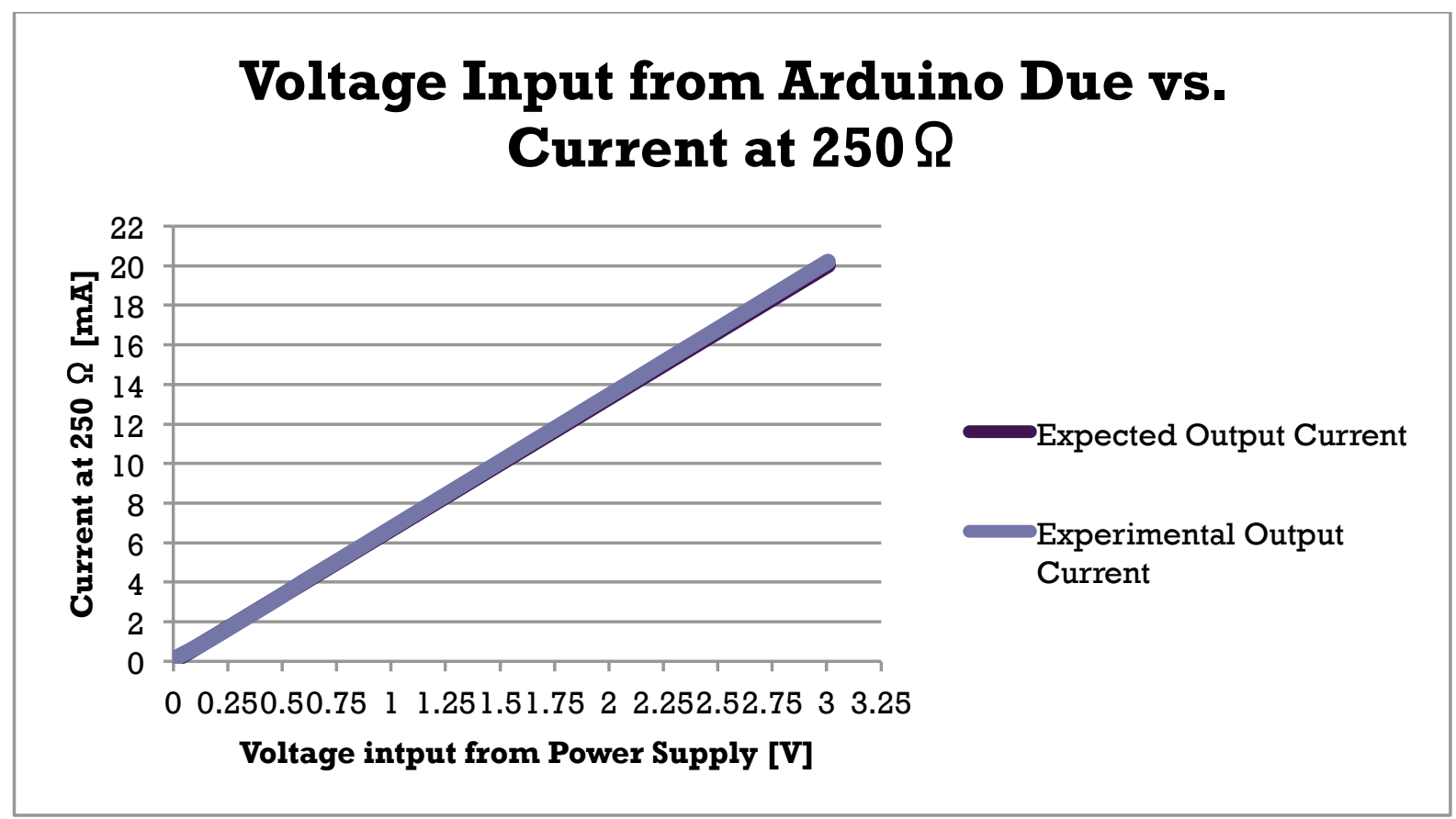

FIGURE 14: 4-20MA TRANSMITTER LOOP TESTING RESULT

\subsection{SOFTWARE}

The purpose of the software program is to provide a user interface platform for the user to command the OIS and monitors the current consumption on all active ports to ensure the OIS board does not exceed the maximum power of $75 \mathrm{~W}$. The three main hardware components for the software platform is the Arduino Due, the SD shield and the USB Port. The Arduino Due is used to initialize the OIS, to command the electronic load, and to calculate the overall power to ensure it does not exceed $75 \mathrm{~W}$. The SD shield includes the SD card. The SD card can store any sensor data and command sensor data. The USB port is used for testing purposes. In a complete design, the USB port will be replaced by the RS232 communication. 


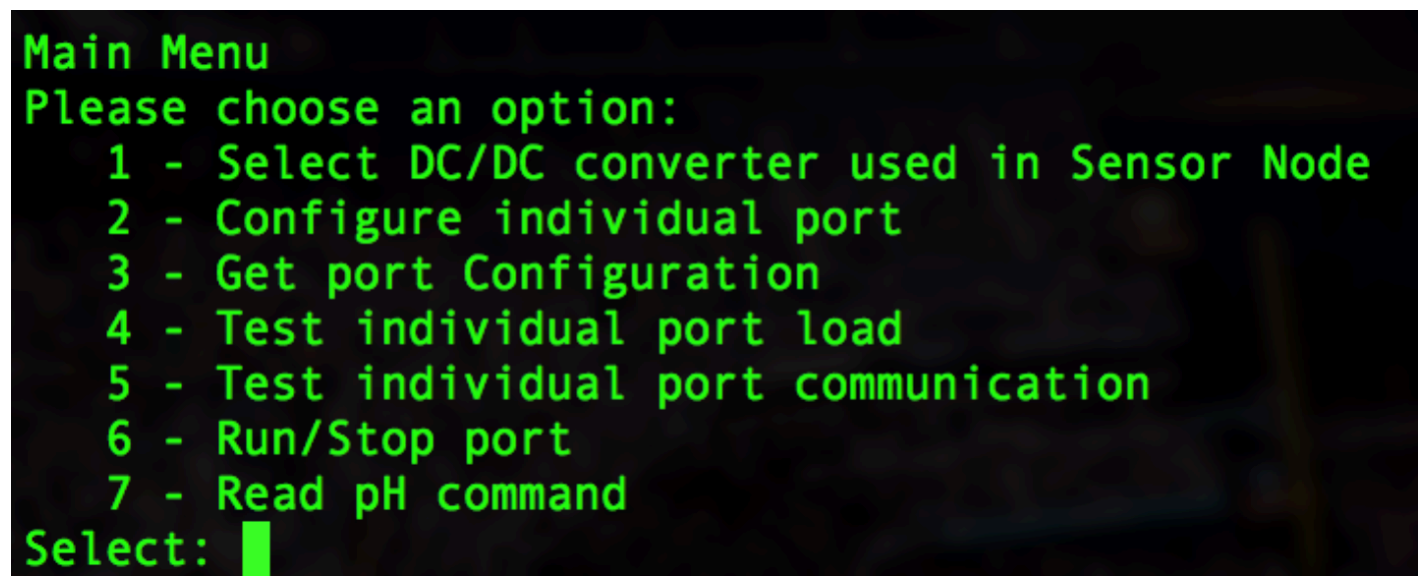

FIGURE 15: MAIN MEAU SCREEN ON HYPERTERMINAL WINDOW

The main menu screen shown in Figure 15 is the terminal program that operates the OIS. Option 1 on the terminal program allows the user to specify the voltage of the sensor node, which could be $12 \mathrm{~V}, 24 \mathrm{~V}$, or $48 \mathrm{~V}$. Option 2 allows the user to specify the desired configure channel and the desired functionality. The desired functionality could either be manual simulation or instrument simulation (described in the next subsection). Option 3 allows the user to check the status of each channel, when the program exceeds the power limit of $75 \mathrm{~W}$, the device will shut down immediately to protect the other hardware components on the OIS. Option 4 can test each individual port's electronic load. Option 5 can test each port's serial communication. Option 6 can run or stop individual ports. Option 7 is currently used for testing individual commands to simulate the SBE18s pH sensor. In the future, these commands will be incorporated into Option 5 for testing the serial communication. 


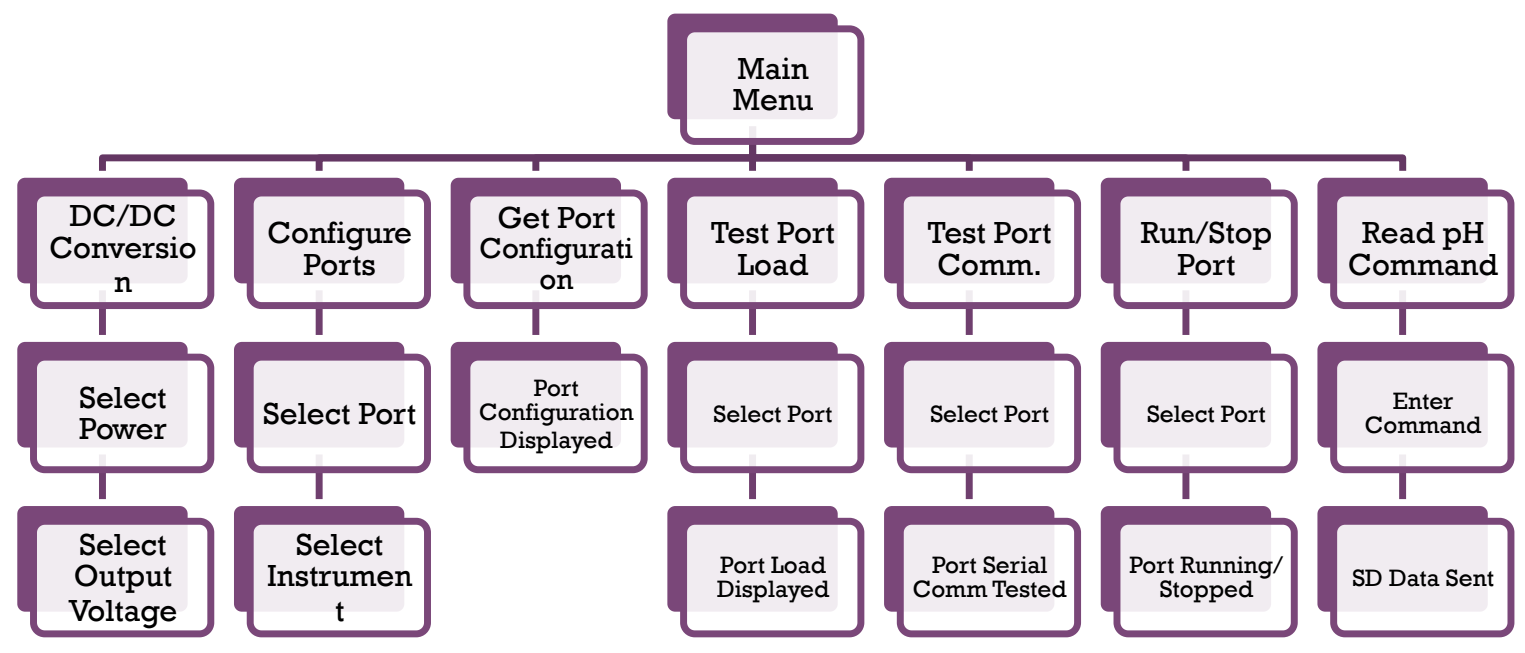

FIGURE 16: SOFTWARE FLOW DIAGRAM OF INSTRUMENT SIMULATOR

Figure 16 is the software flow diagram built within the main menu shown in Figure 15. DC/DC conversion gives the user the option to select power input from the sensor node, $12 \mathrm{~V}, 24 \mathrm{~V}$ or $48 \mathrm{~V}$. Configure ports gives the user the option to select either manual mode or sensor mode. Get port configuration shows the port data. Test port load will obtain the port data. Test port communication allows each port to be tested in sensor mode. Run/Stop ports run and stop individual ports. For now, there is three different pH commands, for each command. Read pH_1 command can be read when the first port is used. Read pH_2 command can be read when the second port is used. Read pH_3 command can be read when the third port is used. The pH_1, pH_2, and pH_3 can be replaced with other sensors and conduct different simulations. 


\subsubsection{MANUAL MODE /SENSOR COMMANDS}

The main menu of the OIS will appear on the computer screen after connecting the USB port to the computer. In order to start the OIS, the user will go through the main menu and configure each port in numerical order as shown in Figure 15.

After configuring the voltage level of the sensor node in option 1, there are two selections for option 2: the manual mode selection and the sensor command selection, as shown as Figure 17.

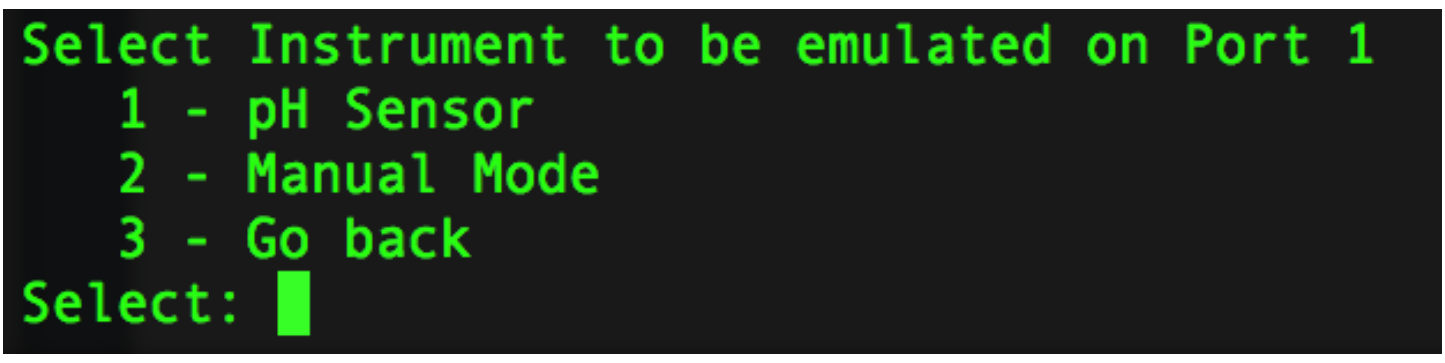

FIGURE 17: PH SENSOR AND MANUAL MODE SELECTION

The manual mode option will allow the user to configure the exact current that the user wants to simulate for the sensor behavior. The sensor command option, will allow the user to simulate sensor behaviors. As for now, the OIS only has $\mathrm{pH}$ sensor data stored. When $\mathrm{pH}$ sensor is selected, the OIS software program streams simulated data from the SD card. The three serial channels can simultaneously run the $\mathrm{pH}$ sensor, for each channel there will be a $\mathrm{pH}$ sensor read function in order to read the $\mathrm{pH}$ data as shown in Figure 18.

Figure 18 shows an example of the OIS responding to the sensor node's command of "gethd" directed toward the SBE18s pH sensor. 


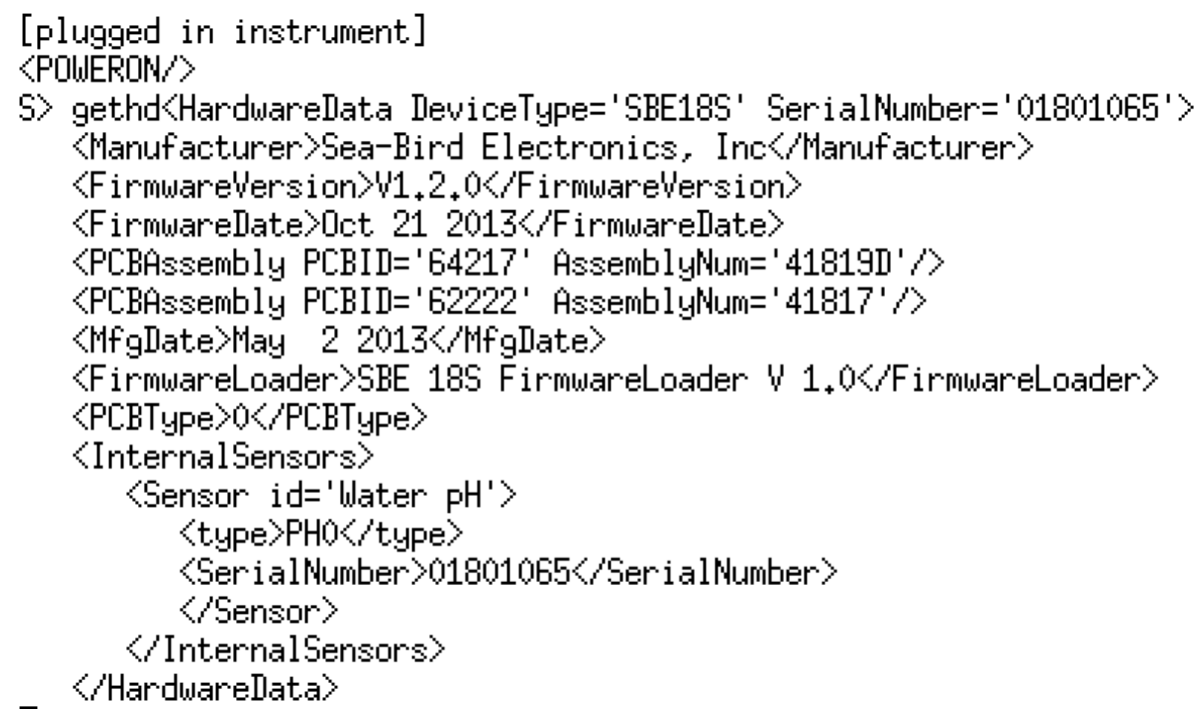

FIGURE 18: EXAMPLE DATA FORMAT FOR PH SENSOR [2] 


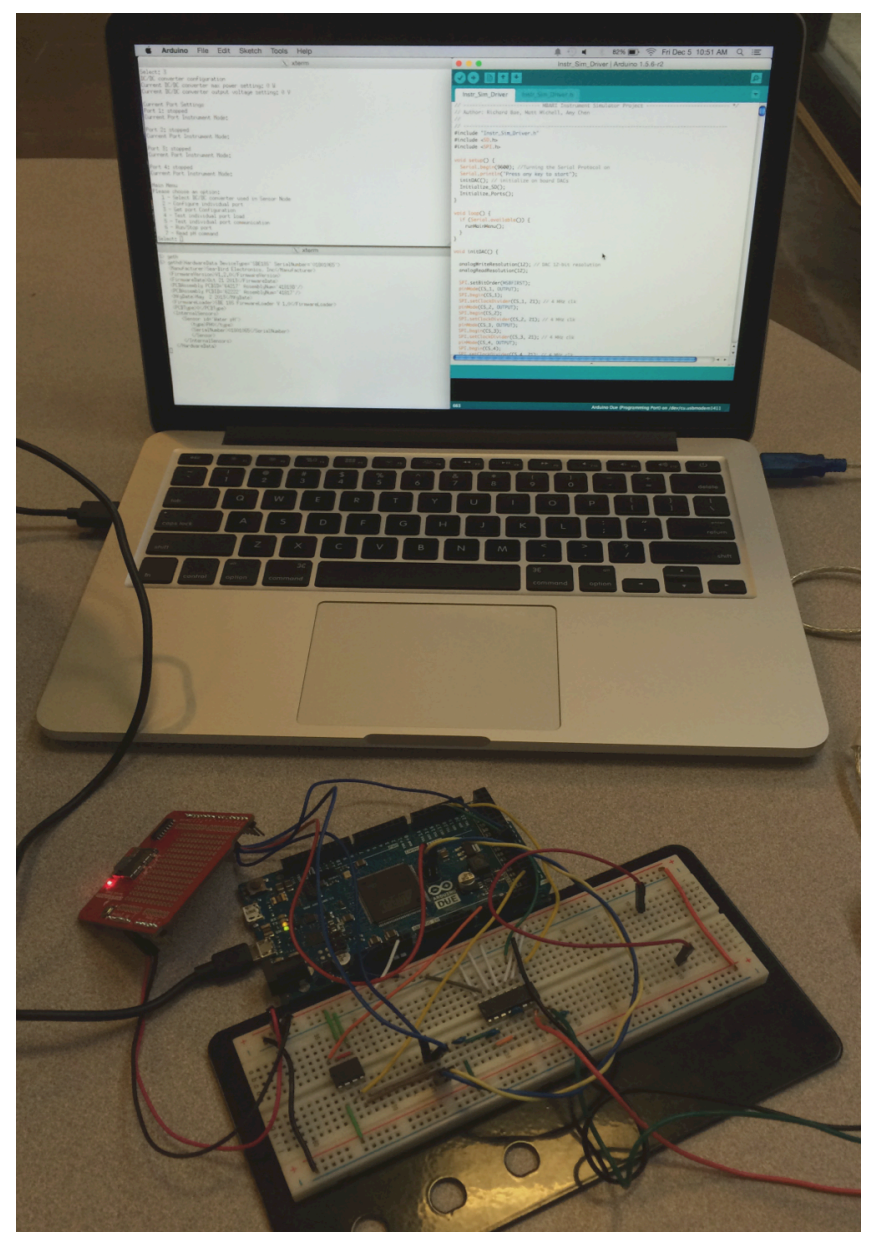

FIGURE 19: ARDUINO DUE CONNECTED TO A COMPUTER THROUGH A USB CONNECTION [2]

Figure 19 shows the Arduino Due connected to the computer through a USB connection. 


\subsubsection{RS232 SERIAL PORT COMMUNICATIONS/ TRANSCEIVER CHIP}

MAX3323E is powered by $3.3 \mathrm{~V}$, supplied from the Arduino Due. RS232 is a commonly used protocol for the oceanographic instruments, which utilizes serial communication. The $1 \mathrm{uF}$ capacitors are used to reduce power supply noise. Figure 20 shows the schematic of the transceiver. Figure 21 shows the setup of the RS232 transceiver chip on the breadboard prior to the layout of the complete OIS board. Figure 22 shows the complete setup of the RS232 along with the Arduino Due and the SD card.

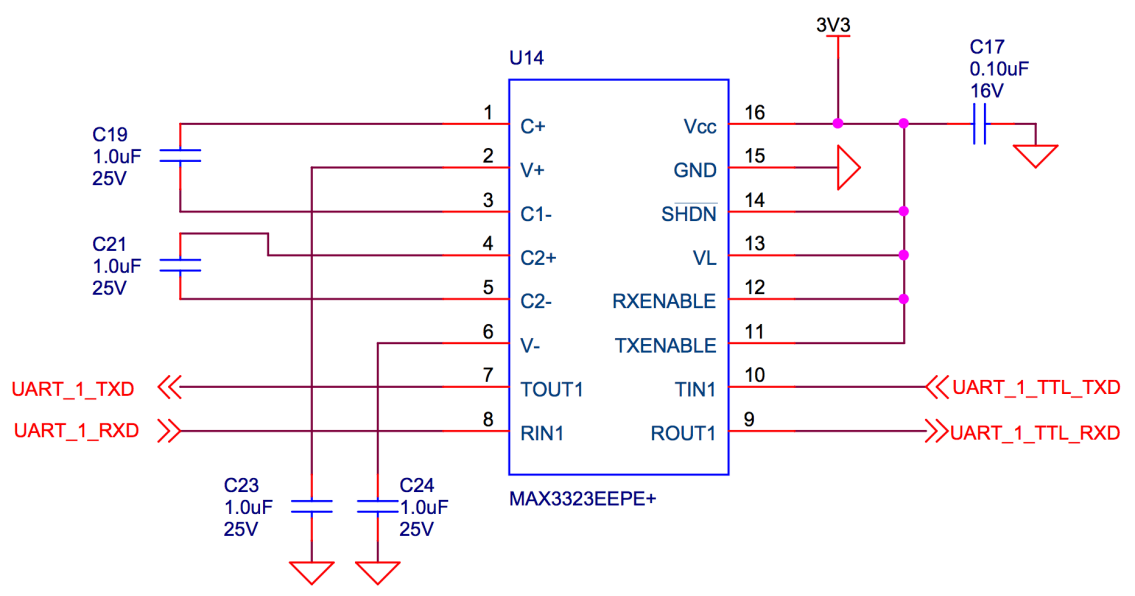

FIGURE 20: TRANSCEIVER SCHEMATIC 


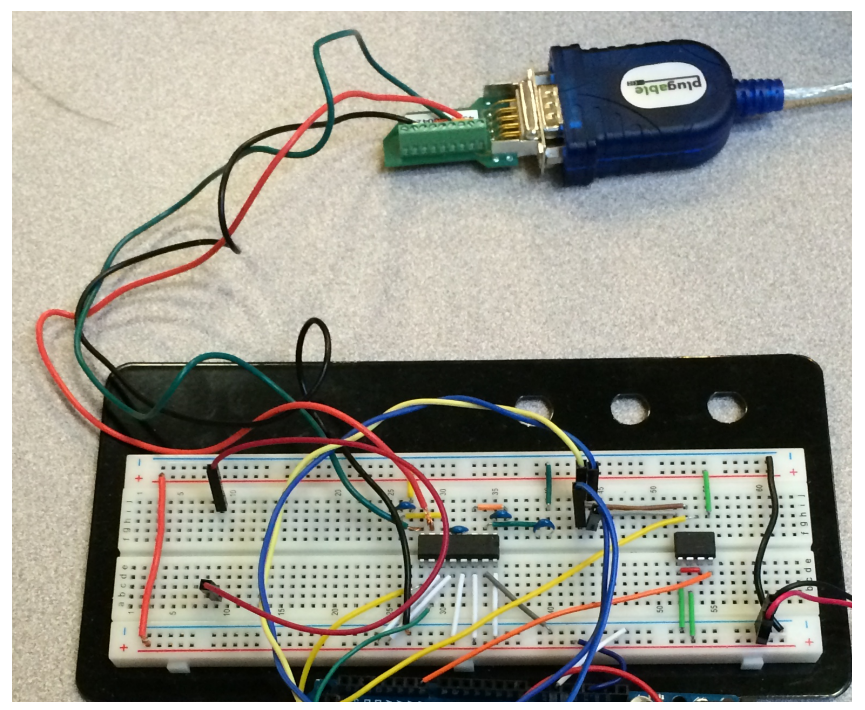

FIGURE 21: RS232 TRANSCEIVER SET UP [2]

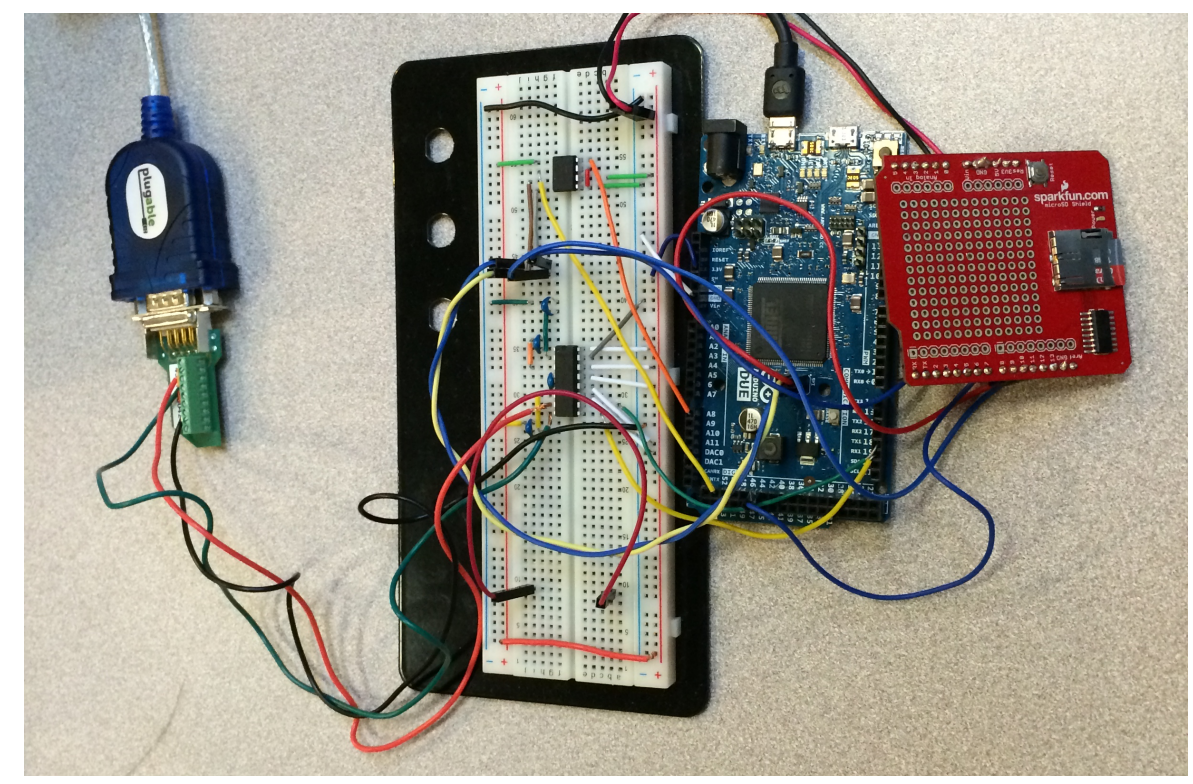

FIGURE 22: ARDUINO DUE CONNECTED TO RS232 CONNECTOR [2] 


\subsubsection{SD CARD}

The purpose of the SD card is to store up the sensor data so the OIS can acquire data when the sensor node requests data. Any sensor data can be stored in the SD card. The SD card is connected through the SD shield to the Arduino Due as shown in Figure 23.

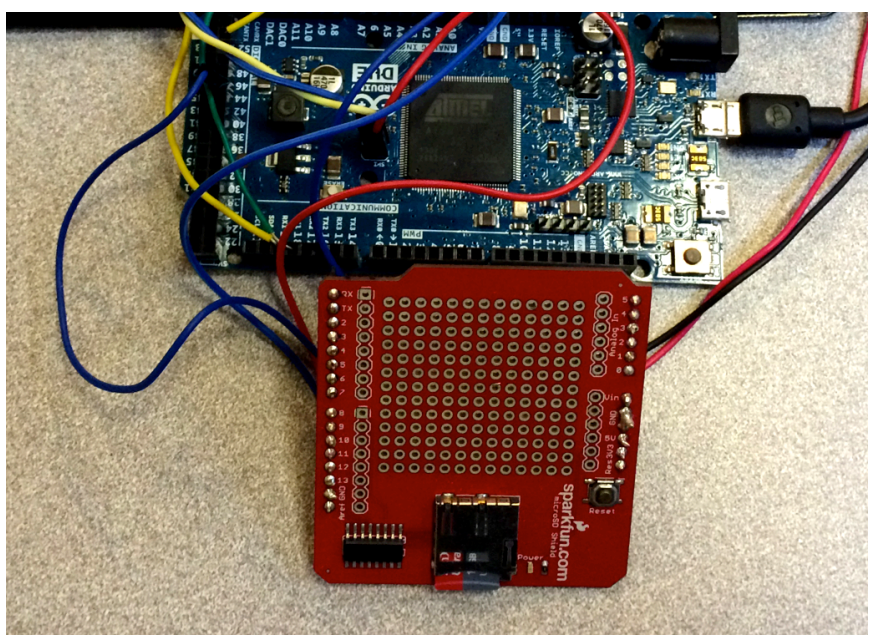

FIGURE 23: ARDUINO DUE WITH SD CARD SHIELD ATTACHED [2] 
Integration testing is essential to ensure the functionality of the OIS board. The following test cases are designed to ensure the OIS board meets the specification and can withhold harsh conditions. The tests include the hardware integration, the hardware and software integration (parallel testing), and the thermal testing.

The purpose of the hardware integration testing is to ensure the hardware board is working properly prior to the integration with the software on the Arduino Due. Same for the software integration, in order to ensure the completion of the OIS, software was tested separately. Finally, after the integration of the hardware and software, thermal testing is conducted to ensure the OIS is protected from overheating. Figure 24 shows the testing diagram of the OIS. There are three transceivers used to test each serial port. Each transceiver will be connected to the USB serial converter then the UART port. 


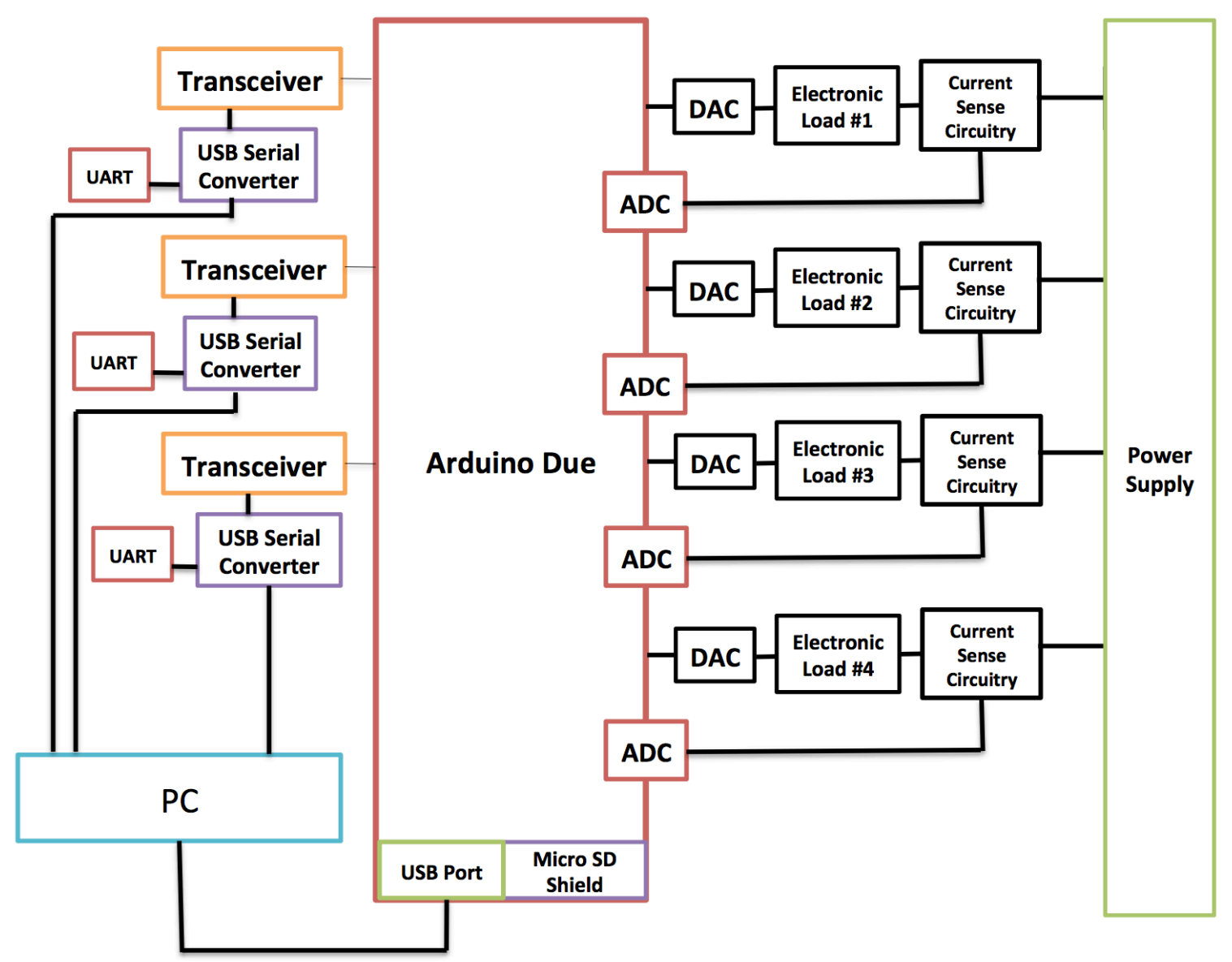

FIGURE 24: OIS TESTING BLOCK DIAGRAM 
The hardware interface includes the interface between the DAC and the electronic load, the current sense circuit and the ADC, the integration of the DAC, electronic load, current sense circuit and ADC, finally the DAC and the 4-20mA current loop transmitter. The hardware interface focuses on any inaccuracy, oscillation, and noise issue.

\subsubsection{DAC \& ELECTRONIC LOAD INTERFACE}

The DAC controlled programmable current sink circuit is shown in Figure 5. A square wave is inputted to the op-amp to test the accuracy of the electronic load. As shown in Figure 25, there are oscillations at the gate of the MOSFET. The scope capture shown in Figure 25 has an input of $1 \mathrm{Vpp}$ square wave with an offset at $500 \mathrm{mV}$. The yellow waveform represents the input square wave to the op-amp and the blue waveform represents the gate of the MOSFET. The gate voltage would vary due to the feedback loop and the input voltage. When the circuit is in ON-state of the square wave, high-frequency oscillation develops. The oscillations are seen here as a "thick band" in the gate voltage waveform, shown in Figure 25.

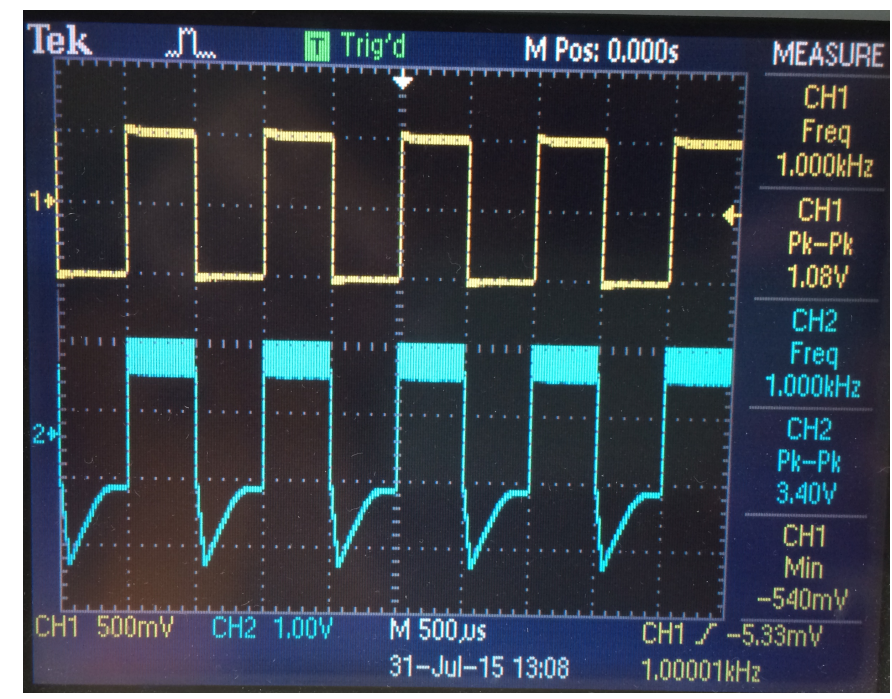

FIGURE 25: INPUT OF 1VPP (YELLOW); OUTPUT OF GATE VOLTAGE (BLUE)

Further research was done to analyze the frequency oscillation that develops within the closed 
loop feedback, shown in Figure 26. Figure 25 shows the three capacitors within the small signal model of the MOSFET: $C_{G D}, C_{G S}$, and $C_{D S} . C_{G S}$ is neglected due to the unity gain from the output of the op-amp to the source of the MOSFET. $C_{D S}$ is relatively small compare to $C_{G D}$, therefore it has no affect compare to $C_{G D}$.

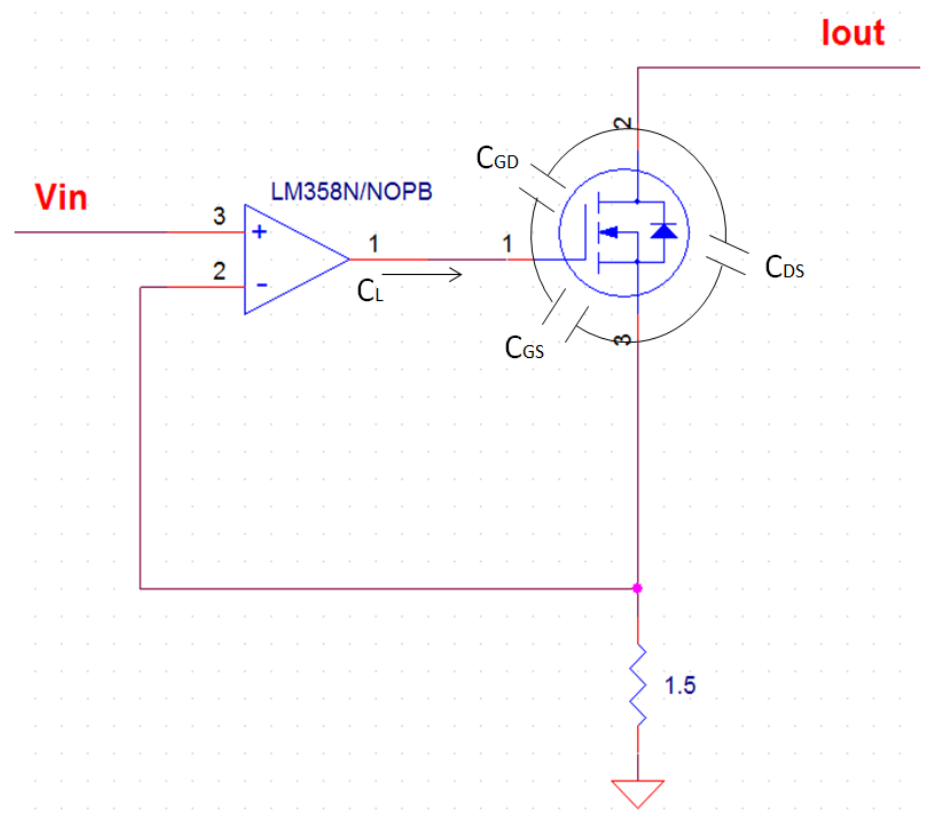

FIGURE 26: ELECTRONIC LOAD WITH SMALL SIGNAL CAPACITORS

The output resistance of the op-amp is approximately $25 \Omega$ according to the LM358 datasheet [5]. According to the FD050AN datasheet, the capacitance input is $3900 \mathrm{pF}$ and the capacitance output is $750 \mathrm{pF}[4]$. 


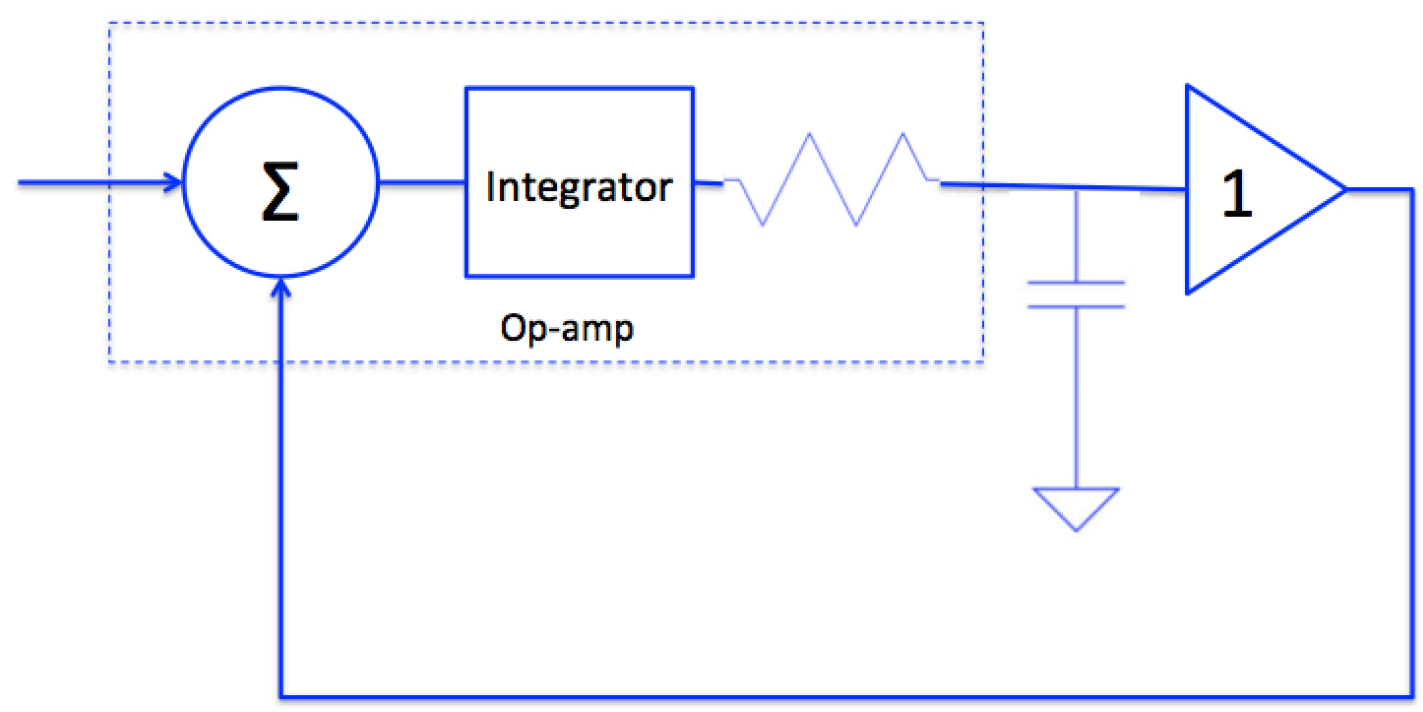

FIGURE 27: CONCEPTUAL ELECTRONIC LOAD CONTROL LOOP

The presence of $C_{G D}$, approximately $3900 \mathrm{pF}$, forms a low pass filter with the internal resistor form the op-amp LM358, 25 $\Omega$, as shown in Figure 11. When feedback is included as shown in Figure 27, the phase shift and gain will cause the oscillation to occur. The MOSFET at the output of the op-amp is shown to be DC grounded, therefore the MOSFET appears to be unity gain. The capacitor shown in Figure 27 is the $C_{G D}$ from Figure 26. The resistor within the op-amp is the internal resistor of LM358. Figure 26 shows the conceptual electronic load control loop and shows the instability of the control through the low pass filter formed by the internal resistance within the op-amp and the capacitive load from the MOSFET. This issue could be easily prevented if the selection process of the op-amp was more careful. The instability within the feedback loop occurs due to the reduced phase margin caused by the parasitic pole. 


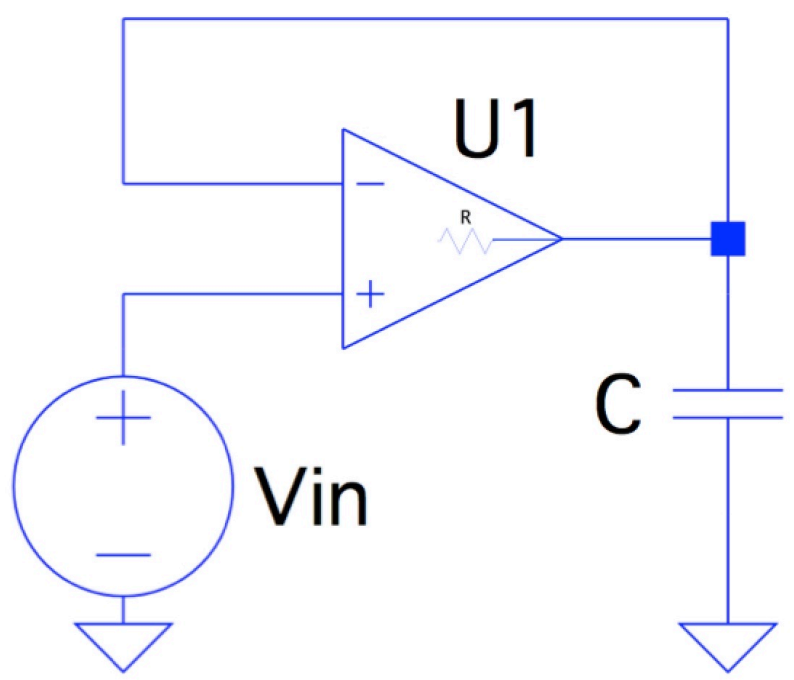

FIGURE 28: LOW PASS FILTER WITH OP-AMP FEEDB ACK

There are many ways to compensate for the instability caused by the feedback loop [8]. The approach chosen is to increase the bias current of the output stage thus lowering the output resistance of the op-amp and pushing the parasitic pole at higher frequency. The resistor $R_{B I A S}$ is inversely proportional to the biased current, in other words $R_{B I A S}$ decreases when there is higher current.

The resistor $R_{B I A S}, 1 \mathrm{k} \Omega$ in the Figure 28 increases the bias current of the output stage of the LM358, op-amp. The large bias current caused the small output resistance at the op-amp, which removes the oscillation caused by the feedback loop. The functional block diagram of the LM358 [5] is shown in Figure 29. 


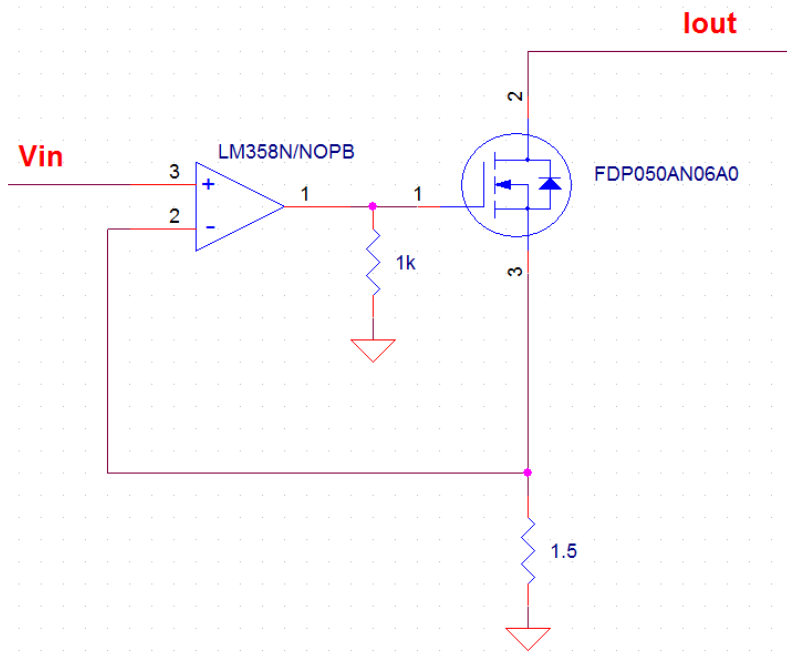

FIGURE 29: ELECTRONIC LOAD WITH ADDITIONAL RESISTOR

The Darlington Pair of the push-pull stage shown in Figure 29 results with the biased current at $50 \mathrm{uA}$. The output resistance of the last stage of the op-amp is estimated to be no less than $1 \mathrm{k} \Omega$.

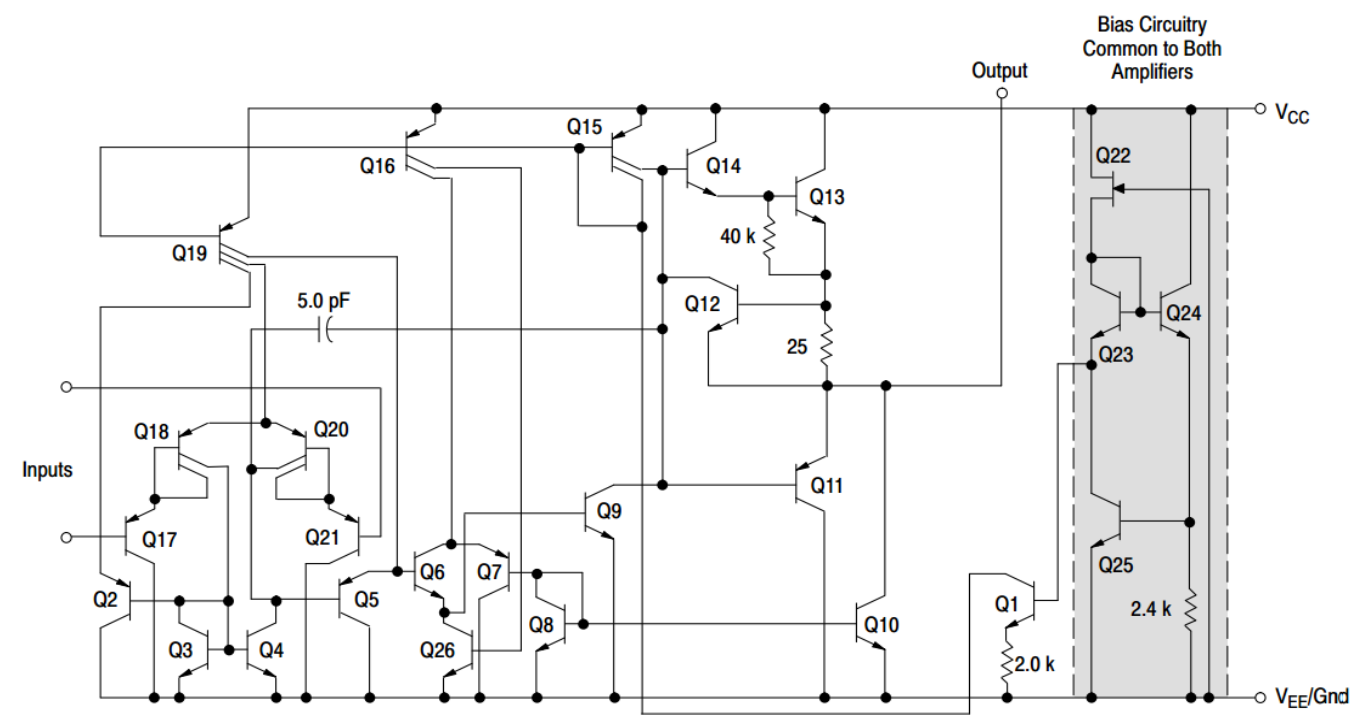

FIGURE 30: SCHMATIC DIAGRAM OF ONE-HALF OF LM358 [5]

As shown in Figure 30, Figure 30 the addition of the $1 \mathrm{k} \Omega$ bias resistor resolves the oscillation issue. 


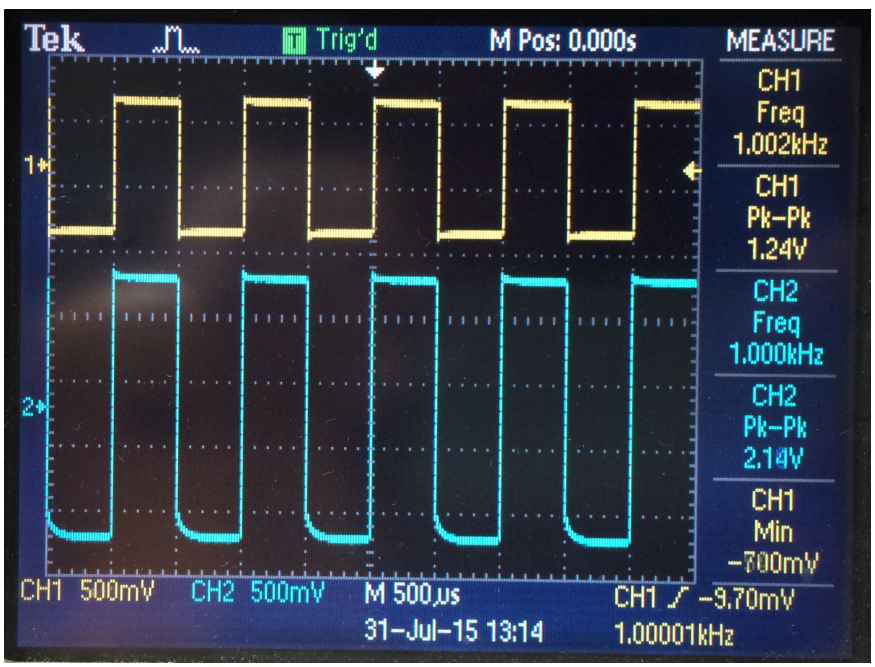

FIGURE 31: INPUT OF 1VPP (YELLOW); OUTPUT OF GATE VOTLAGE (BLUE)

After testing the DAC, the DAC is integrated with the tested electronic load, shown in Figure 32.

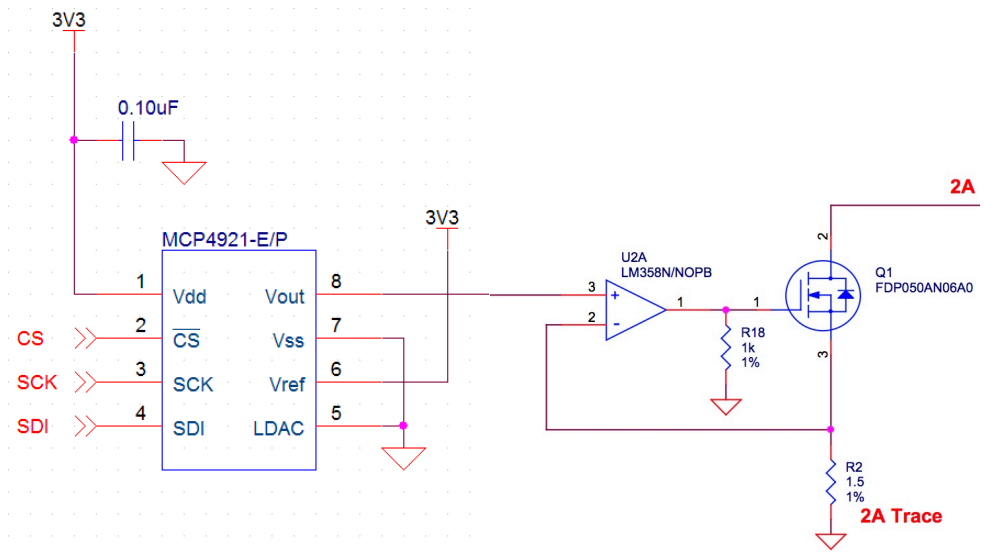

FIGURE 32: DAC CONTROLLED ELECTRONIC LOAD SCHEMATIC 


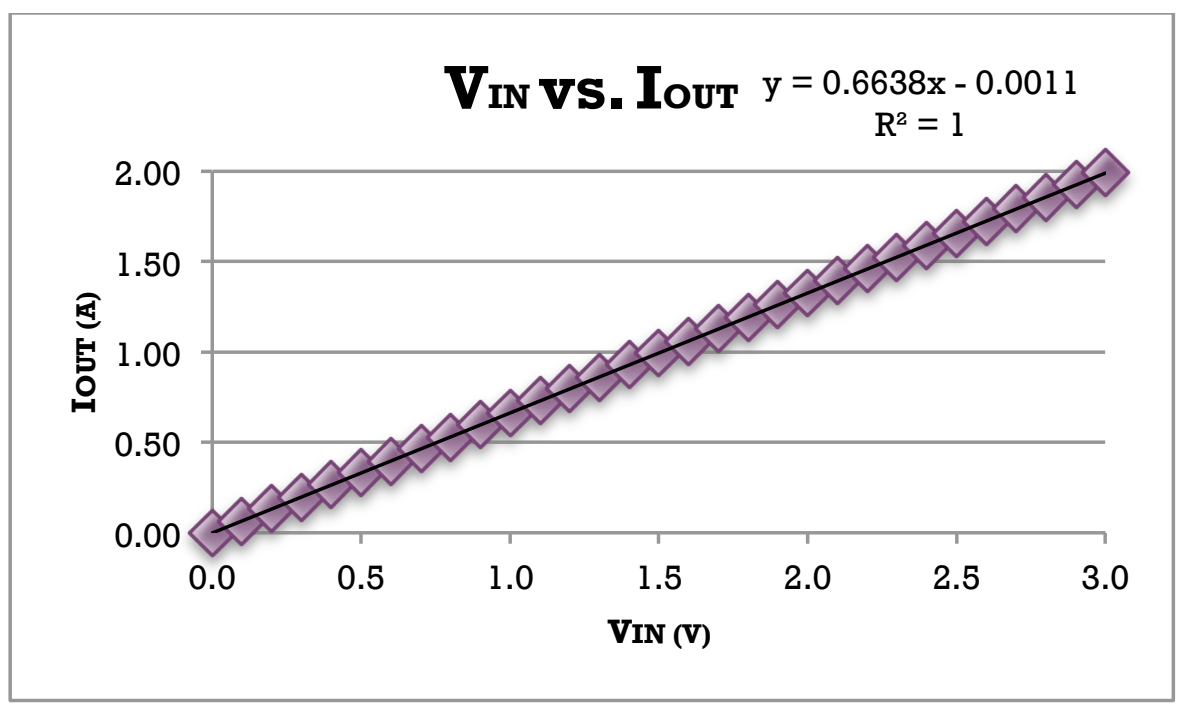

FIGURE 33: VOLTAGE INPUT FROM THE DAC VS. CURRENT OUTPUT TO THE $12 \mathrm{~V}$ SUPPLY SENSOR NODE

Figure 33 shows the voltage input from the DAC verses the current output to the $12 \mathrm{~V}$ supply sensor node. As shown in Figure 33, the input voltage ranging from $0 \mathrm{~V}$ to $3 \mathrm{~V}$ corresponds to the output current ranging from $0 \mathrm{~A}$ to $2 \mathrm{~A}$.

\subsubsection{CURRENT SENSE CIRCUIT \& ADC INTERFACE}

The current sense circuitry and the ADC are tested after integration, as shown in Figure 34. There is a ground voltage at 0 volt and a voltage reference which lowered to $1 \mathrm{~V}$ with voltage division as shown below. Due to the different voltages, the troubleshooting took a while during this integration. Table 7 shows the voltage relationship between the ADC voltage and the current sense circuit current, the experimental data matches the expected data. 


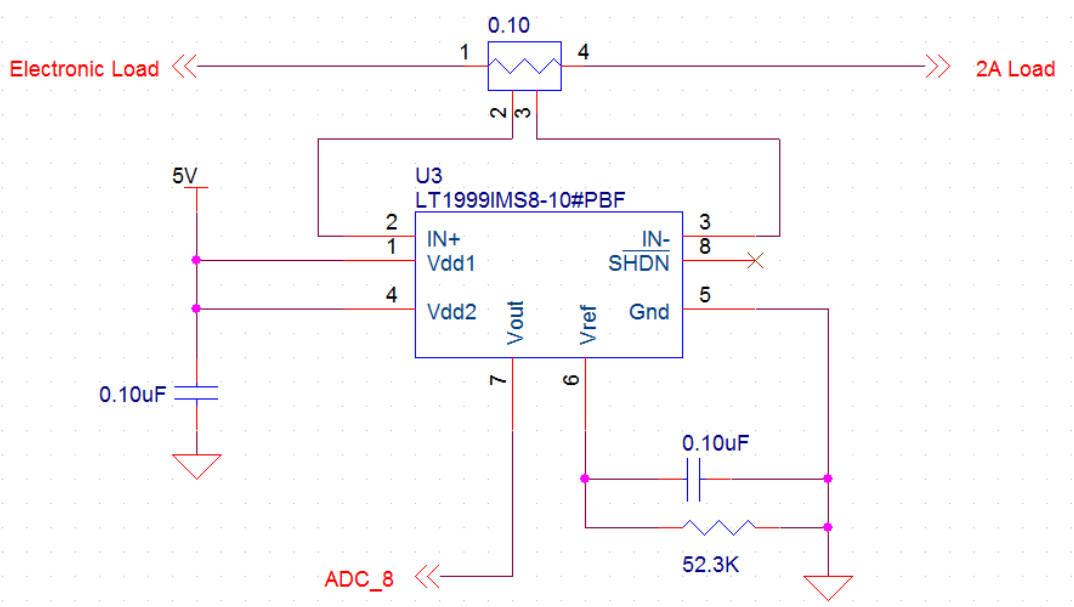

FIGURE 34: CURRENT SENSE CIRCUIT AND ADC SCHEMATIC

TABLE 7: CURRENT SENSE CIRCUIT VS. ADC

\begin{tabular}{|c|c|}
\hline $\begin{array}{c}\text { ADC } \\
{[\mathrm{V}]}\end{array}$ & Current Sense Circuit [A] \\
\hline 1.0 & 0 \\
\hline 1.5 & 1 \\
\hline 2.0 & 1.5 \\
\hline 2.5 & 2.0 \\
\hline 3.0 & \\
\hline
\end{tabular}

4.1.3 DAC \& ELECTRONIC LOAD \& CURRENT SENSE CIRCUITRY \& ADC INTERFACE

The testing set up for the hardware integration is shown in Figure 35. The Arduino Due is used to control the input to the DAC and the drain of the MOSFET is connected to the $12 \mathrm{~V}$ power supply. The result is shown in Figure 36, which displays the theoretical data, the experimental data reading from the power supply and the ADC data from the Arduino Due. The reading from the Arduino Due matches the theoretical data and the actual data result on the power supply, which represents the sensor node. 


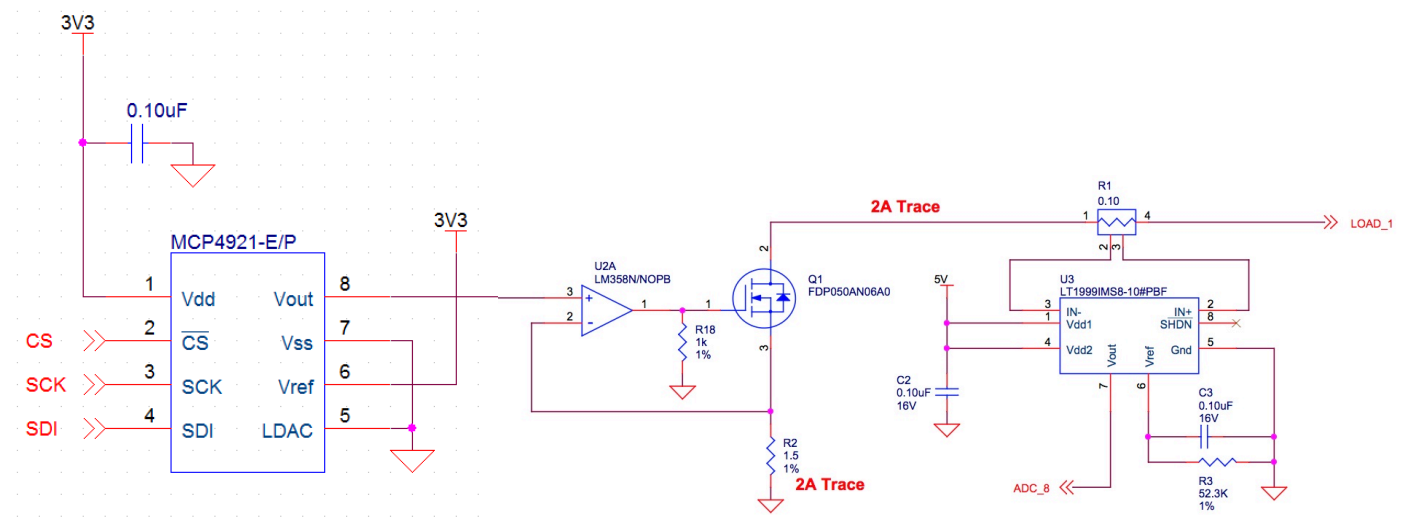

FIGURE 35: DAC AND ELECTRONIC LOAD AND CURRENT SENSE CIRCUIT AND ADC SCHEMATIC

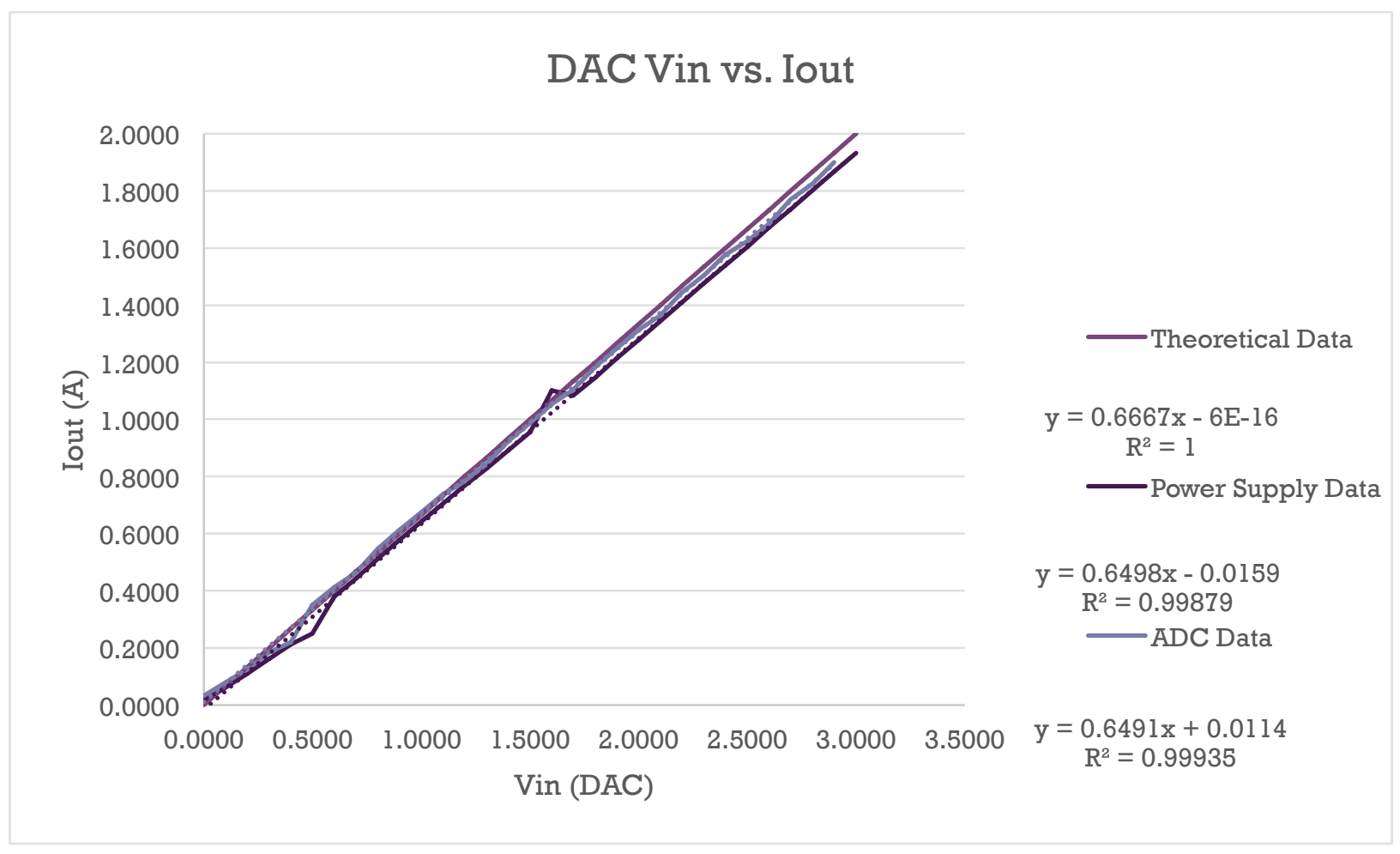

FIGURE 36: INTEGRATION TESTING RESULT 


\subsubsection{DAC \& 4-20MA CURRENT LOOP TRANSMITTER INTERFACE}

4-20mA transmitter is an unique communication protocol commonly used in oceanographic instruments. In order to include this protocol into OIS, the 4-20mA transmitter is designed and implemented, as shown in Figure 37. Other than the increase in noise, the DAC and 4-20mA current loop transmitter interface went well. The result is verified and shown in Figure 38.

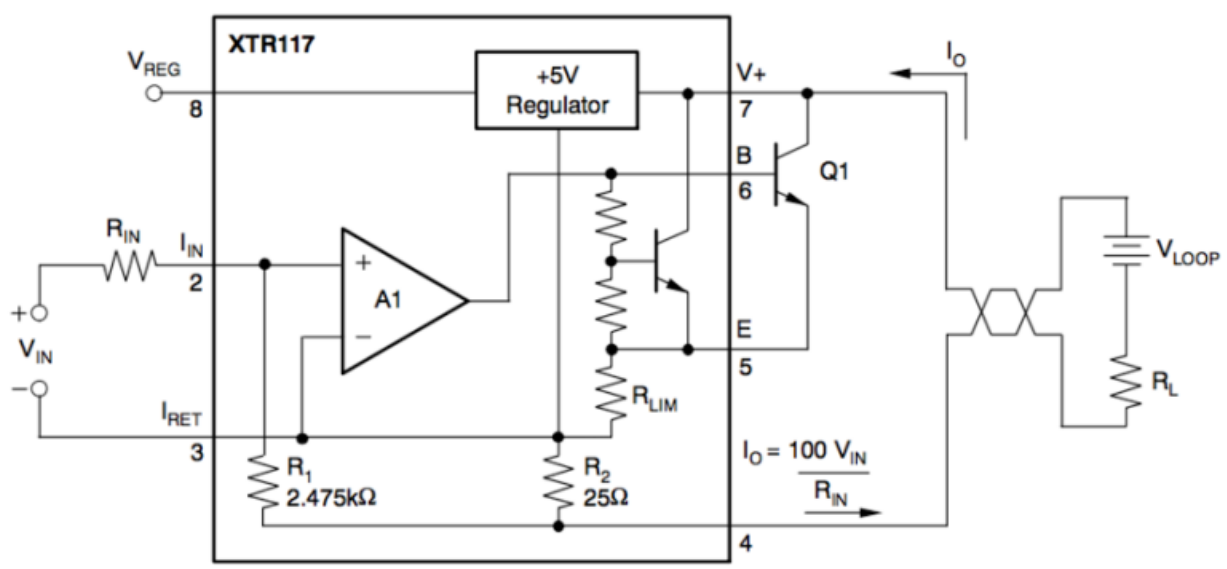

FIGURE 37: DAC 4-20MA CURRENT LOOP TRANSMITTER

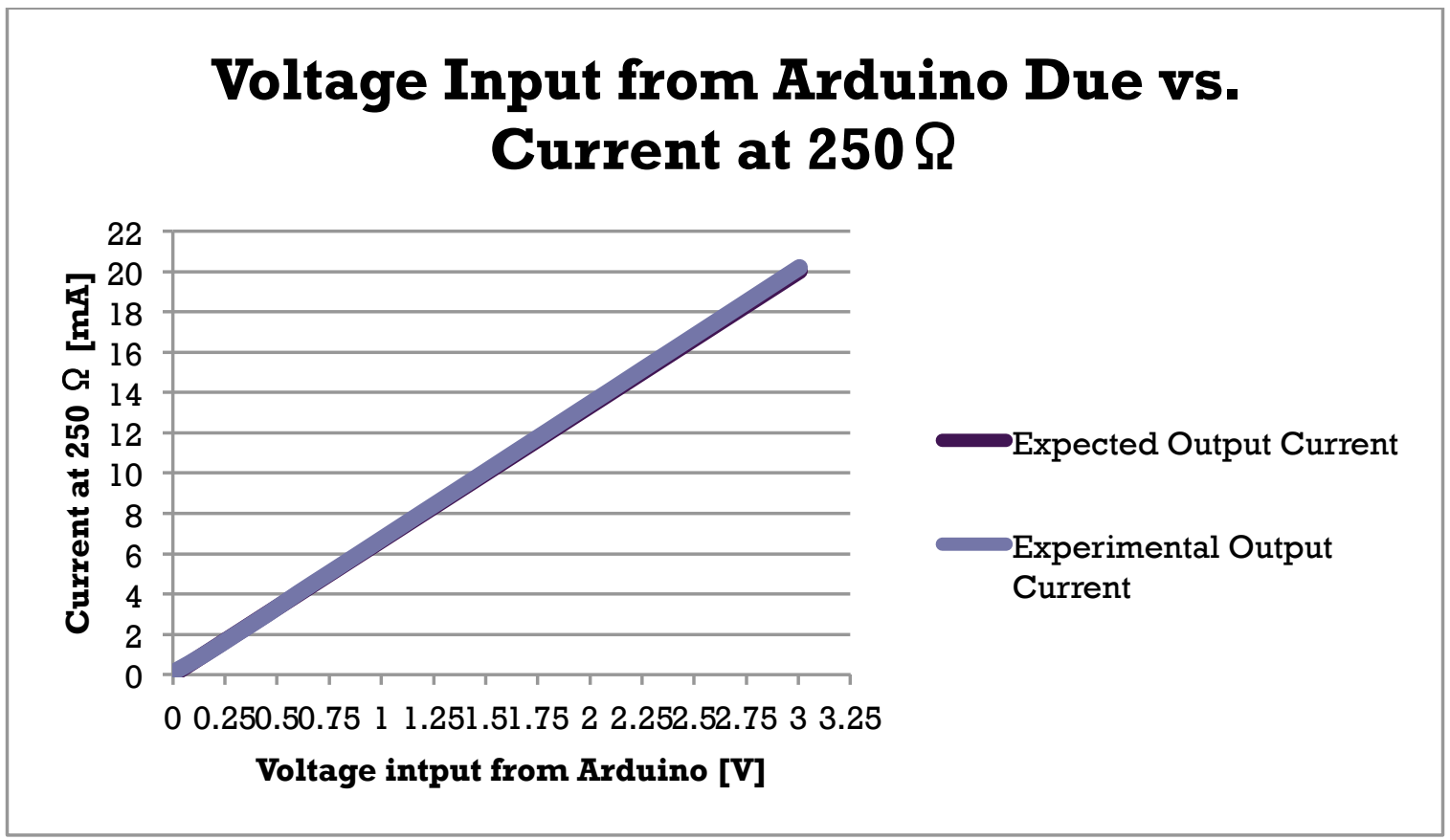

FIGURE 38: DAC AND 4-20MA CURRENT LOOP TRANSMITTER RESULT 


\subsection{SOFTWARE AND HARDWARE SYSTEM INTEGRATION}

After testing each individual part of the hardware board, the layout schematic was designed and implemented, as shown in Figure 39. Finally, the Software program on the Arduino Due was then integrated with the hardware board to do further testing.

There are two major modes of the OIS: The manual mode and the sensor mode. The manual mode is previous discussed in the set-up of the OIS. The sensor mode allows the user to select whichever sensor desired by the user. Finally the thermal testing ensures the board does not get burned when misused.

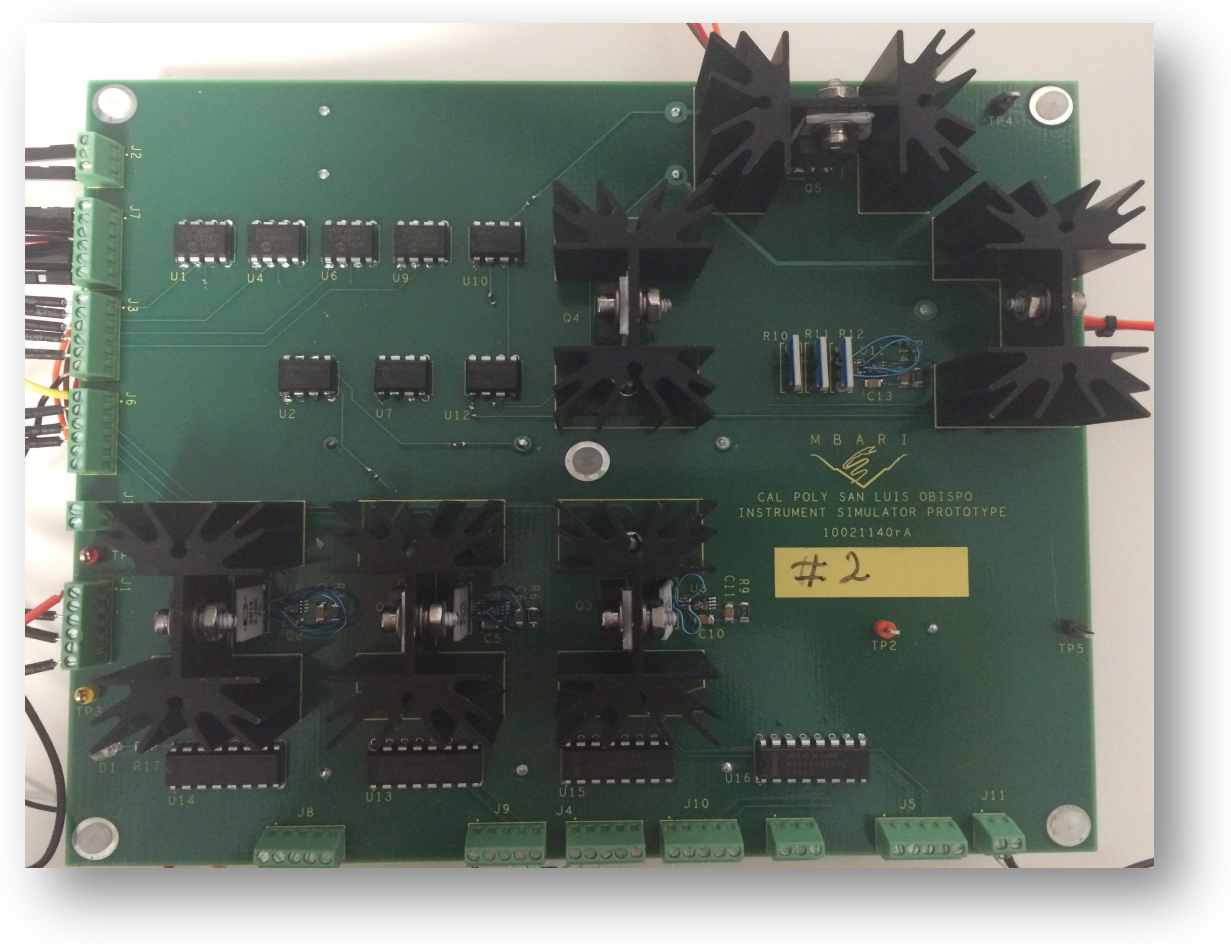

FIGURE 39: THE OIS CIRCUIT BOARD 


\subsubsection{PARALLEL MANUAL MODE TESTING}

In order to show each channel does not interfere from each other, there are testing done separately on single $2 \mathrm{~A}$ load, three $2 \mathrm{~A}$ loads and the single $2 \mathrm{~A}$ load on the OIS. The manual mode allows the user to simulate each channel up to full load (2A) for testing purposes. Manuel mode allows the user to run different channels at the same time within the total power limitation of $75 \mathrm{~W}$. (Within the power limitation of $75 \mathrm{~W}$, the user can input any desired current output and expect the entered current to be outputted.)

The parallel testing of multiple sensors is necessary to ensure the accuracy of the system. As shown in Figure 40, Figure 41, and Figure 42, the parallel testing result demonstrates the consistency of the accuracy of the OIS. The expected current is the current the user would input to the OIS (the expected output current from the sensor node) and the output current is the current that is displayed on the power supply (which should match the expected current). Figure 39, Figure 40, and Figure 41 show that the overall OIS system remains linear and accurate when all loads are running.

The following single $2 \mathrm{~A}$ load, three parallel $2 \mathrm{~A}$ load and single $6 \mathrm{~A}$ load show the stability of the device. The expected output load matches the actual output load, which would be the output from the sensor node connected to the OIS. Therefore the figures shown below confirmed the stability of the device. 


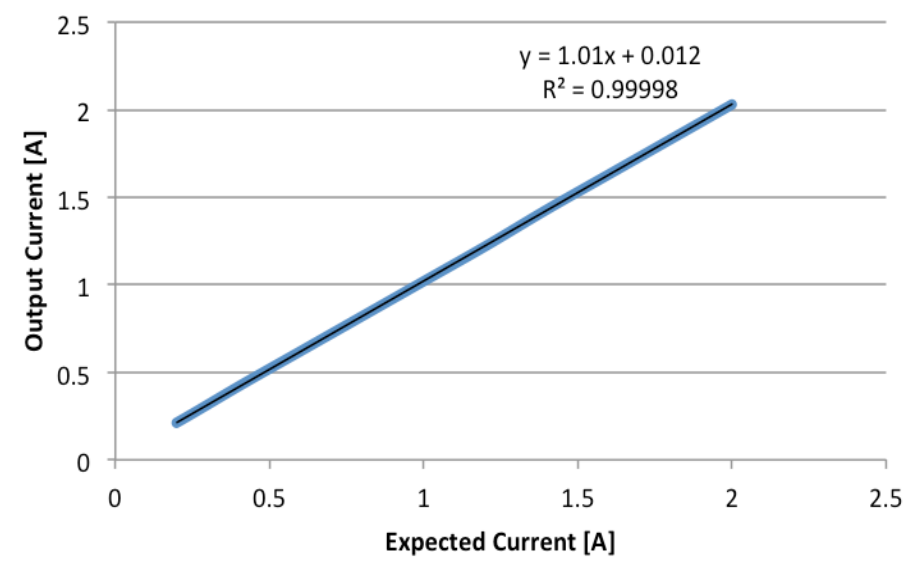

FIGURE 40: SINGLE LOAD TEST

Figure 40 shows the linear relationship between the expected current and the output current.

\subsubsection{THREE 2A LOADS}

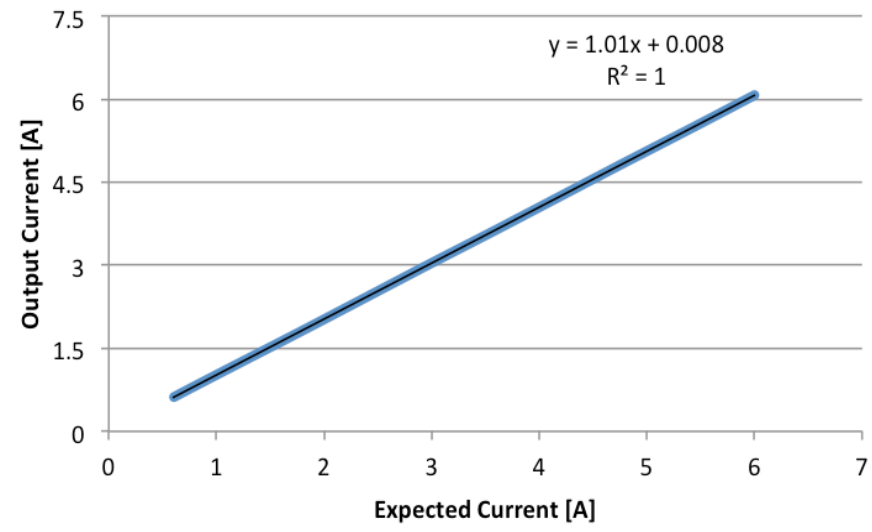

FIGURE 41: PARALLEL TESTING FOR THREE LOADS AT THE SAME TIME

Figure 41 shows the linear relationship between the expected current and the output current. 


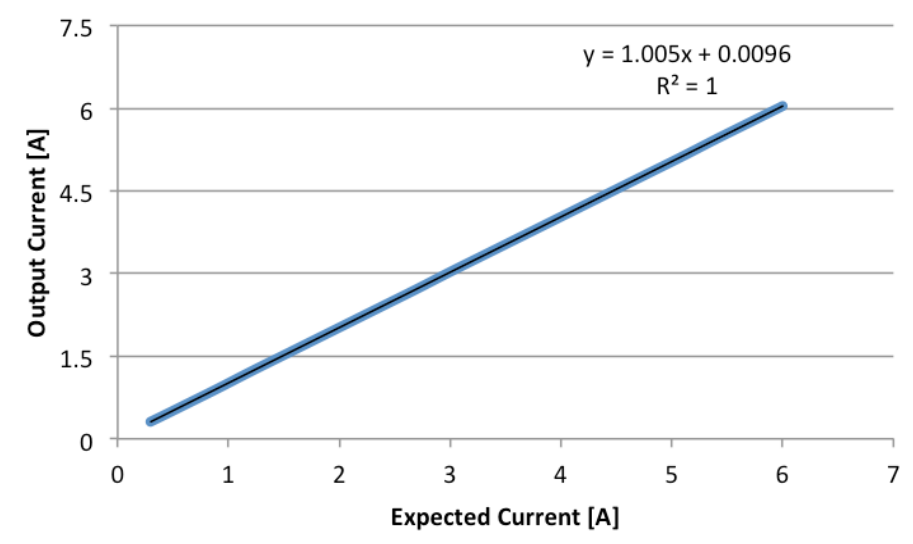

FIGURE 42: PARALLEL TESTING FOR LOAD \#4

Figure 42 shows the linear relationship between the expected current and the output current.

\subsubsection{PARALLEL SENSOR DATA/ SENSOR MODE}

In order to test the sensor data, all three channels with $2 \mathrm{~A}$ load extract the $\mathrm{pH}$ sensor data from the SD card. Figure 17 shows the $\mathrm{pH}$ sensor format. The feedback of the $\mathrm{pH}$ sensor format confirms the working sensor mode. When three channels are running at the same time, there will be three displays on the computer screen to show the functional sensor mode, as shown in Figure 43. Similar to the parallel testing, the three $\mathrm{pH}$ sensors can run at the same time and do not interfere with each other. The $\mathrm{pH}$ sensor can also be replaced with an Oxygen sensor or Conductivity, Temperature, and Depth (CTD) sensor. 


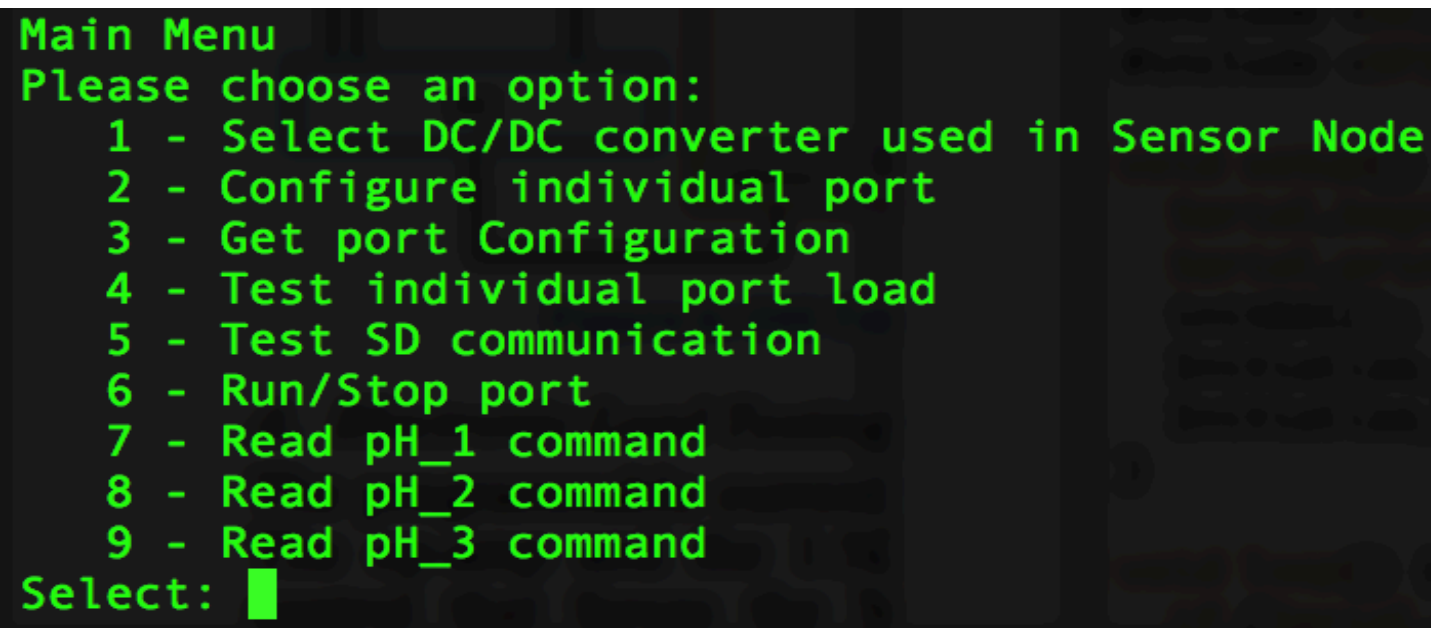

FIGURE 43: PH SENSORS COMMAND

\subsubsection{THERMAL TESTING}

The thermal testing is required to better mange the temperature of the OIS and ensure the OIS board does not overheat and burn the components. The specification given by MBARI requires the board to not exceed $75 \mathrm{~W}$. Therefore when the board reaches $75 \mathrm{~W}$, the Arduino Due will automatically turn off.

The purpose of the thermal test is to ensure proper functionality of the OIS under a fully loaded condition. Excessive heat can cause instability of the system or even overheat the components used in the simulator. A sudden and excessive rise in temperature could cause failure of the electronic load. Thermal noise issues can be further reduced after adding a fan as well. Without the fan, a load up to $6 \mathrm{~A}$ would go over $100^{\circ} \mathrm{C}$ in less than 7 minutes, as shown in Figure 44, result in the need of forced-air cooling. A load up to $2 \mathrm{~A}$ would go over $80^{\circ} \mathrm{C}$ within 5 minutes. Two fans were selected to accommodate the anticipated heat. Each fan is $92 \times 92 \times 25 \mathrm{~mm}$, covering the surface of the heat sinks. 


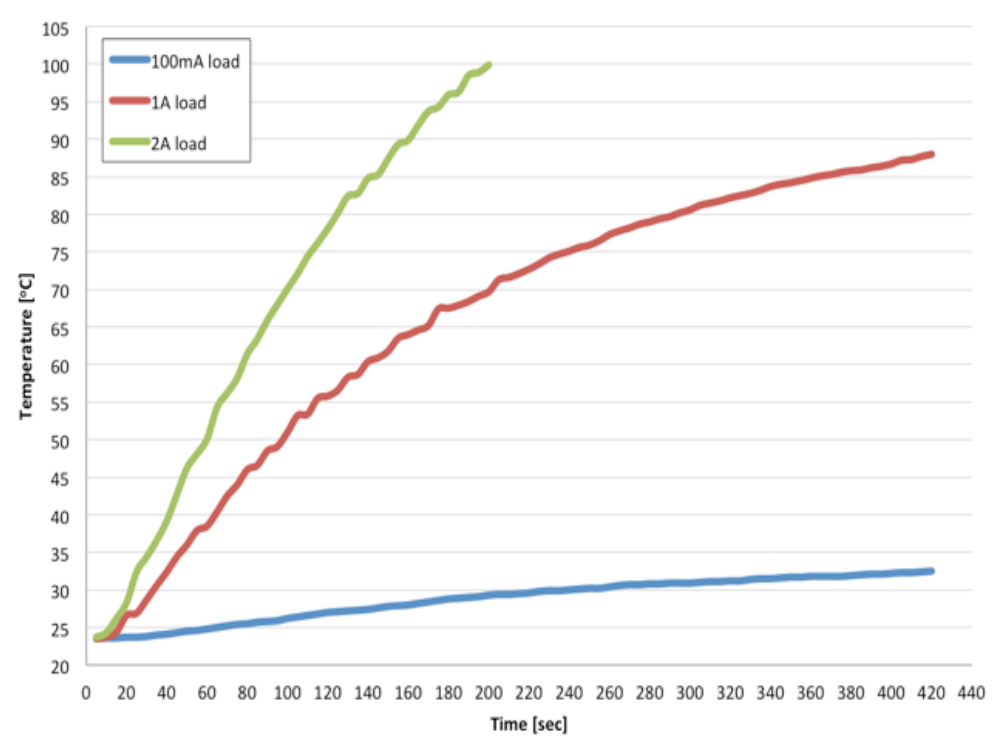

FIGURE 44: THERMAL TEST WITHOUT FAN

In the process of selecting the fan, the $12 \mathrm{~V}$ supply is considered due to the simplification of the power supply needed for the OIS.

The $12 \mathrm{~V}$ supply is recommended to be turned-on when the sink in current is greater than $1 \mathrm{~A}$. Currently, there is no control button or monitor to control the fan. The purpose of the fan will be ensuring the OIS is constantly under $45^{\circ} \mathrm{C}$. With the fan on, as shown in Figure 45, a load up to 6A would remain around $45^{\circ} \mathrm{C}$ over a long period, thus providing the necessary stability of the entire system. There is currently no on/off control for the fan, but it is recommended when the current simulation ranges above $1 \mathrm{~A}$ would need a fan. In the future, the fan can be monitored and be turned on when the temperature is above $45^{\circ} \mathrm{C}$. 


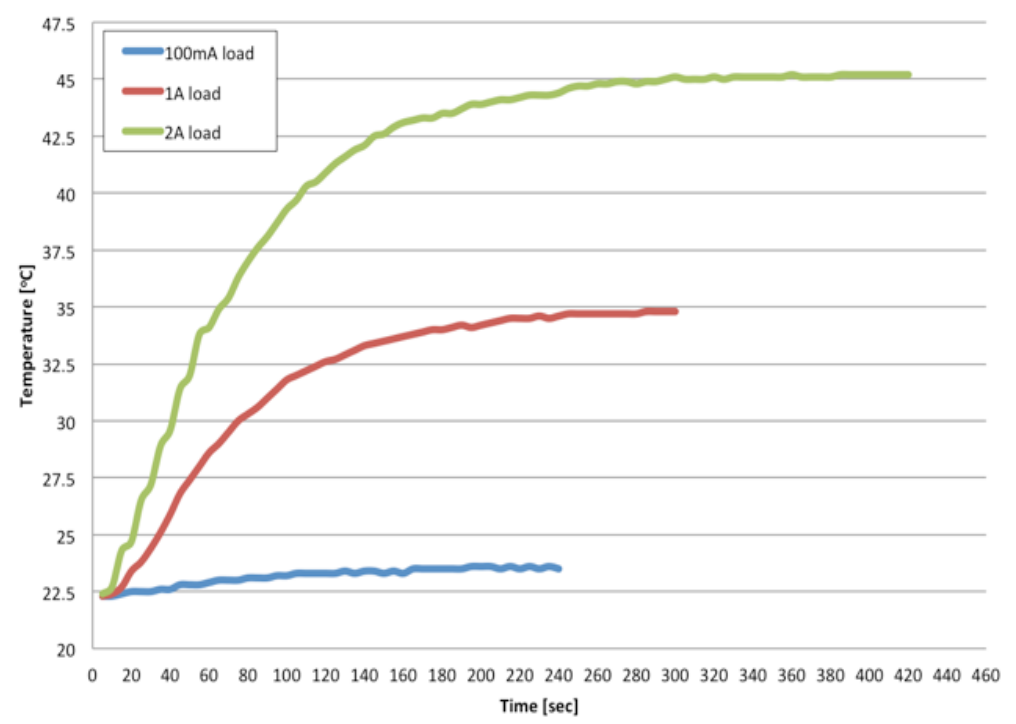

FIGURE 45: THERMAL TEST WITH FAN

TABLE 8: POWER BUDGET

\begin{tabular}{|c|c|c|c|c|}
\hline Circuit & Part number & $\begin{array}{c}\text { Voltage } \\
\text { [V] }\end{array}$ & $\begin{array}{c}\text { Current } \\
{[\mathrm{mA}]}\end{array}$ & \# Used \\
\hline DAC & MCP4921 & 3.3 & 0.35 & 5 \\
\hline $\begin{array}{l}\text { Current-Sense } \\
\text { Amplifier }\end{array}$ & LT1999 & 5 & 1.55 & 4 \\
\hline Dual Op-amp & LM358 & 12 & 6 & 5 \\
\hline Interface Circuit & $\operatorname{Max} 3323$ & 3.3 & 1 & 4 \\
\hline Fan & 259-1464-ND & 12 & 165 & 2 \\
\hline LED & $\begin{array}{l}\text { WP710A10CGC } \\
\text { K }\end{array}$ & 3.3 & 20 & 1 \\
\hline & \multicolumn{2}{|c|}{ Estimated Value [mA] } & \multicolumn{2}{|c|}{ Actual Value [mA] } \\
\hline Total Current from 12V & \multicolumn{2}{|l|}{360} & \multicolumn{2}{|c|}{378.47} \\
\hline Total Current from $5 \mathrm{~V}$ & \multicolumn{2}{|l|}{6.2} & \multicolumn{2}{|c|}{6.17} \\
\hline Total Current from 3.3V & \multicolumn{2}{|c|}{25.75} & \multicolumn{2}{|c|}{28.5} \\
\hline
\end{tabular}


Table 8 shows the estimated power budget for the OIS. The OIS will be supplied with $3.3 \mathrm{~V}$ and $5 \mathrm{~V}$ from the Arduino Due and supplied with $12 \mathrm{~V}$ from an external power supply (Hewlett Packard 6028A DC Power Supply 0-60V/0-10A, 200W). The estimated power budget matched the experimental power supply, shown in Table 8 . The additional $\mathrm{R}_{\mathrm{BIAS}}$ added to electronic load increases the power consumption of the op-amps. With the current rating around $50 \mathrm{uA}$, the current draw by the $1 \mathrm{k} \Omega$ would cause an increase of $3 \mathrm{uW}$, with four $1 \mathrm{k} \Omega$ there will be $12 \mathrm{uW}$. The 12V HP power supply is used to represent the sensor node. Therefore with the sensor node present, there will be no need of the HP power supply.

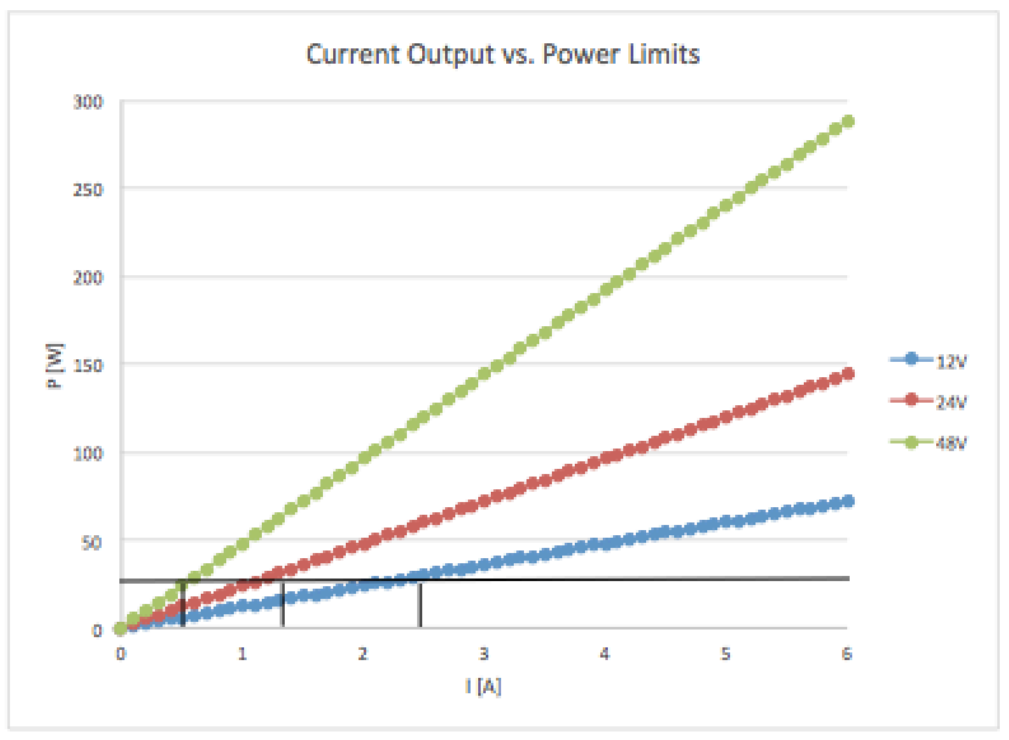

FIGURE 46: CURRENT OUTPUT VS. POWER LIMITS

Figure 46 shows the power limitation on the OIS and when the power exceeds $75 \mathrm{~W}$, the Arduino Due will automatically shut down the device to ensure the hardware components do not overheat. The shut down feature is tested on the Arduino Due prior to the integration of the OIS board. 


\section{CHAPTER 5: CONCLUSION}

Currently, the hardware and software design of the OIS are working properly and the OIS is providing MBARI engineers with an inexpensive means to test the swFOCE platform. The hardware design of the OIS could be improved to further increase the stability of the electronic load output and the software design could be improved with a graphical user interface. After the improvements, the OIS can then be interfaced with the swFOCE platform.

Although the OIS was designed specifically to test the swFOCE platform, the OIS can be used as a general oceanographic instrument simulator for other applications as it can be manually configured to emulate many different electronic loads and serial data streams. The OIS can serve as an excellent testing platform for the entire oceanographic community. 


\section{REFERENCES}

[1] Kecy, C.D.; Peltzer, E.T.; Walz, P.M.; Headley, K.; Herlien, R.A.; Maughan, T.; Matsumoto, G.I.; O'Reilly, T.C.; Salamy, K.A.; Shane, F.; Lovera, C.; Schofield, J.; Kirkwood, W.; Barry, J.P.; Brewer, P.G., "Open source instrumentation nodes for the greater oceanographic community," Oceans - San Diego, 2013 , vol., no., pp.1,7, 23-27 Sept. 2013

[2] A. Y. Chen, M. Mitchell, and R. Bae, "MBARI swFOCE Shallow Water Free Ocean Carbon Enrichment Experiment: Oceanographic Instrument Simulator," California Polytechnic State University, San Luis Obispo, Senior Project, Dec. 2014.

[3] Microchip, “12-bite DAC with SPI Interface,” MCP4921 datasheet, 2007

[4] Fairchild Semicondoctor, "N-Channel Power Trench MOSFET," FDP050AN06A0 datasheet, Oct. 2013

[5] ON Semiconductor, "Single Supply Dual Operational Amplifiers," LM358 datasheet, Jan. 2015

[6] Sunon, "MagLev Motor Fan”, ME92251V1-000U-A99, 2014

[7] Texas Instruments, "Implementation and Applications of current sources and current receivers,” Application Bulletin March. 1999

[8] S. Bendaoud, and G. Marino, "Practical Techniques to Aviod Instability Due to Capacitance Loading," Ask The Application Engineer - 32, June. 2012

[9] Texas Instruments, “4-20mA Current-Loop Transmitter,” XTR117 datasheet, May. 2012

[10] Linear Technology, “ High Voltage, Bidirectional Current Sense Amplifier,” LT1999 datasheet, 2010

[11] Sea-Bird Electronics, “SBE 18 pH Sensor,” SBE 18 pH Sensor, 2015 


\section{APPENDICES}

\section{APPENDIX A - TESTING RESULTS}

\begin{tabular}{|c|c|c|c|c|c|c|c|c|}
\hline \multirow{2}{*}{$\begin{array}{c}\text { Given Value } \\
\text { V(DAC) }\end{array}$} & \multicolumn{5}{|c|}{ Actual Testing Data } & \multicolumn{2}{|c|}{ Expected Data } & \multirow{2}{*}{$\%$ error } \\
\hline & $\mathrm{Vr}$ & $\mathrm{Vg}$ & Vgs & $\begin{array}{c}\text { Iout (0A- } \\
2 \mathrm{~A})\end{array}$ & $\begin{array}{l}\mathrm{P}(12 \mathrm{~V} \\
\text { supply) }\end{array}$ & $\mathrm{Ir}=\mathrm{Imosfet}$ & $\begin{array}{c}\mathrm{P} \text { expected } \\
(12 \mathrm{~V})\end{array}$ & \\
\hline 0.1000 & 0.9800 & 3.2900 & 2.3100 & 0.0650 & 0.7800 & 0.0667 & 0.8000 & 2.5000 \\
\hline 0.2000 & 0.1980 & 3.4800 & 3.2820 & 0.1310 & 1.5720 & 0.1333 & 1.6000 & 1.7500 \\
\hline 0.3000 & 0.2980 & 3.6300 & 3.3320 & 0.1980 & 2.3760 & 0.2000 & 2.4000 & 1.0000 \\
\hline 0.4000 & 0.3980 & 3.7600 & 3.3620 & 0.2640 & 3.1680 & 0.2667 & 3.2000 & 1.0000 \\
\hline 0.5000 & 0.4980 & 3.8800 & 3.3820 & 0.3310 & 3.9720 & 0.3333 & 4.0000 & 0.7000 \\
\hline 0.6000 & 0.5980 & 4.0000 & 3.4020 & 0.3970 & 4.7640 & 0.4000 & 4.8000 & 0.7500 \\
\hline 0.7000 & 0.6980 & 4.1100 & 3.4120 & 0.4640 & 5.5680 & 0.4667 & 5.6000 & 0.5714 \\
\hline 0.8000 & 0.7970 & 4.2200 & 3.4230 & 0.5300 & 6.3600 & 0.5333 & 6.4000 & 0.6250 \\
\hline 0.9000 & 0.8970 & 4.3300 & 3.4330 & 0.5960 & 7.1520 & 0.6000 & 7.2000 & 0.6667 \\
\hline 1.0000 & 0.9960 & 4.4300 & 3.4340 & 0.6620 & 7.9440 & 0.6667 & 8.0000 & 0.7000 \\
\hline 1.1000 & 1.0900 & 4.4500 & 3.3600 & 0.7300 & 8.7600 & 0.7333 & 8.8000 & 0.4545 \\
\hline 1.2000 & 1.1900 & 4.5500 & 3.3600 & 0.7960 & 9.5520 & 0.8000 & 9.6000 & 0.5000 \\
\hline 1.3000 & 1.2900 & 4.6600 & 3.3700 & 0.8620 & 10.3440 & 0.8667 & 10.4000 & 0.5385 \\
\hline 1.4000 & 1.3900 & 4.7600 & 3.3700 & 0.9280 & 11.1360 & 0.9333 & 11.2000 & 0.5714 \\
\hline 1.5000 & 1.4900 & 4.8500 & 3.3600 & 0.9950 & 11.9400 & 1.0000 & 12.0000 & 0.5000 \\
\hline 1.6000 & 1.5900 & 4.9500 & 3.3600 & 1.0610 & 12.7320 & 1.0667 & 12.8000 & 0.5313 \\
\hline 1.7000 & 1.6900 & 5.0300 & 3.3400 & 1.1270 & 13.5240 & 1.1333 & 13.6000 & 0.5588 \\
\hline 1.8000 & 1.7900 & 5.1200 & 3.3300 & 1.1940 & 14.3280 & 1.2000 & 14.4000 & 0.5000 \\
\hline 1.9000 & 1.8900 & 5.2100 & 3.3200 & 1.2600 & 15.1200 & 1.2667 & 15.2000 & 0.5263 \\
\hline 2.0000 & 1.9900 & 5.3000 & 3.3100 & 1.3260 & 15.9120 & 1.3333 & 16.0000 & 0.5500 \\
\hline 2.1000 & 2.0900 & 5.4100 & 3.3200 & 1.3940 & 16.7280 & 1.4000 & 16.8000 & 0.4286 \\
\hline
\end{tabular}




\begin{tabular}{|lcccccccc|}
\hline 2.2000 & 2.1900 & 5.4400 & 3.2500 & 1.4600 & 17.5200 & 1.4667 & 17.6000 & 0.4545 \\
\hline 2.3000 & 2.2900 & 5.5300 & 3.2400 & 1.5260 & 18.3120 & 1.5333 & 18.4000 & 0.4783 \\
\hline 2.4000 & 2.3900 & 5.6200 & 3.2300 & 1.5900 & 19.0800 & 1.6000 & 19.2000 & 0.6250 \\
\hline 2.5000 & 2.4900 & 5.7300 & 3.2400 & 1.6560 & 19.8720 & 1.6667 & 20.0000 & 0.6400 \\
\hline 2.6000 & 2.5900 & 5.8300 & 3.2400 & 1.7250 & 20.7000 & 1.7333 & 20.8000 & 0.4808 \\
\hline 2.7000 & 2.6800 & 5.9100 & 3.2300 & 1.7920 & 21.5040 & 1.8000 & 21.6000 & 0.4444 \\
\hline 2.8000 & 2.7800 & 6.0200 & 3.2400 & 1.8580 & 22.2960 & 1.8667 & 22.4000 & 0.4643 \\
\hline 2.9000 & 2.8800 & 6.1400 & 3.2600 & 1.9250 & 23.1000 & 1.9333 & 23.2000 & 0.4310 \\
\hline 3.0000 & 2.9800 & 6.2600 & 3.2800 & 1.9910 & 23.8920 & 2.0000 & 24.0000 & 0.4500 \\
\hline
\end{tabular}

FIGURE 47: ELECTRONIC LOAD (WITHOUT CURRENT SENSE CIRCUITRY) TESTING DATA 
APPENDIX B - OCEANOGRAPHIC INSTRUMENT SIMULATOR SCHEMATICS

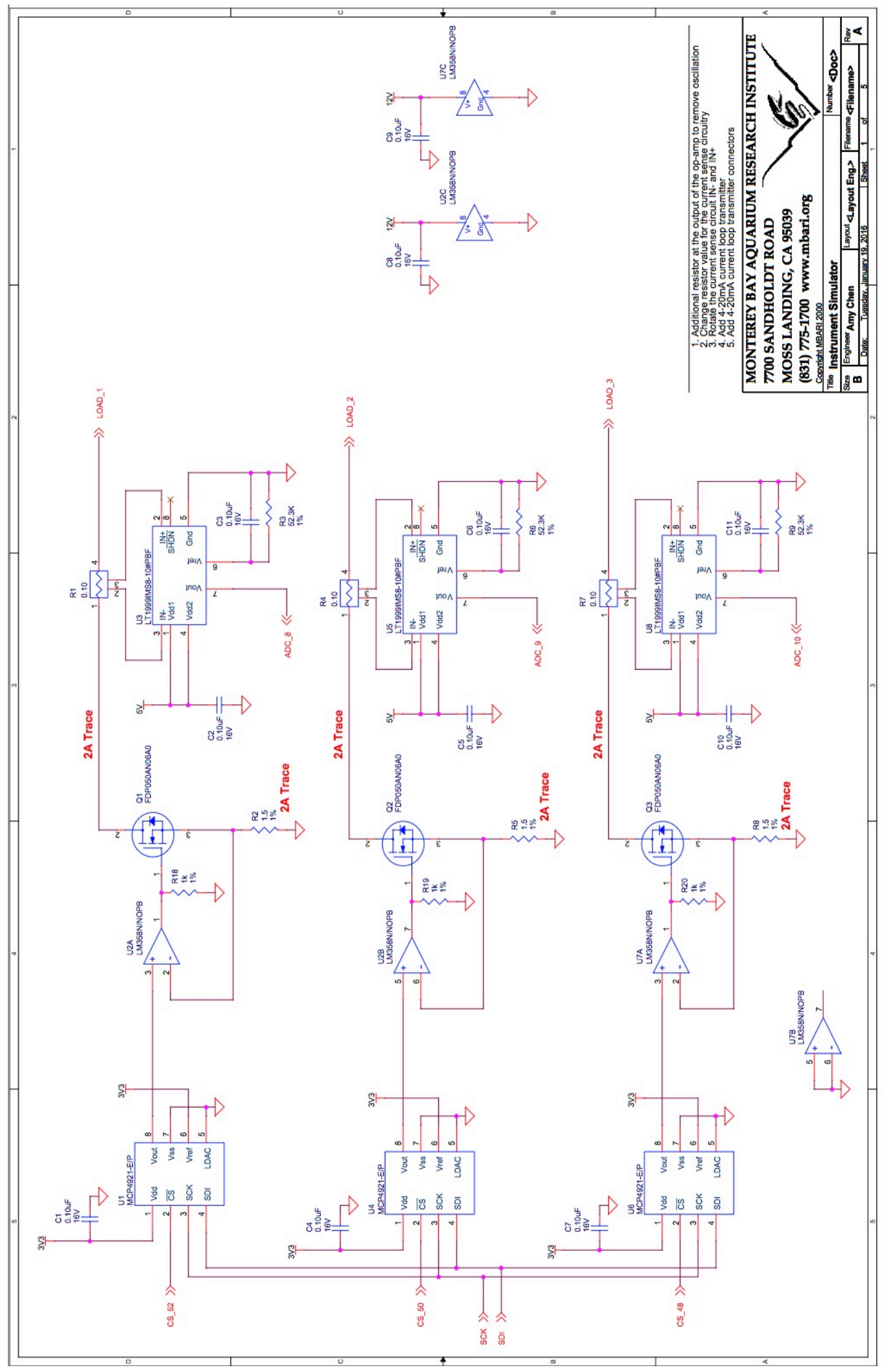




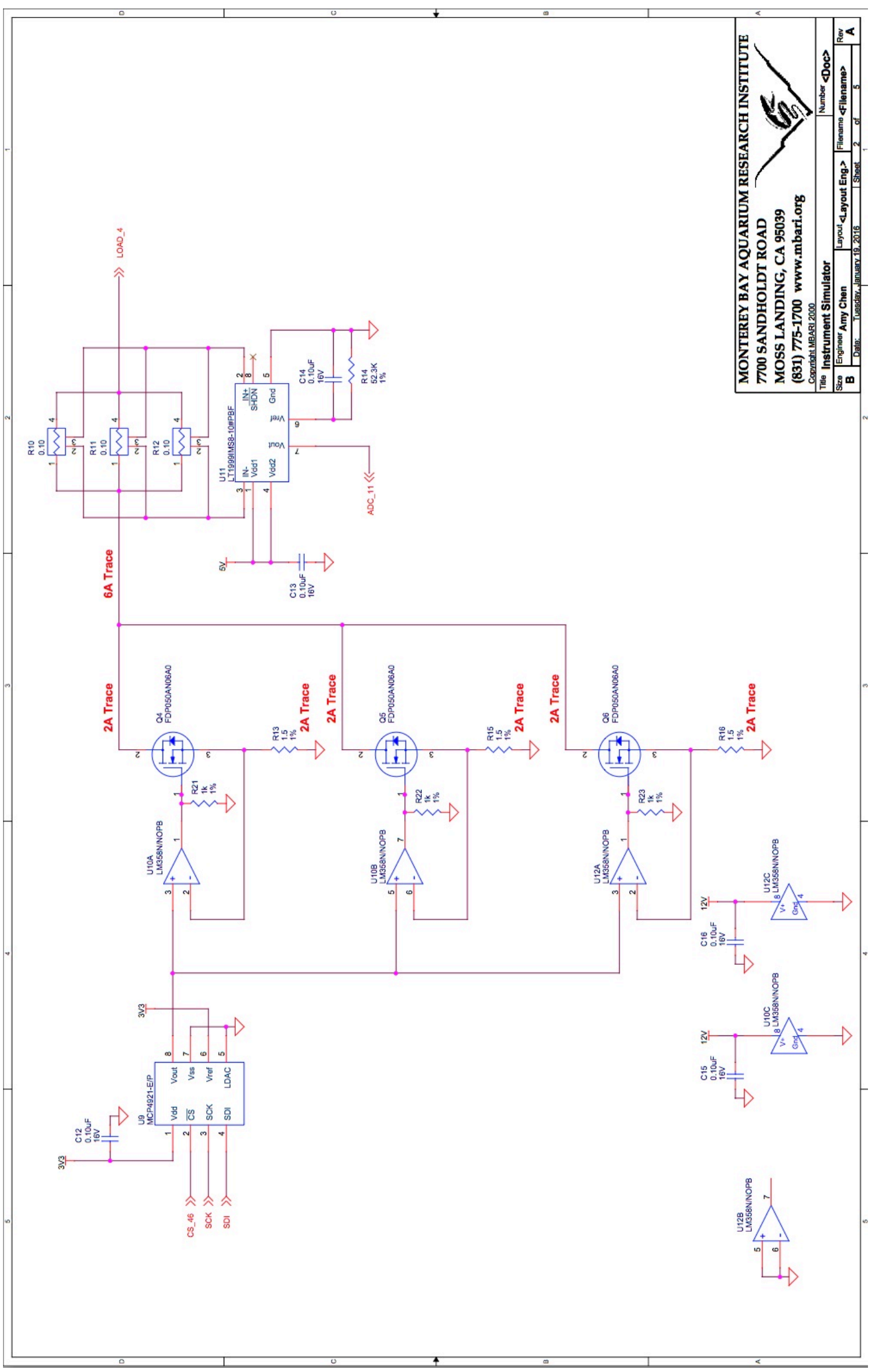




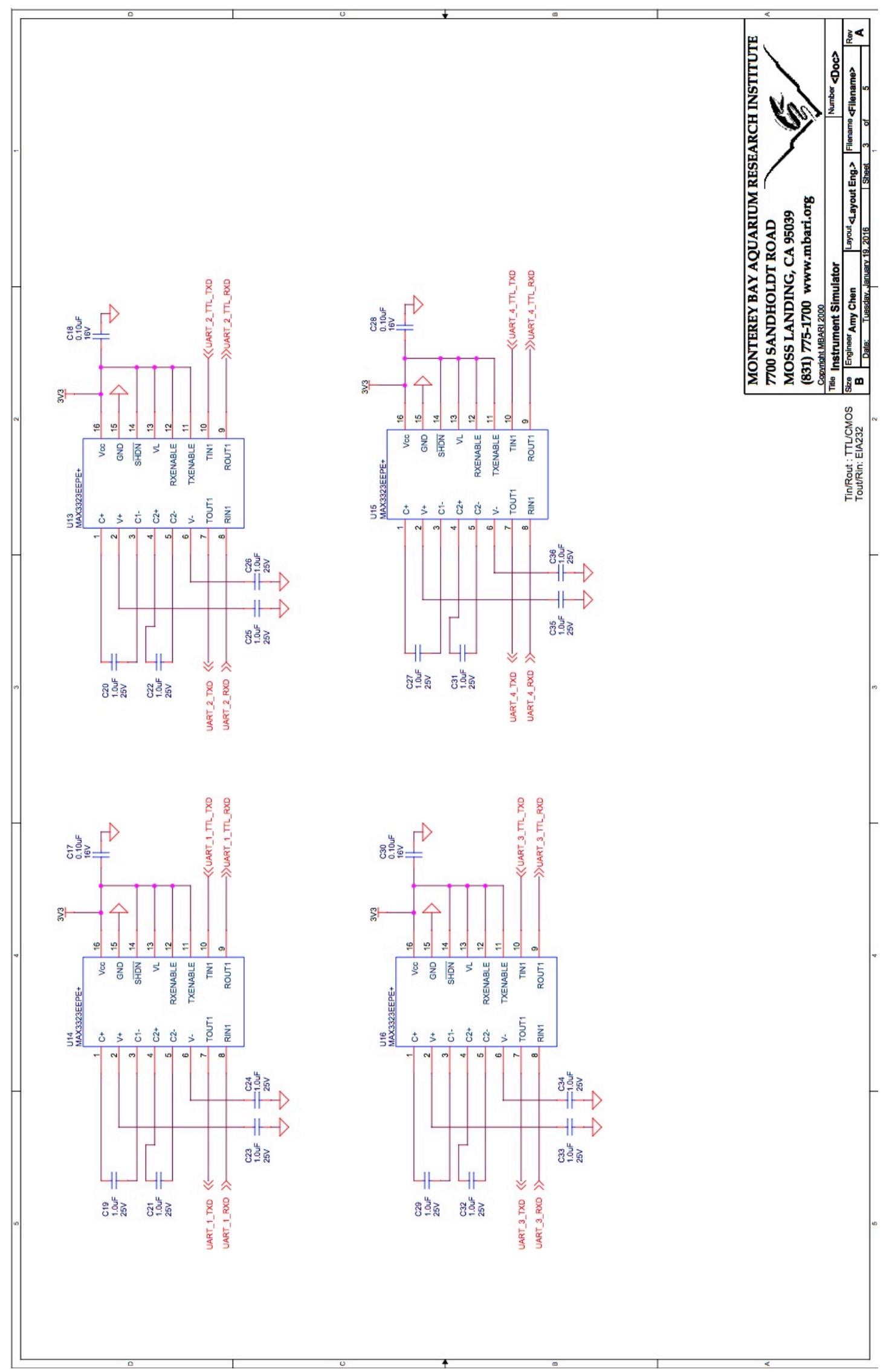




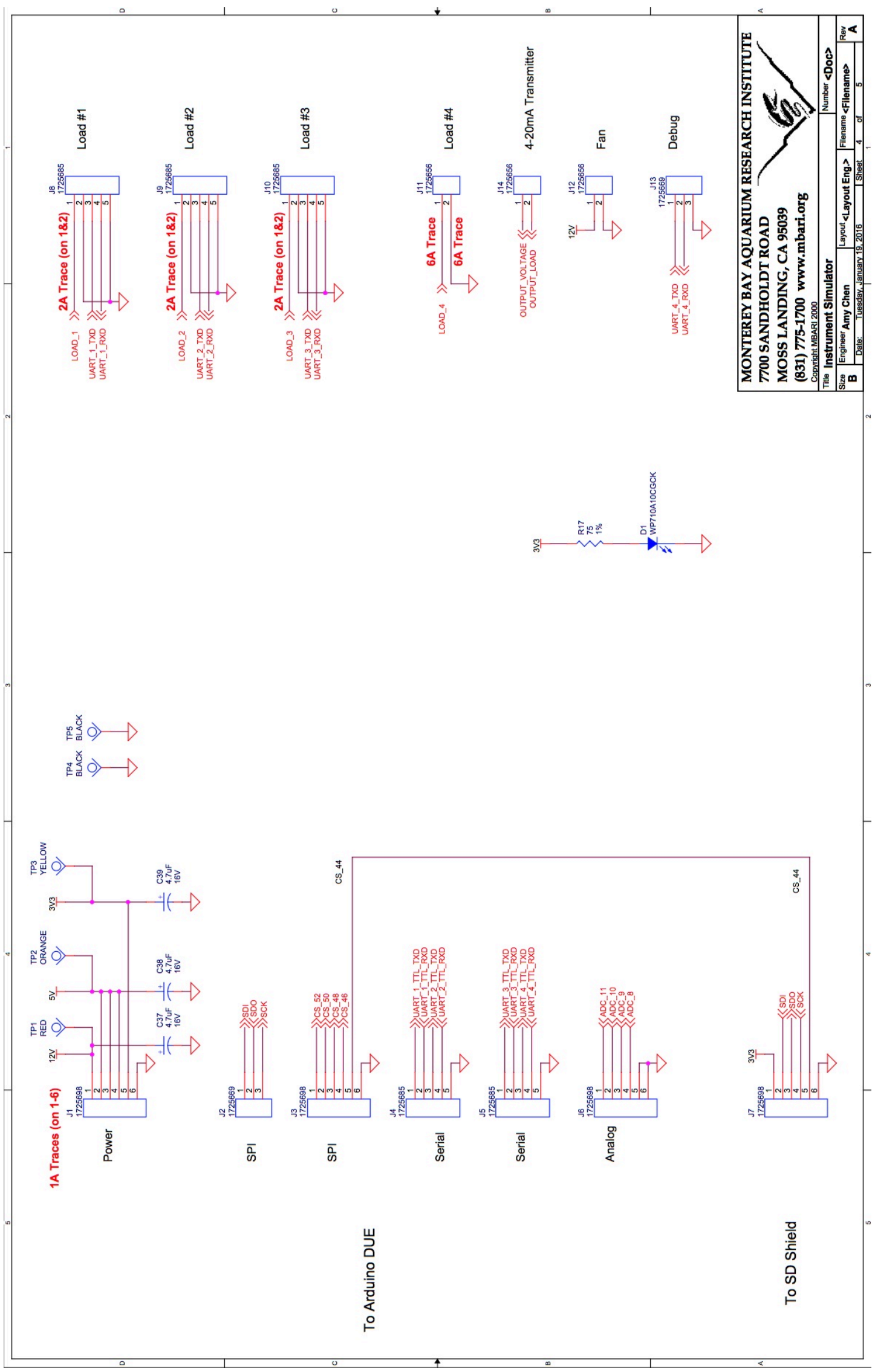




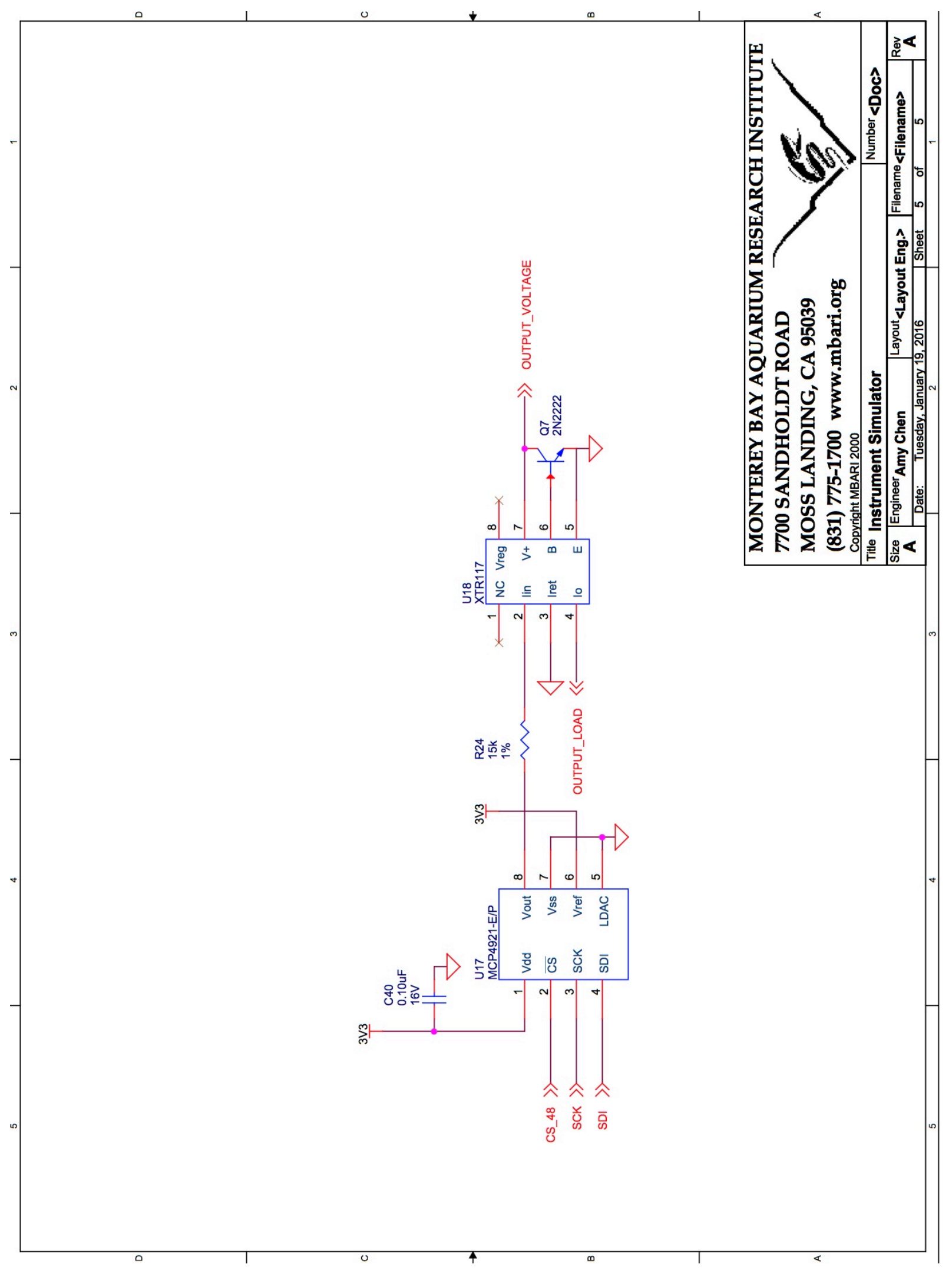




\section{APPENDIX C - ARDUINO CODE}

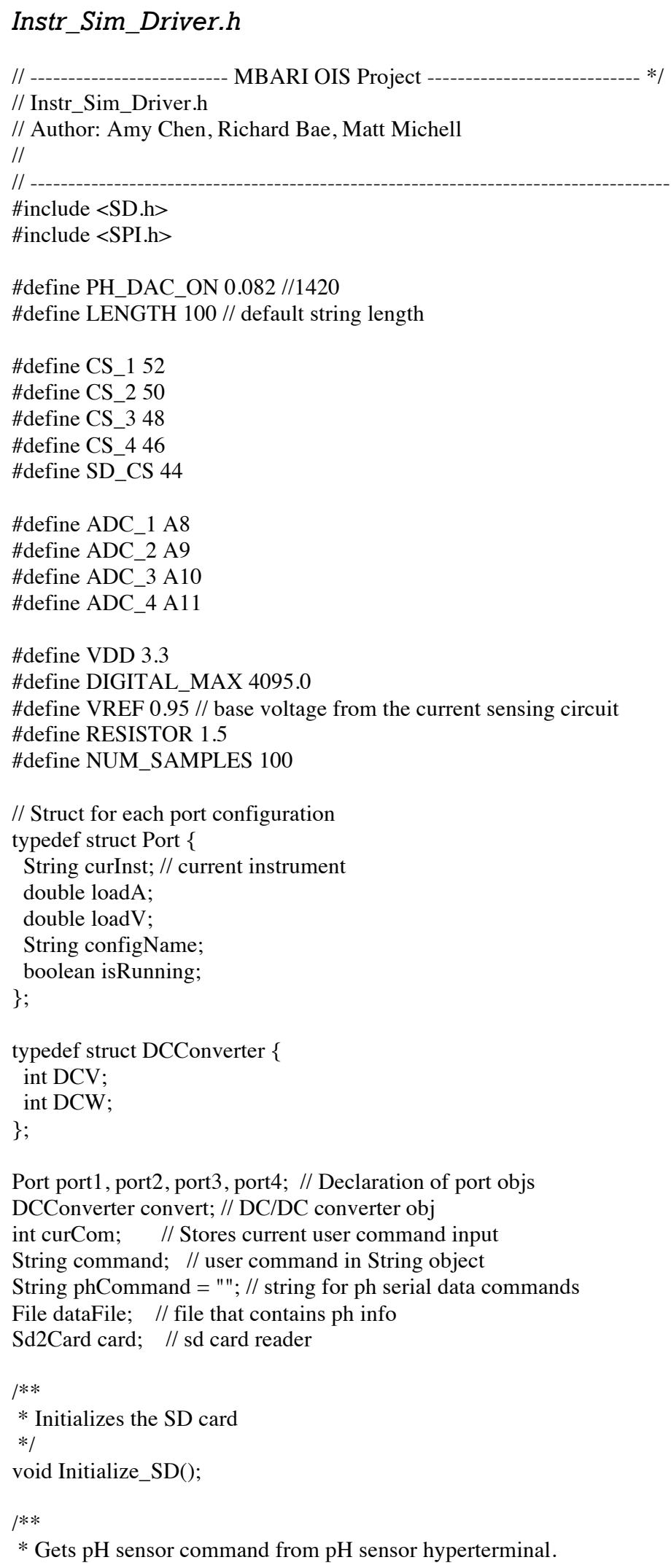


* The function then compares received string to a set

* of implemented commands. If the string matches a command,

* the function transmits static data from SD card to

* sensor hyperterminal.

$* /$

void Ph_Serial_Read();

/**

* Prompts user to input a number selection for the current menu.

* If the number is recognized, a menu option will be selected.

* If it is not recognized, the user will be prompted again.

* "return" key submits user's input. Both the 'd' and "return" keys delete the current

* input and re-prompts the user.

*@return an int representing the user's input selection

$* /$

int readNumInput();

/**

* Initializes each of the 4 port structs to 0 .

$* /$

void Initialize_Ports();

/**

* Runs the DC/DC power menu. Allows the user to select

* DC voltage provided by sensor node and max allowed power

* consumption.

$* /$

void runDCSetPwrMenu(); // begins DC power menu

/**

* Stores DC power information after submitted by

* the user. Displays available sensor node output

* voltage options based upon max power selection

* @ param pwrInfo power option selected by user in previous menu

$* /$

void DCSetVoltMenu(int pwrInfo);

$/ * *$

* Select instrument (sensor). Allows user to choose between

* available instruments for a specific port. User also has the

* option of selecting "Manual Mode" where they can specify

* their own instrument name and current.

* @ param thisPort port to attach selected instrument to

*/

void chooseInst(Port* thisPort);

/**

* Runs manual mode selection menu. User specifies what name

$*$ and current consumption for current manual mode port.

* @ param thisPort port to attach configure manual instrument to $* /$

void runManualMode(Port* thisPort);

/**

* Select port menu.

*

*@return a pointer to the selected port struct

*/ 
Port *selectPort();

/**

* Test port load menu. User selects running port to test load on.

* Calculate drawn current and power consumption on selected port.

*/

void runTestPortLoad();

/**

* Tests SD card communication. Confirms that sensor attached to port

* can access serial data from SD card. Prints a test string from SD card

* to confirm communication.

*/

void runTestPortComm();

/**

* Menu to run or a stop a previously configured port. The function will

$*$ report an error is the selected port has not yet been configured.

$* /$

void runStopPort(); 


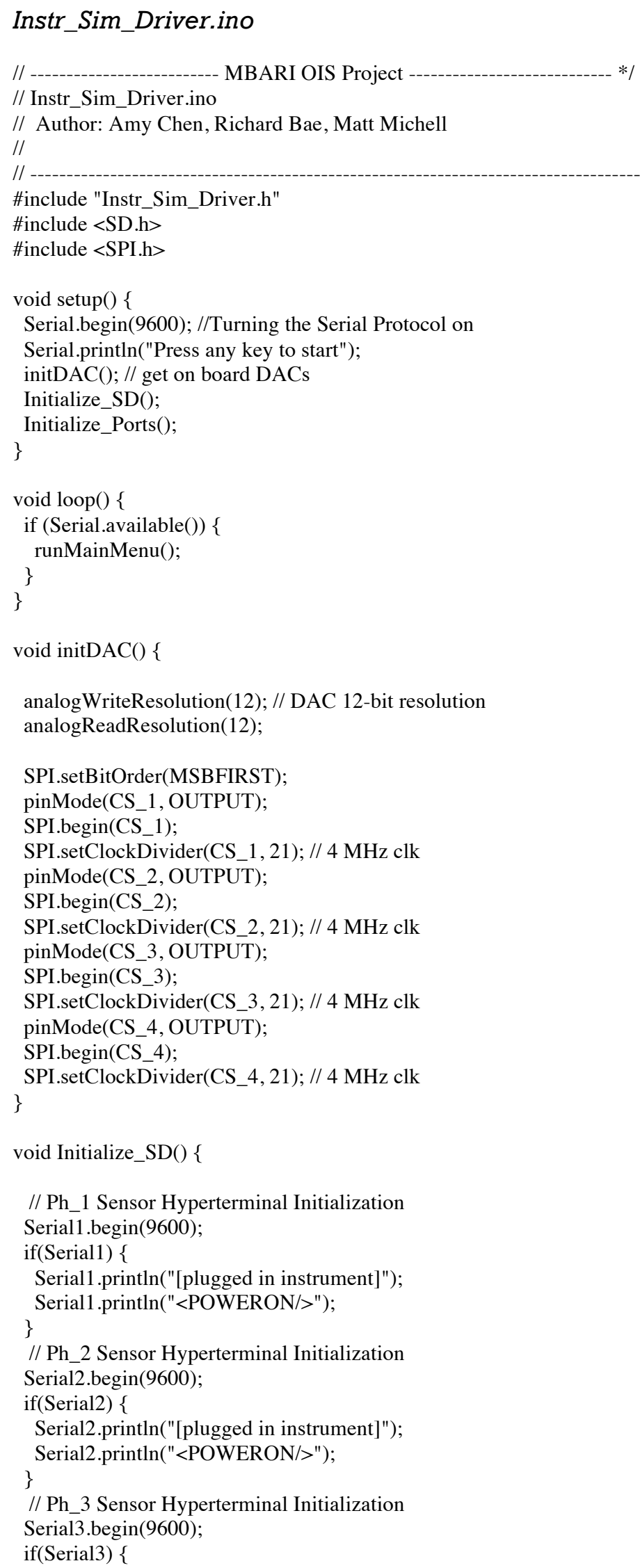




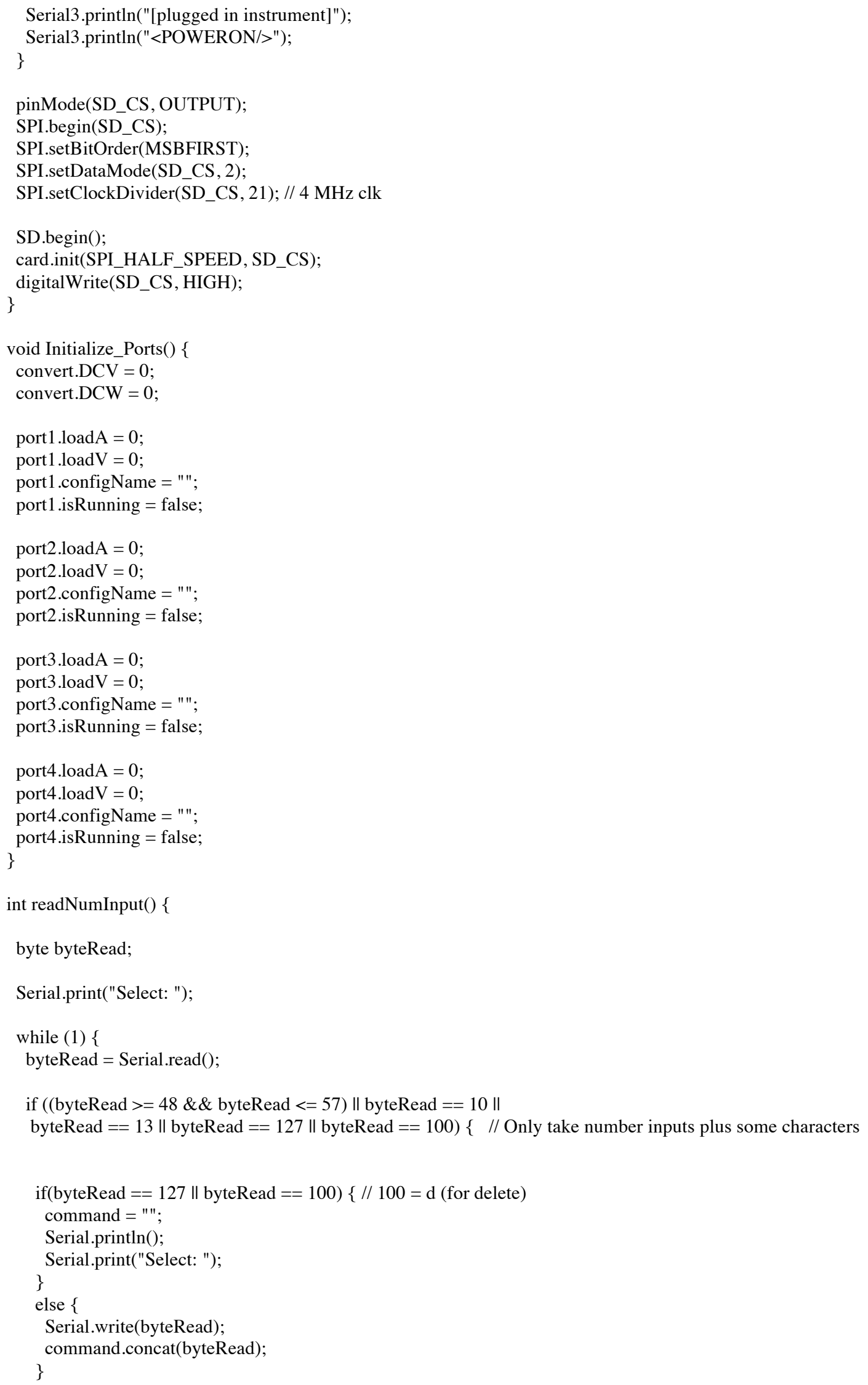




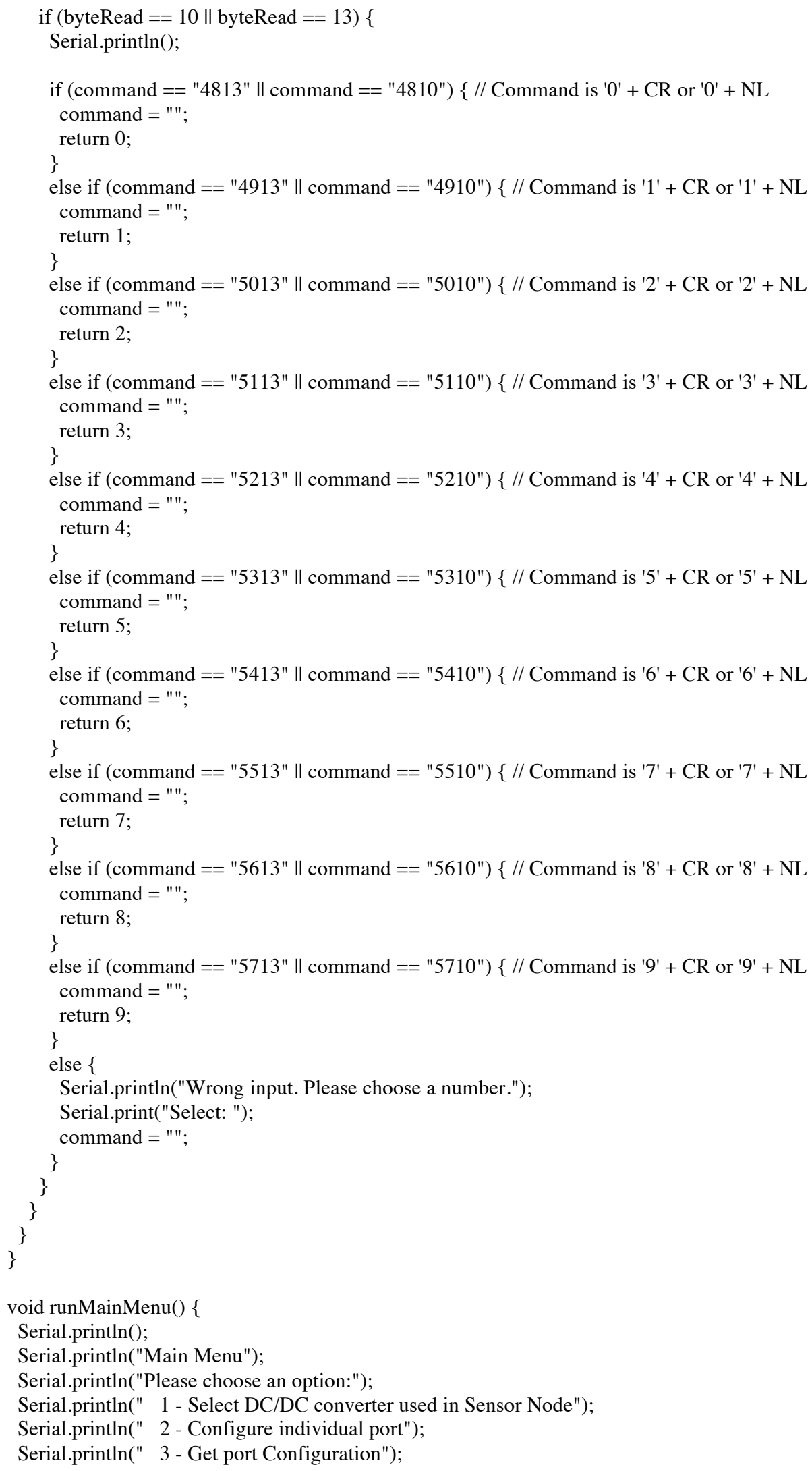




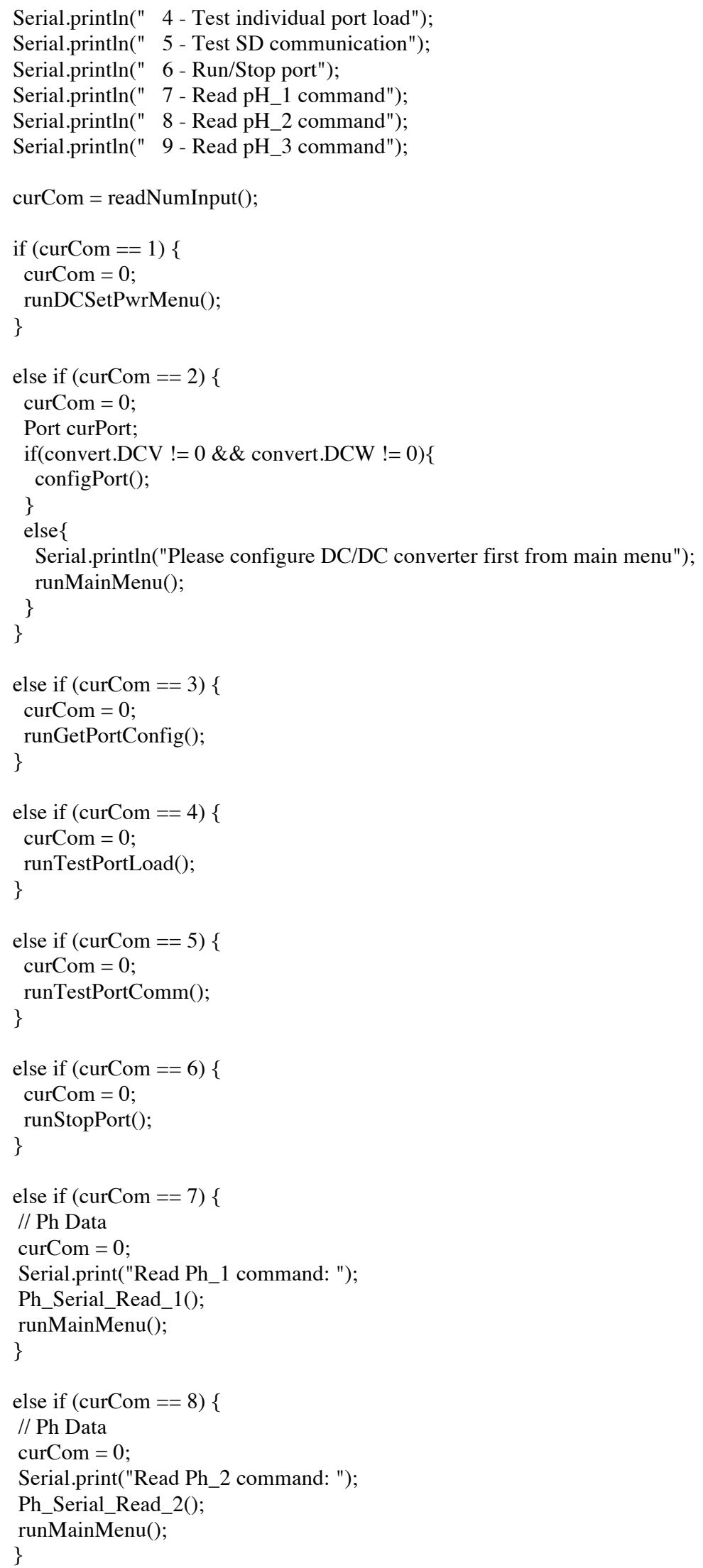




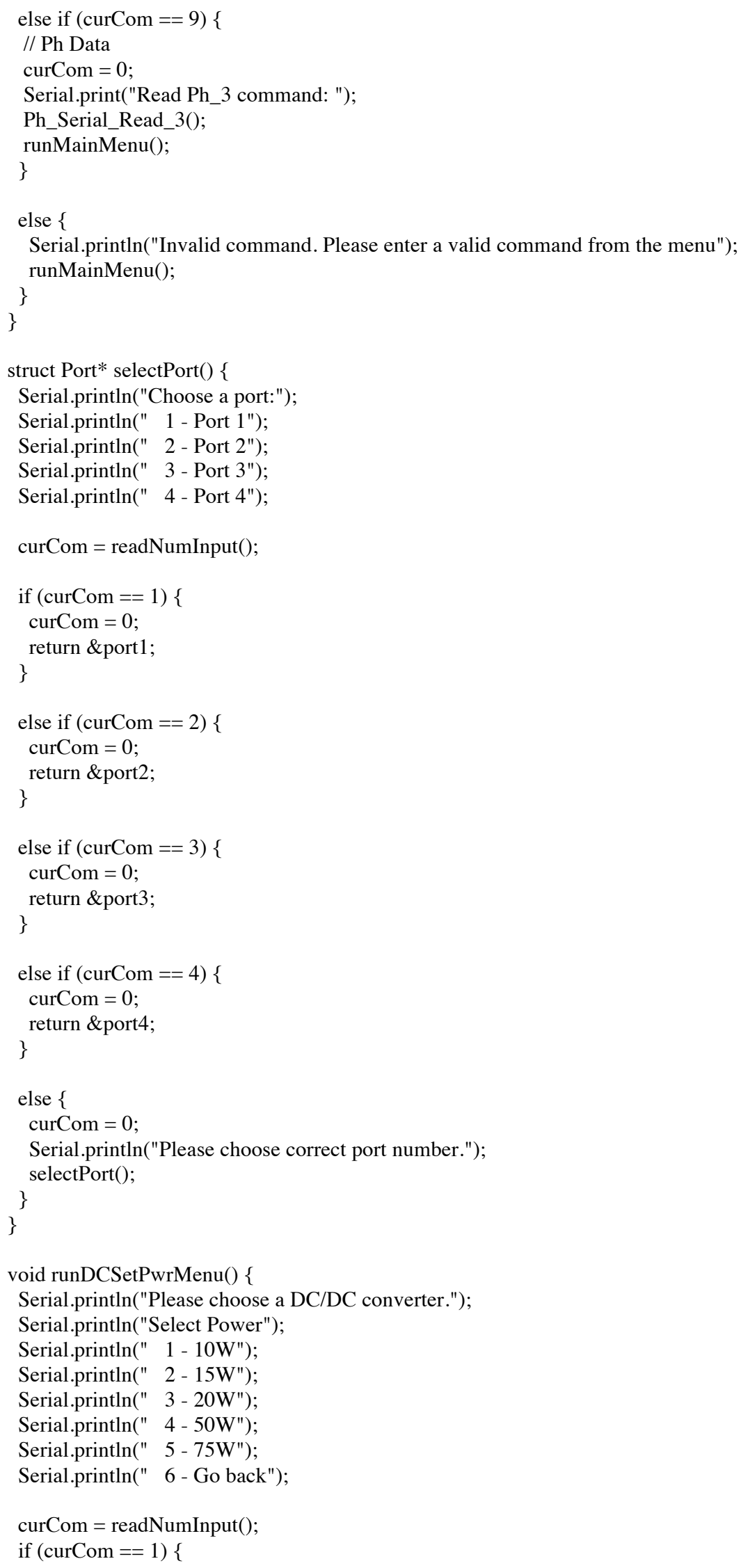




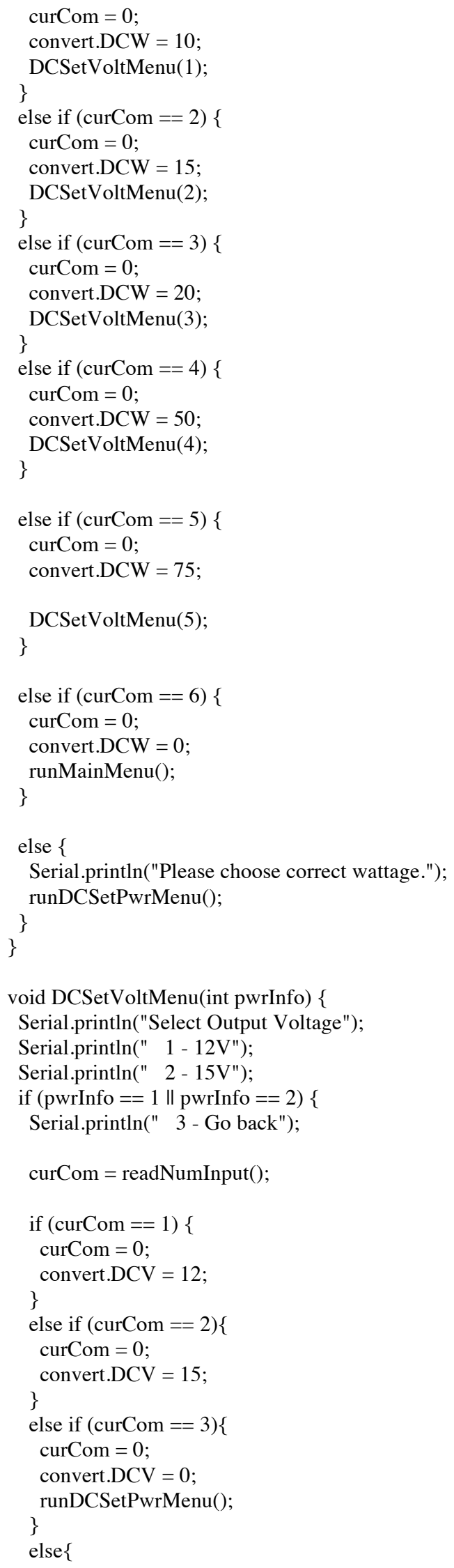




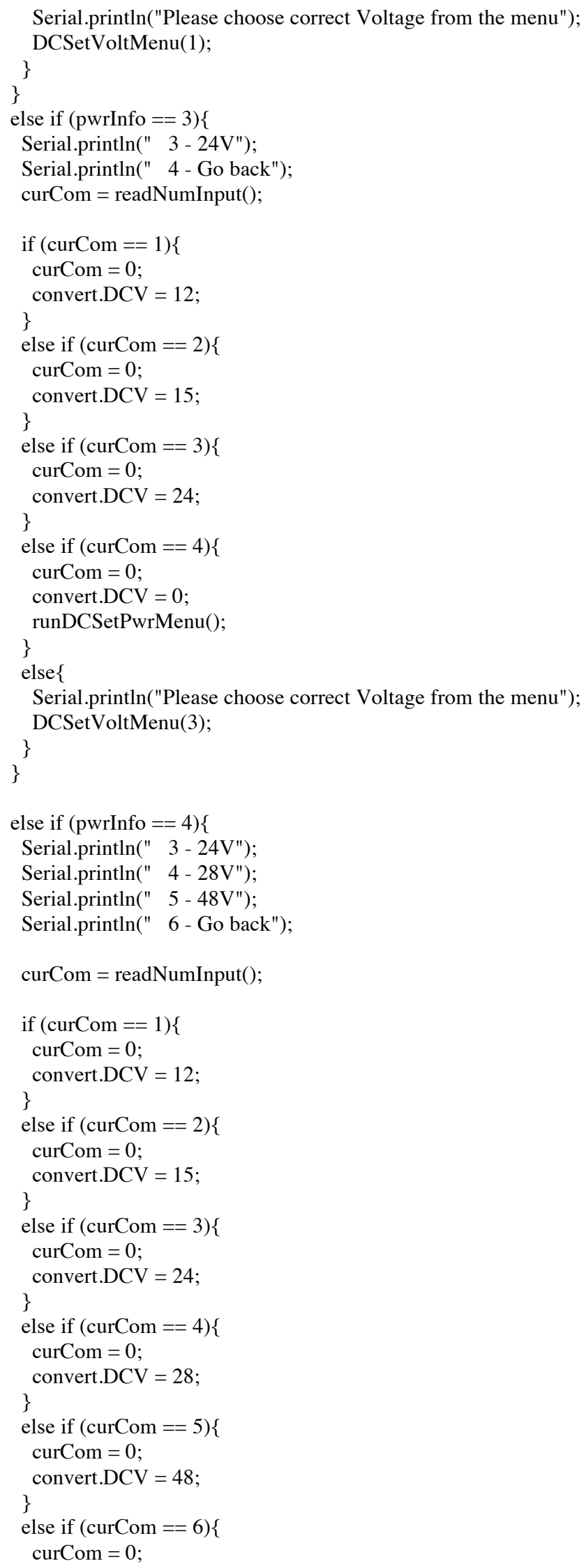




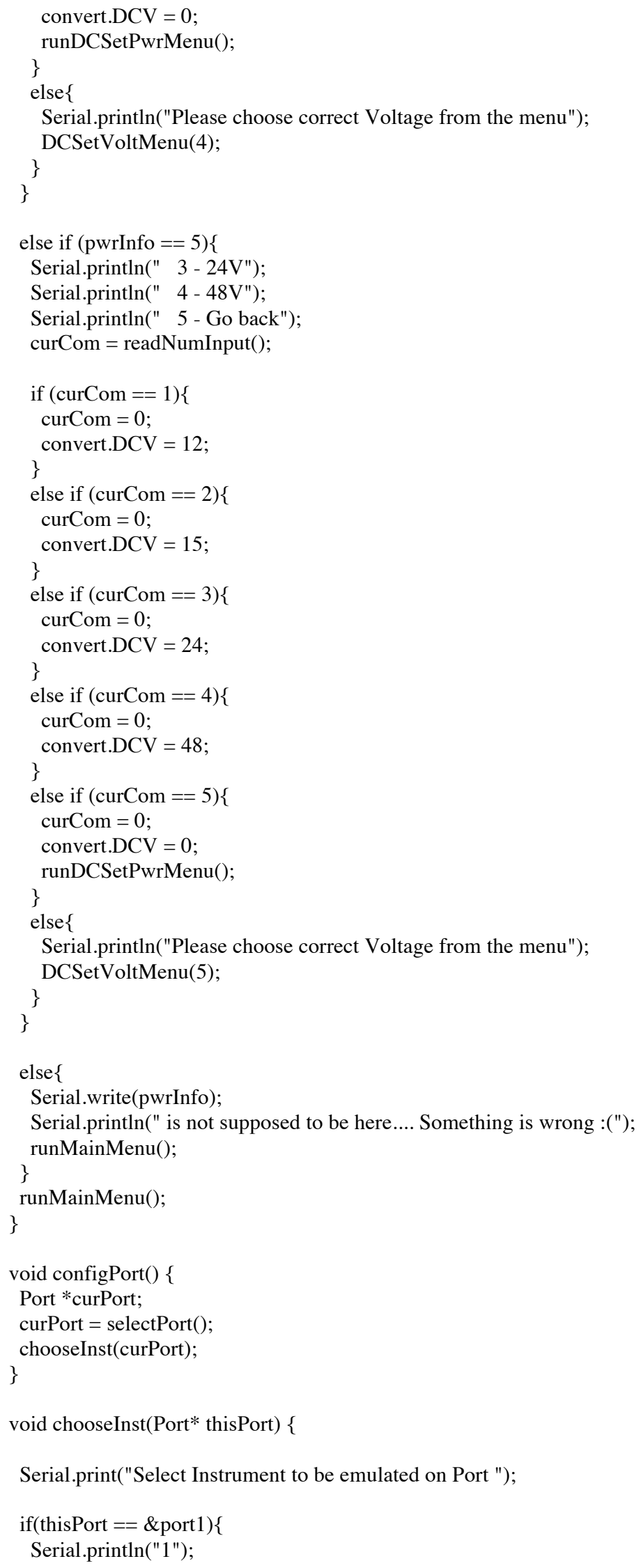




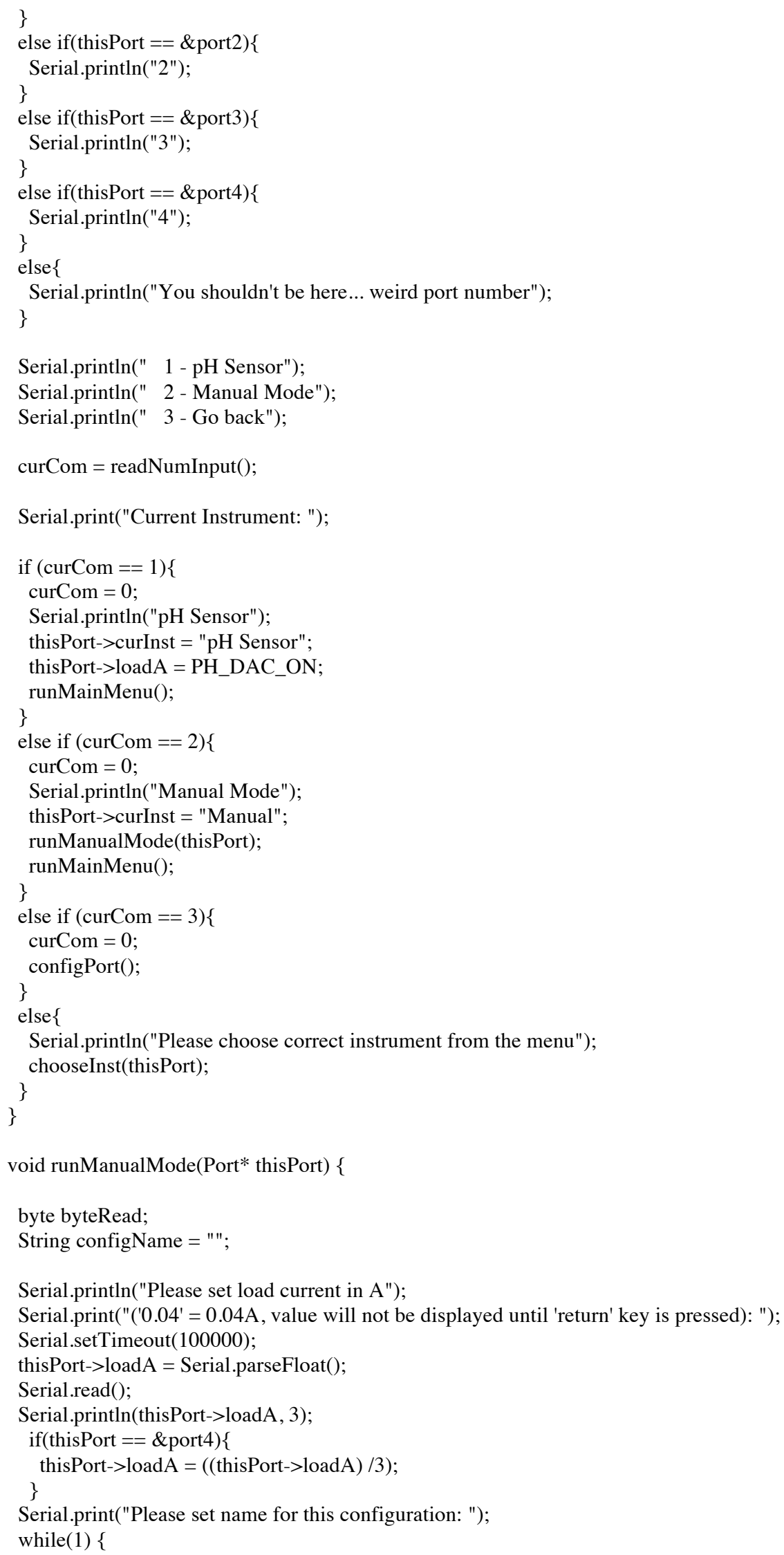




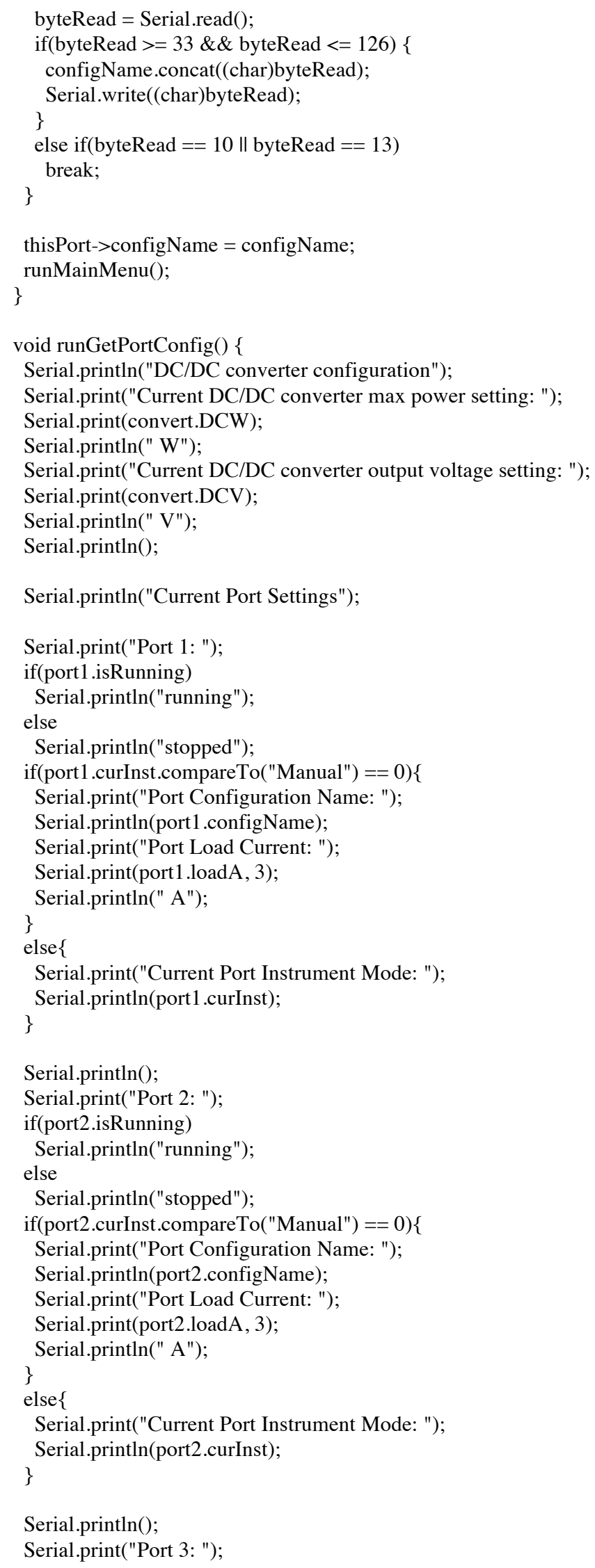




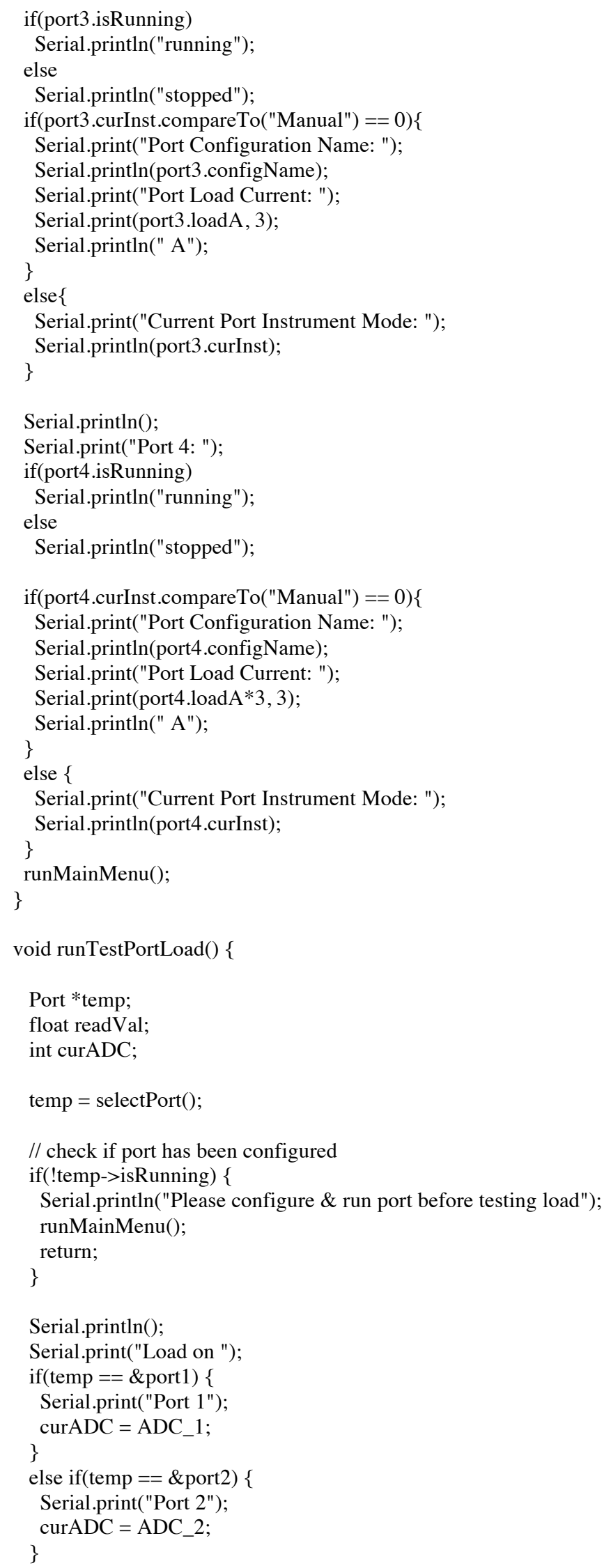




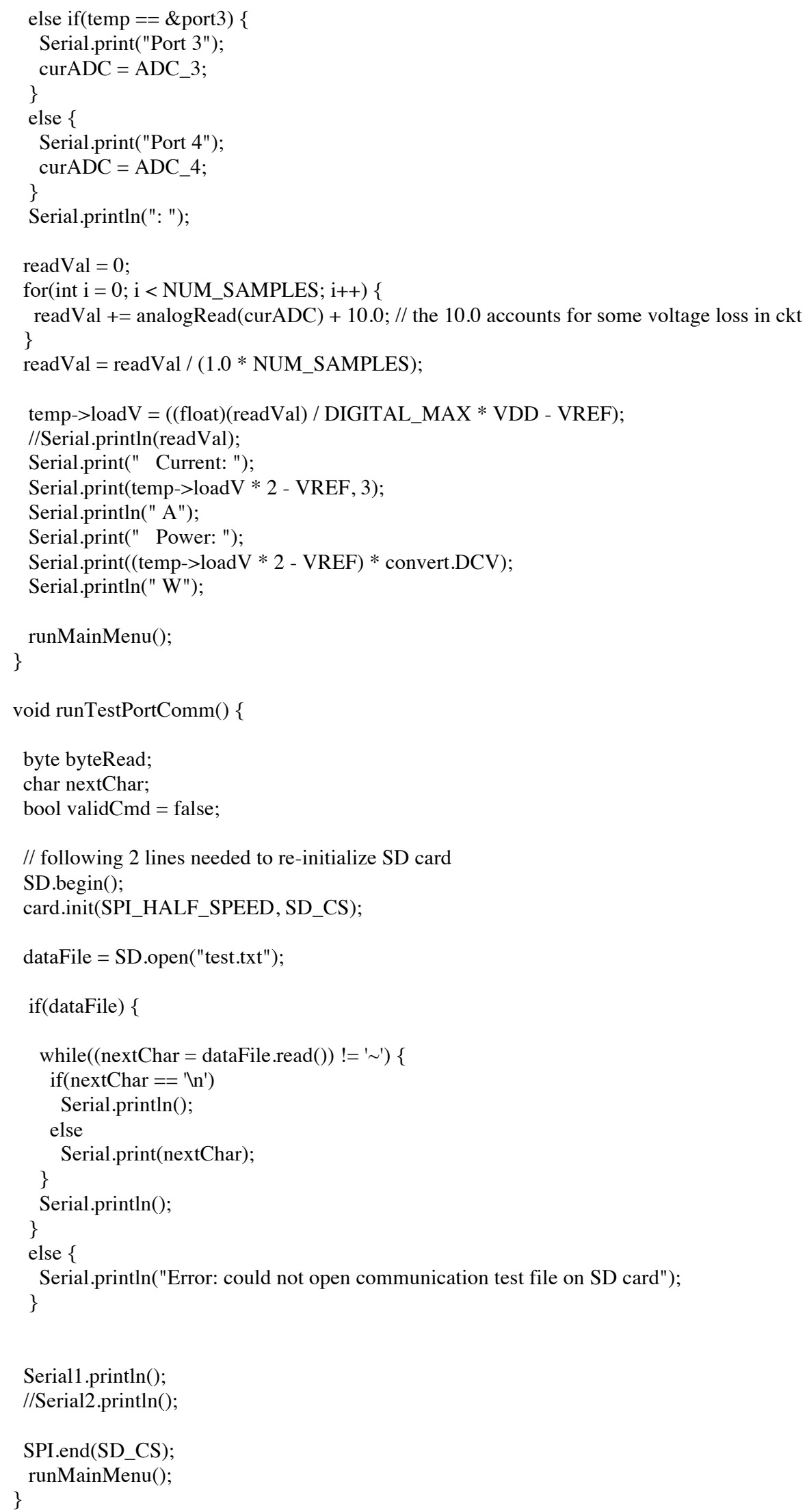




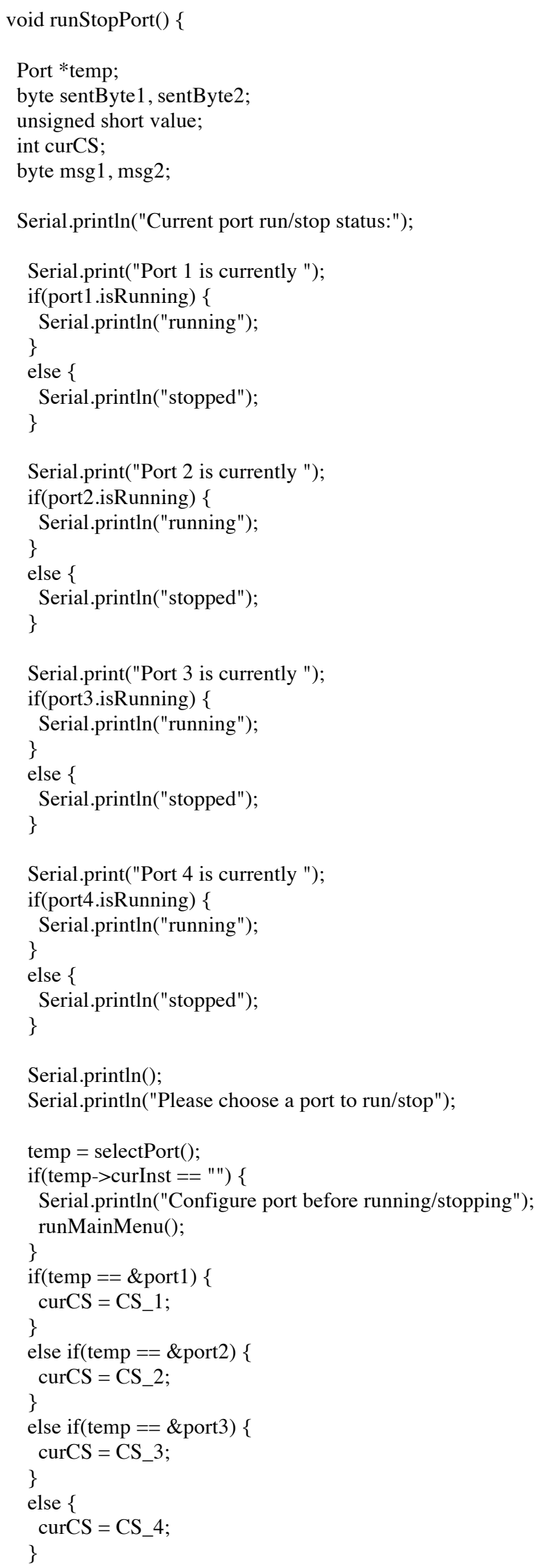




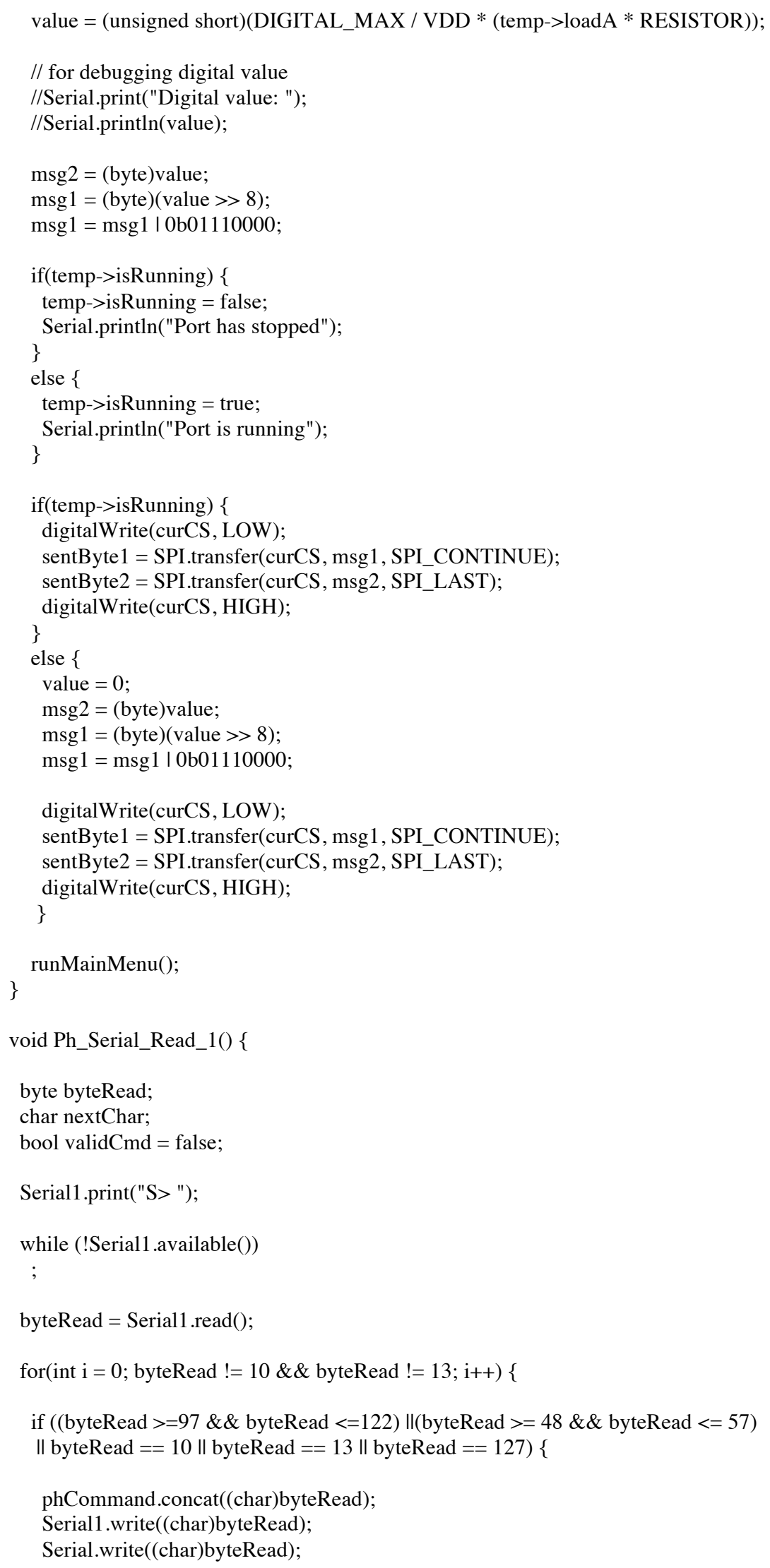




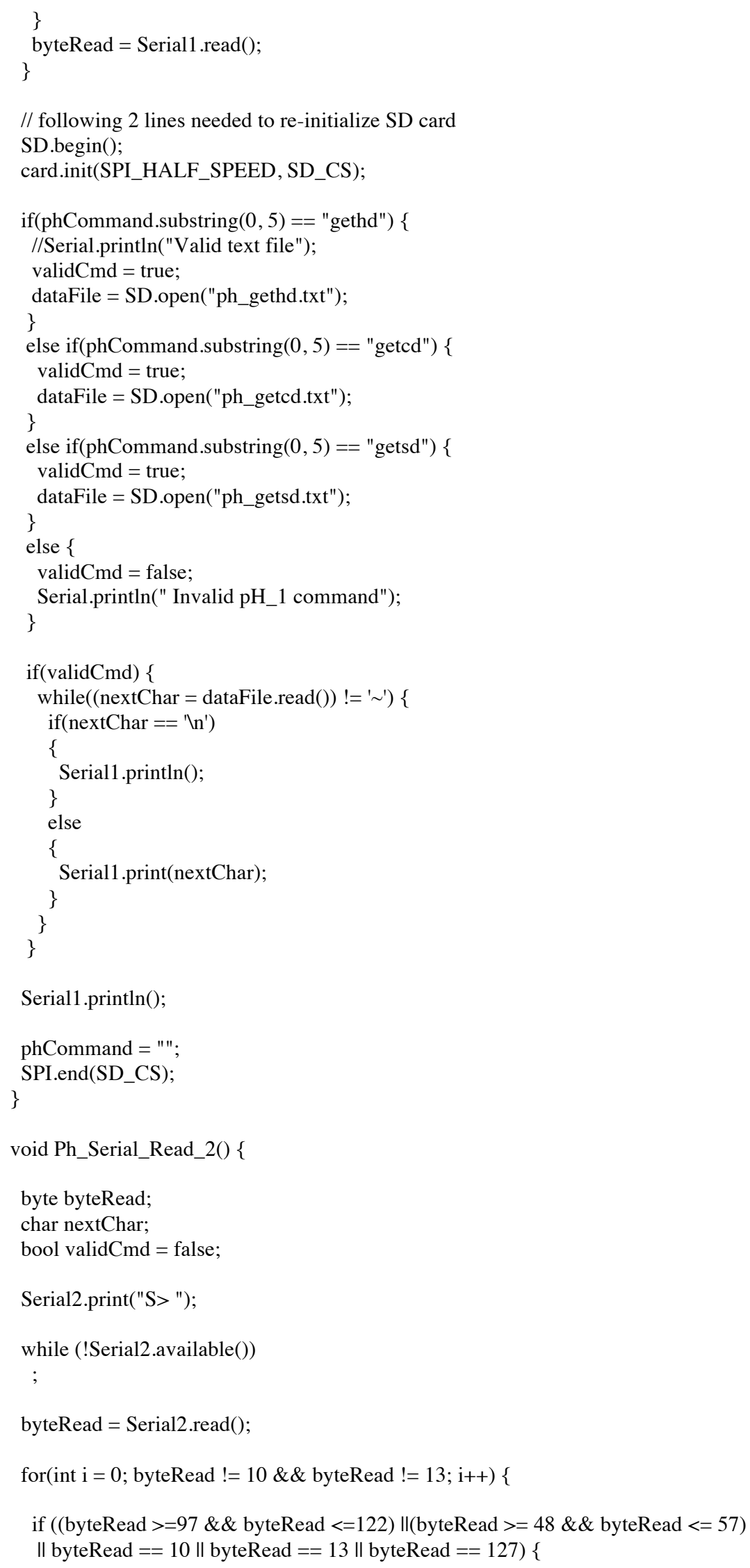




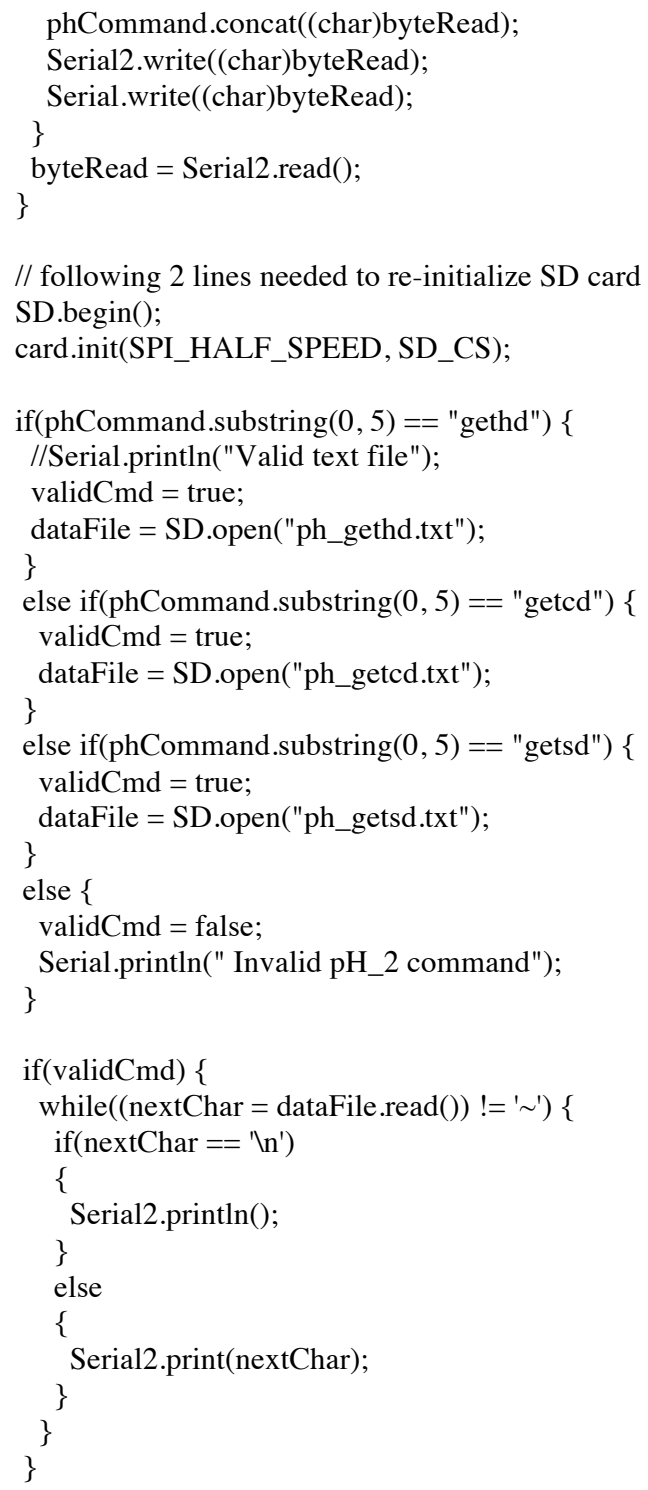




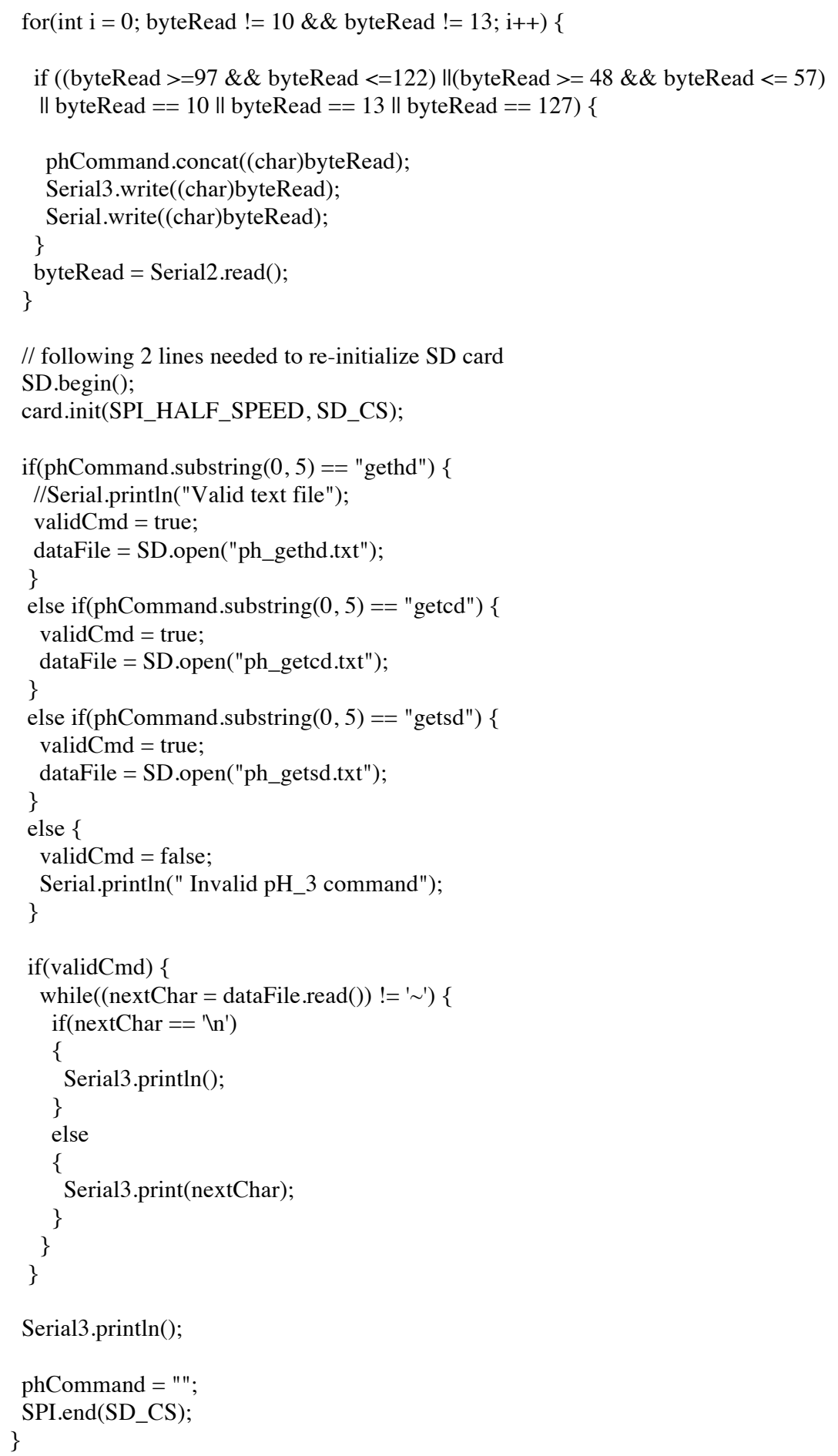

